\title{
The Impact of Risk and Uncertainty on Expected Returns
}

\author{
EVAN W. ANDERSON, ERIC GHYSELS, and JENNIFER L. JUERGENS*
}

April 11, 2007

\begin{abstract}
We study asset pricing when agents face risk and uncertainty and empirically demonstrate that uncertainty has a substantial effect on asset prices. We measure risk with past volatility and uncertainty with the degree of disagreement of professional forecasters, attributing different weights to each forecaster. We run regressions representing the typical risk-return trade-off and augment these regressions with a measure of uncertainty. We find stronger empirical evidence for a uncertainty-return trade-off than for the traditional risk-return trade-off. We investigate the performance of a two-factor model with risk and uncertainty in the cross-section.
\end{abstract}

${ }^{*}$ Evan Anderson: Northern Illinois University, Department of Economics, Zulauf 515, DeKalb, IL 60115, phone: (630) 450-0533, email: ewanderson@niu.edu. Eric Ghysels: Department of Finance, Kenan-Flagler Business School, and Department of Economics, University of North Carolina - Chapel Hill, Chapel Hill, NC 27599-3305, phone: (919) 966-5325, email: eghysels@ unc.edu. Jennifer L. Juergens: Arizona State University, W.P. Carey School of Business, Department of Finance, Tempe, AZ 85287, phone: (480) 965-3131, email: Jennifer.Juergens@asu.edu. We would like to thank Lars Hansen, Peter Hansen, Chris Jones, Leonid Kogan, Jianjun Miao, Athanasios Orphanides, Simon Potter, Eric Renault, Robert Rich, Tom Sargent and Raman Uppal for very helpful comments. This paper was presented at Northern Illinois University, SAMSI Opening Workshop, 2006 EFA meetings, 2006 Winter Meetings of the Econometric Society, the SAMSI Conference on Model Uncertainty, 2006 NBER Summer Institute Asset Pricing Workshop, 2007 AFA meetings, UC Santa Cruz, University of Illinois at Urbana-Champaign, and University of Wisconsin-Madison. Early versions of the ideas in this paper were also presented at the Board of Governors, the FDIC, the Federal Reserve Bank of New York, Simon Fraser University and Stanford University. We thank seminar participants for helpful comments. 
One of the most studied theoretical relationships in empirical finance is that the expected excess return of the market over a risk-free bond should vary positively and proportionally to the volatility of the market return. This risk-return trade-off is so fundamental that it could well be described as the "first fundamental law of finance." Merton (1973) derived this theoretical relationship in a continuous time model in which all agents have power preferences and hedging concerns are negligible, and it is sometimes referred to as Merton's ICAPM or simply the ICAPM.

The empirical evidence for a risk-return trade-off is mixed. Many studies have run versions of the following regression:

$$
E_{t} r_{e t+1}=\gamma V_{t}
$$

where $r_{e t+1}$ is the excess return of the market over a risk-free bond, $\gamma$ is a risk aversion coefficient, and $V_{t}$ is (market) risk. $^{1}$ The goal has been to find a significantly positive $\gamma$ coefficient that captures the trade-off between risk and return. Baillie and DeGennaro (1990); French, Schwert, and Stambaugh (1987); and Campbell and Hentschel (1992) find a positive but mostly insignificant relation between the conditional variance and the conditional expected return. On the other hand, Campbell (1987); Nelson (1991); Brandt and Kang (2004); among others, find a significantly negative relation. Glosten, Jagannathan, and Runkle (1993); Harvey (2001); and Turner, Startz, and Nelson (1989) find both a positive and a negative relation depending on the method used. Finally, Ghysels, Santa-Clara, and Valkanov (2005) find a significant and positive relationship between the market return and conditional volatility using Mixed Data Sampling, or MIDAS, estimation methods.

An important strand of recent research in finance developed by Lars Hansen and Thomas Sargent contends that uncertainty, in addition to risk, should matter for asset pricing. When agents are unsure of the correct probability law governing the market return they demand a higher premium in order to hold the market portfolio. Papers by Hansen and Sargent (1995, 2001, 2003, 2005, 2006); Hansen, Sargent, and Tallarini (1999); Anderson, Hansen, and Sargent (2003); Hansen, Sargent, Turmuhambetova, and Williams (2006); Chen and Epstein (2002); Maenhout (2004, 2006); Uppal and Wang (2003); Kogan and Wang (2002); and Liu, Pan, and Wang (2005) among many others have shown how uncertainty effects optimal decisions and asset prices. So far the literature has been mostly theoretical. The main contribution of this paper is to empirically investigate the performance of asset pricing models when agents face uncertainty in addition to risk.

Kogan and Wang (2002) show that in the presence of uncertainty the traditional risk-return regression needs to be augmented since both risk and uncertainty carry a positive premium:

$$
E_{t} r_{e t+1}=\gamma V_{t}+\theta M_{t}
$$

\footnotetext{
${ }^{1}$ We take (market) risk, $V_{t}$, to be the conditional volatility of the market.
} 
where $\theta$ is a measure of aversion to uncertainty and $M_{t}$ measures the amount of uncertainty in the economy. When there is no uncertainty, so that $M_{t}=0$, or if agents are not averse to uncertainty, so that $\theta=0$, Merton's original formulation is recovered. Kogan and Wang (2002) derive the decomposition in a two-period discrete time model in which agents are concerned about alternative normally distributed models for asset returns. We provide an alternative derivation of this theoretical relationship in the setting of an infinite horizon continuous time model and show that it holds when hedging returns are negligible and agents have power preferences. It is this relationship we empirically investigate to assess the importance of the uncertainty-return trade-off in conjunction with the traditional risk-return trade-off.

There is an abundant literature on estimating risk aversion, $\gamma$, and measuring risk, $V_{t}$; and many different approaches have been used. In this paper we face the additional challenges of estimating uncertainty aversion, $\theta$, and measuring uncertainty, $M_{t}$. One approach that has been proposed is to set uncertainty equal to volatility and to use detection probabilities to calibrate uncertainty aversion [see Anderson, Hansen, and Sargent (2003) and Maenhout (2006)]. In this paper we measure uncertainty with the degree of disagreement of professional forecasters parameterized in a flexible way. We simultaneously estimate uncertainty aversion, risk aversion, and nonlinear parameters, which determine risk and uncertainty, from observed asset prices.

The relationship between the disagreement of professional forecasters and expected returns has been discussed in many recent papers, without a link to uncertainty. A number of authors, including Anderson, Ghysels, and Juergens (2005) and Qu, Starks, and Yan (2003) find that more disagreement, as measured by the dispersion of earnings forecasts, implies higher expected returns. In particular, Anderson, Ghysels, and Juergens (2005) observe that the dispersion factors (portfolios that long high dispersion stocks and short low dispersion stocks) are positively related to expected returns and have explanatory power beyond traditional Fama-French and momentum factors. Similarly, Qu, Starks, and Yan (2003) observe a positive relation between expected returns and a factor for disagreement, constructed from the annual volatility of a firm's earnings dispersion. Others, including Diether, Malloy, and Scherbina (2002) and Johnson (2004), find that higher dispersion stocks have lower future returns.

In contrast to all these papers, we emphasize aggregate measures of disagreement whereas the prior literature emphasizes disagreement about individual stocks or portfolios. Most of the existing literature measures disagreement with the dispersion of earnings forecasts made by financial analysts of individual stocks and studies the relationship between this measure and individual stock returns. We emphasize the effect of disagreement on the market return and use data on forecasts of aggregate corporate profits rather than earning forecasts of individual stocks. We theoretically show that disagreement (or uncertainty) matters for individual stocks only when the divergence of opinions about the stock is correlated with market disagreement.

Several different rationales have been proposed to explain the effect of disagreement on expected returns. Anderson, Ghysels, and Juergens (2005) took the disagreement of forecasters about the future values of variables as an 
indication of heterogeneity in the beliefs of agents and showed how the disagreement is priced in a heterogeneous agents model with micro-foundations. Diether, Malloy, and Scherbina (2002) rationalize their findings that higher dispersion stocks have lower future returns with arguments from the short-sale constraints literature, in particular Miller (1977). They argue dispersion proxies for differences of opinions among traders where only the most optimistic opinions are reflected, thereby driving up current prices. Johnson (2004) offers an alternative explanation to the findings of Diether, Malloy, and Scherbina (2002). In his model, levered firms may be able to reduce the cost of capital by increasing idiosyncratic risk of earnings volatility and subsequently the dispersion of earnings forecasts. Johnson views dispersion as a manifestation of idiosyncratic risk relating to the opacity in the underlying value of a stock.

This paper suggests an alternative explanation for why disagreement is priced: Economic agents interpret disagreement as uncertainty. Economic agents think a particular model, labeled the reference model, is a good description of the world but are worried that it is misspecified and realize there are a variety of probability laws which could possibly correctly describe the world. From the point of view of agents, the amount of disagreement of forecasters is an indication of which models are plausible. When there is little disagreement agents are concerned only about models which are close to the reference model but when there is a lot of disagreement agents care about models that are both close and far from the reference model.

We assume that agents choose not to act like Bayesians and combine possible probability models, because they are not sure which probabilities should be used to combine possible models. Instead agents solve a robust control problem to find optimal decision rules. We quantify the dispersion of predictions of mean market return forecasts with an empirical measure which we label $M_{t}$. Our empirical results show that assets that are correlated with uncertainty, as measured by $M_{t}$, carry a substantial premium.

One of the key innovations of our paper is how we measure disagreement. From the previous discussion, one might be tempted to think that simply computing standard dispersion measures from the raw forecasts might be enough. Indeed, the existing literature does measure disagreement with cross-sectional sample variances, attributing equal weight to each forecaster. Unfortunately, this is not sufficient because not all forecasts matter equally. For us, the empirical success depends on assigning different weights across forecasts. We find that disagreement matters only with unequal weighting schemes. In particular, to construct $M_{t}$, we measure disagreement with a flexible weighting scheme across forecasts that can accommodate assigning more or less weight across forecasts. Parameters determining the weights are estimated by quasi-maximum likelihood and GMM. We find estimates of the parameters determining the optimal weights to be significantly different from equal weights and entail putting more weight on the center of the cross-sectional distribution of forecasts.

We study empirical asset pricing with risk and uncertainty both in the time series and the cross-section. The time series estimates are concerned with aggregate market excess returns whereas the cross-sectional analysis is 
concerned with other portfolios. For the cross-section, like Kogan and Wang (2002), we show that the expected excess return on any asset $k$ depends on a risk beta, denoted $\beta_{v k}$, times risk aversion and the amount of aggregate risk; and an uncertainty beta, denoted $\beta_{u k}$, times uncertainty aversion and the amount of aggregate uncertainty:

$$
E_{t} r_{k t+1}=\beta_{v k} \gamma V_{t}+\beta_{u k} \theta M_{t}
$$

We investigate the empirical performance of risk and uncertainty in the cross-section by constructing portfolios with varying degrees of risk uncertainty; estimating the prices of risk and uncertainty; and testing if risk and uncertainty have additional explanatory power over the Fama-French factors.

We find for the market that uncertainty is more important determinant of expected returns than risk. The correlation between our estimated measure of uncertainty and the market excess return is 0.28 whereas the correlation of our measure of risk with the market excess return is only 0.15 . We find that the price of uncertainty is significantly positive and helps explain the returns of many portfolios in the cross-section of stocks. We find there is not a significant relationship between uncertainty and lagged volatility, very little contemporaneous correlation between uncertainty and volatility, and very little correlation between uncertainty and future volatility.

The paper is organized as follows. Section 1 describes an economy with uncertainty and derives a theoretical decomposition of excess returns into risk and uncertainty components. Section 2 discusses the separation of uncertainty and risk. Section 3 describes how we measure risk from daily volatility and Section 4 describes how we measure uncertainty from the dispersion of forecasts. Section 5 empirically investigates risk-return and uncertaintyreturn trade-offs for the market and Section 6 empirically investigates the importance of risk and uncertainty for the cross-section of returns. Section 7 concludes.

\section{The theoretical impact of risk and uncertainty on returns}

In this section we decompose asset returns into risk and uncertainty components. We show that the expected excess market return depends on a measure of risk aversion times the amount of market risk plus a measure of uncertainty aversion times the amount of market uncertainty. The expected excess return on any other asset depends on a risk beta times times risk aversion and the amount of market risk; and an uncertainty beta times uncertainty aversion and the amount of market uncertainty.

We derive the decomposition in a general equilibrium model in which all agents are identical; have power utility functions; are worried about model misspecification; and can invest in many risky assets and a risk-free bond. In equilibrium agents fully invest all of their wealth in the market and do not hold other risky assets or the risk-free bond. This model is the environment proposed by Merton (1973) populated with agents who are worried about 
model misspecification as in Hansen and Sargent (2001). Our setup closely follows approaches taken by Hansen and Sargent except that we break the link between uncertainty and risk; and allow concerns for robustness to vary over time in ways that are not related to risk. Similar to work by Uppal and Wang (2003), we allow concerns for robustness to vary with states. Following Maenhout (2004) we scale concerns for robustness by the value function.

The decomposition of returns into risk and uncertainty components has been previously obtained by Kogan and Wang (2002) in a two-period discrete time model under different assumptions. The approach taken in Kogan and Wang (2002) allow agents to worry about alternative Gaussian models and is appropriate when agents have quadratic or exponential utility functions but does not apply when agents have the power utility functions used in this paper. Our formulation allows agents to consider general alternative models, allows them to have power utility functions, and sets the analysis in the context of an infinite horizon continuous time dynamic equilibrium model.

In our formulation, there is an underlying state vector $x$ which agents believe approximately follows the process

$$
d x_{t}=a_{t} d t+\Lambda_{t} d B_{t}
$$

where $B_{t}$ is a vector of independent standard Brownian motions; and $a_{t}=a\left(x_{t}\right)$ and $\Lambda_{t}=\Lambda\left(x_{t}\right)$ are functions of the current state. Agents perceive that the instantaneous risk-free rate is $\rho_{t}=\rho\left(x_{t}\right)$. Agents can invest in a set of assets and perceive that the price of the $k$ th asset, $P_{k t}$, approximately follows the process

$$
d P_{k t}=d_{k t} P_{k t} d t+\zeta_{k t} P_{k t} d B_{t}
$$

where $d_{k t}=d_{k}\left(x_{t}\right)$ is a scalar and $\zeta_{k t}=\zeta_{k}\left(x_{t}\right)$ is a row vector. The first asset is interpreted as the market. Let $d_{t}$ and $P_{t}$ be vectors whose $k$ th elements are $d_{k t}$ and $P_{k t}$ respectively. Let $\zeta_{t}$ be a matrix whose $k$ th row is $\zeta_{k t}$. The wealth $y_{t}$ of an agent approximately follows the process

$$
d y_{t}=\left(\psi_{t}^{\prime} \lambda_{t} y_{t}+\rho_{t} y_{t}-c_{t}\right) d t+\psi_{t}^{\prime} \zeta_{t} y_{t} d B_{t}
$$

where $\lambda_{t}=d_{t}-\rho_{t}$ is the expected excess return of the available assets over the risk-free bond, $\psi_{t}$ is a vector of portfolio weights whose $k$ th element gives the fraction of wealth (possibly greater than one or less than zero) invested in the $k$ th asset, and $c_{t}$ is consumption. Wealth approximately, and not necessarily exactly, follows equation (3) because the price of the assets only approximately, and not necessarily exactly, follows the process in equation (2). We call the processes in equations (1), (2), and (3) the reference model.

Agents believe that the reference model provides a reasonable approximation for the processes that govern the state, the returns on assets, and wealth though they are concerned that the approximation may be misspecified. In particular, they wonder about whether or not they have correct specifications of the conditional means and consider 
the possibility that the conditional mean of the state is $a_{t}-\Delta_{t} g_{t}$ rather than $a_{t}$ and the conditional expected return of the assets is $d_{t}-\eta_{t} g_{t}$ rather than $d_{t}$. Here $g_{t}=g\left(x_{t}, y_{t}\right)$ is a vector of the same dimension as $B_{t}, \Delta_{t}=\Delta\left(x_{t}\right)$ is a matrix of the same dimension as $\Lambda_{t}$, and $\eta_{t}=\eta\left(x_{t}\right)$ is a matrix of the same dimension as $\zeta_{t}$. Agents believe (and indeed they are correct) that the reference model correctly specifies the conditional variances of the state $\left(\Lambda_{t}\right)$, the conditional variances of the assets $\left(\zeta_{t}\right)$, and the risk-free rate $\left(\rho_{t}\right)$. In summary, they worry that the underlying state, the price of assets and the evolution of the wealth are given by

$$
\begin{aligned}
d x_{t} & =\left(a_{t}-\Delta_{t} g_{t}\right) d t+\Lambda_{t} d B_{t} \\
d P_{k t} & =\left(d_{k t}-\eta_{k t} g_{t}\right) P_{k t} d t+\zeta_{k t} P_{k t} d B_{t}, \quad \forall k \\
d y_{t} & =\left(\psi_{t}^{\prime} \lambda_{t} y_{t}-\psi_{t}^{\prime} y_{t} \eta_{t} g_{t}+\rho_{t} y_{t}-c_{t}\right) d t+\psi_{t}^{\prime} \zeta_{t} y_{t} d B_{t}
\end{aligned}
$$

instead of equations (1), (2), and (3). In equation (4b), $\eta_{k t}$ is the $k$ th row of $\eta_{t}$. Agents are uncertain about the conditional mean of their wealth because they are uncertain about the conditional mean returns on the assets. We assume agents have full knowledge of the matrices $\Delta_{t}$ and $\eta_{t}$ but do not know the value of the vector $g_{t}$. Rather than acting as Bayesians and using a distribution for $g_{t}$, agents find $g_{t}$ by solving a robust control problem. The solution to the control problem provides the value of $g_{t}$ as a function of the exogenous state and wealth.

Agents consider a worst case specification for $g_{t}$ that is constrained to be close to the reference model. We capture the requirement that $g_{t}$ is close to the reference model by penalizing deviations from the reference model with the quadratic term

$$
\frac{1}{2 \phi_{t}} g_{t}^{\prime} g_{t}
$$

where $\phi_{t}=\phi\left(x_{t}, y_{t}\right)$ is a function that can be depend on the exogenous state and wealth. The functions $\Delta$ and $\eta$ allow some perturbations of $x$ and $y$ to be penalized more heavily than others. For example, consider a model in which both $x$ and $B$ (as well as $g$ ) are two-dimensional, there is only one risky asset which is the market, and for some $t$

$$
\Delta_{t}=\left[\begin{array}{ll}
1 & 0 \\
0 & 0
\end{array}\right] \quad \eta_{t}=\left[\begin{array}{ll}
0 & 100
\end{array}\right] .
$$

In this case a higher penalty is imposed for perturbing the first element of $x$ than the market return. In particular, perturbing the first element of $x$ by 0.001 has the same penalty as perturbing the market return by 0.1 . The second element of $x$ is presumed to be known exactly so that under no circumstances will agents consider perturbations in it since the second element of $\Delta_{t} g_{t}$ is zero for any finite $g_{t}$. In this way, $\Delta$ and $\eta$ allow us to capture the notion that agents may have more or less doubts about the conditional means of some variables compared to others.

In work by Hansen and Sargent $\phi_{t}$ is taken to be constant; and $\Delta$ and $\eta$ are linked to volatility so that $\Delta_{t}=\Lambda_{t}$ and $\eta_{t}=\zeta_{t}$ for all $t$. Hansen and Sargent suggest this is reasonable because it is more difficult to learn about conditional 
means in the presence of high volatility. ${ }^{2}$ We do not restrict $\Delta$ and $\eta$ to necessarily being tied to volatility and allow for the possibility that they depend more flexibly on the state. For example, there may be some state variables that have a high conditional variance but agents have very little doubt about their conditional mean. In addition doubts may vary over time in interesting ways that are not linked to conditional variances. For example, during the oil crisis in the mid 1970's agents may have been willing to consider more perturbations in all variables than they were in mid 1990's. For the reasons discussed in Maenhout (2004) we will let $\phi$ depend on the exogenous state and wealth (also see below for more details). ${ }^{3}$

The objective of agents is

$$
\int_{0}^{\infty} \exp (-\delta t)\left[\frac{c_{t}^{1-\gamma}}{1-\gamma}+\frac{1}{2 \phi_{t}} g_{t}^{\prime} g_{t}\right] d t
$$

where $\delta$ a time discount rate. At any date, the first component of the objective is the utility obtained from consumption where $\gamma$ is a risk aversion parameter which is greater than zero and not equal to one. The second component penalizes deviations from the reference model and is added rather than subtracted. Agents want to maximize their objective by choosing adapted consumption and portfolio holdings; and minimize their objective by choosing $g$ subject to the constraints in equations (4a), (4b), and (4c).

The agents' value function, denoted $J(y, x)$, satisfies the Hamilton-Jacobi equation

$$
\begin{aligned}
0=\max _{\psi, c} \min _{g}\left\{\frac{c^{1-\gamma}}{1-\gamma}+\frac{1}{2 \phi} g^{\prime} g-\delta J+J_{x}^{\prime}[a-\Delta g]+J_{y}\left[\psi^{\prime} \lambda y-\psi^{\prime} y \eta g+\rho y-c\right]+\right. \\
\left.\frac{1}{2} \operatorname{tr}\left[\Lambda \Lambda^{\prime} J_{x x}\right]+\frac{1}{2} J_{y y} \psi^{\prime} \zeta \zeta^{\prime} \psi y^{2}+\psi^{\prime} \zeta \Lambda^{\prime} J_{x y} y\right\}
\end{aligned}
$$

where we drop the $t$ subscripts and the subscripts on $J$ denote differentiation. In the limit as $\phi$ approaches zero at every date, the functional equation (8) becomes the usual Hamilton-Jacobi equation studied by Merton (1973) and many subsequent researchers. The additional terms present are the same terms present in Hansen and Sargent's formulation except that $\Delta$ and $\eta$ are flexible functions of the state and $\phi$ is a flexible function of the state and wealth. The minimizing choice of $g$ is

$$
g=\phi \Delta^{\prime} J_{x}+\phi \eta^{\prime} \psi y J_{y}
$$

which illustrates how specifications of $\phi, \Delta$ and $\eta$ endogenously determine the perturbations of conditional means that agents consider. The optimal choice of the fraction of wealth to invest in the market, $\psi$, satisfies the first-order condition:

$$
J_{y} \lambda y-J_{y} y \eta g+J_{y y} \zeta \zeta^{\prime} \psi y^{2}+\zeta \Lambda^{\prime} J_{x y} y=0
$$

\footnotetext{
${ }^{2}$ For example see Anderson, Hansen, and Sargent (2003), Hansen, Sargent, and Tallarini (1999) and Hansen, Sargent, Turmuhambetova, and Williams (2006) .

${ }^{3}$ Uppal and Wang (2003) allow the parameter $\phi$ to vary across assets and state variables, though they require their parameters to be time-invariant. Our model could be viewed as a generalization of their model in which the uncertainty parameters are allowed to vary over time.
} 
In equilibrium, market clearing requires that all agents invest in the market and no other asset so that (since the market is the first asset) $\psi_{1}=1$ and $\psi_{k}=0$ when $k>1$. Substituting in the right hand side of equation (9) for $g$, imposing the equilibrium conditions on $\psi$ and rearranging terms allows us to write equation (10) as

$$
\lambda=\gamma \varsigma+\phi J_{y} y \varrho+\phi \eta \Delta^{\prime} J_{x}-\zeta \Lambda^{\prime} \frac{J_{x y}}{J_{y}}
$$

where $\varsigma$ and $\varrho$ denote the first columns of the matrices $\zeta \zeta^{\prime}$ and $\eta \eta^{\prime}$. The $k$ th element of $\varsigma$ is the covariance between the market (the first asset) and the $k$ th asset. Likewise, the $k$ th element of $\varrho$ represents the "covariance" between the uncertainty in the market and the uncertainty in the $k$ th asset.

We consider the specification of $\phi$ proposed by Maenhout (2004):

$$
\phi(x, y)=\frac{\theta}{(1-\gamma) J(x, y)}
$$

where $\theta$ is a time-invariant constant. With this specification formula (11) simplifies to

$$
\lambda=\gamma \varsigma+\theta \varrho+\theta \eta \Delta^{\prime} \frac{J_{x}}{(1-\gamma) J}-\zeta \Lambda^{\prime} \frac{J_{x y}}{J_{y}}
$$

since $J_{y} y /[(1-\gamma) J]=1$. The term

$$
\theta \eta \Delta^{\prime} \frac{J_{x}}{(1-\gamma) J}-\zeta \Lambda^{\prime} \frac{J_{x y}}{J_{y}}
$$

comes from the hedging component of optimal portfolios. To simplify the analysis we make sufficient assumptions for this hedging component to be zero. We assume the noise driving the market is orthogonal to the noise driving the state (so that $\zeta_{t} \Lambda_{t}^{\prime}=0$ for all $t$ ) and the uncertainty in the market is unrelated to the uncertainty in the state (so that $\eta_{t} \Delta_{t}^{\prime}=0$ for all $\left.t\right) .{ }^{4}$ It follows that

$$
\lambda=\gamma \varsigma+\theta \varrho .
$$

In our empirical work we estimate this model in discrete time for the market in Section 5 and for the cross-section of returns in Section 6. In order to estimate this model we need to relate the true expected excess return for stocks to $\lambda$. We make the assumption that $\lambda$ is the expected excess return on stocks. This assumption is appropriate if the reference model is correct and the agents' fears of misspecification are unwarranted. For the market, we consider a discrete time approximation to equation (15) in which the quarterly excess return of the market over a risk-free bond between periods $t$ and $t+1$, denoted $r_{e t+1}$, satisfies

$$
E_{t} r_{e t+1}=\gamma V_{t}+\theta M_{t}
$$

\footnotetext{
${ }^{4}$ It is probably unreasonable to assume that the noise and uncertainty underlying the market and the state are not related. Alternatively, we could view equation (15) as a good approximation to equation (13) when $\gamma$ is close to one, $\zeta_{t} \Lambda_{t}^{\prime}$ is close to a matrix of zeros for all $t$, and $\eta_{t} \Delta_{t}^{\prime}$ is close to a matrix of zeros for all $t$.
} 
where $V_{t}=\varsigma_{1 t}$ is the (conditional) variance and $M_{t}=\varrho_{1 t}$ the (conditional) uncertainty of the market. For any other asset $k$ we define

$$
\beta_{v k}=\frac{\varsigma_{k t}}{V_{t}} \quad \beta_{u k}=\frac{\varrho_{k t}}{M_{t}}
$$

and assume $\beta_{v k}$ and $\beta_{u k}$ are constant over time. This assumption implies restrictions on the exogenous processes for the state vector and asset prices and allows us to think of $\beta_{v k}$ and $\beta_{u k}$ as respectively being regression coefficients of the risk in asset $k$ on market risk and of the uncertainty in asset $k$ on market uncertainty. We estimate

$$
E_{t} r_{k t+1}=\beta_{v k} \gamma V_{t}+\beta_{u k} \theta M_{t}
$$

where $r_{k t+1}$ is an excess return and where, like for the market, we have assumed the reference model is correct. The above equation provides the theoretical underpinnings for the empirical cross-sectional analysis covered in Section 6. Kogan and Wang (2002) derive equations (16) and (18) under different assumptions. Their derivation, however, does not apply when agents have power utility functions.

In reality, the reference model may indeed be not correct and the agents fears of misspecification may be justified. We deal with this in several ways. First, for some of our estimations, we use quasi-maximum likelihood which allows us to obtain consistent estimates in the presence of certain types of misspecification. Second, when estimating (16) and (18) we include additional constant terms. If there is a constant level of misspecification then the constant terms would be significant. Third, in some of our specifications we allow uncertainty to affect the quarterly conditional volatility of asset returns. Although uncertainty should not affect volatility in our continuous time model, it is plausible that uncertainty affects quarterly volatility because model misspecification might appear as additional noise at the quarterly frequency. It is important to remember that even if the reference model is false, it is by assumption a good description of reality so that the additional constant terms and the additional noise should be small in magnitude.

\section{Empirically distinguishing uncertainty from risk}

In this section we discuss how we distinguish uncertainty from risk. Following Knight (1921), Keynes (1937) described uncertainty by saying:

By 'uncertain' knowledge, let me explain, I do not mean merely to distinguish what is known for certain from what is only probable. The game of roulette is not subject, in this sense, to uncertainty; nor is the prospect of a Victory bond being drawn. Or, again, the expectation of life is only slightly uncertain. Even the weather is only moderately uncertain. The sense in which I am using the term is that in which the prospect of a European war is uncertain, or the price of copper and the rate of interest twenty years hence, or the obsolescence of a new invention, or the position of private wealth owners in the social system in 1970. About these matters there is no scientific basis on which to form any calculable probability whatever. We simply do not know. 
One could adopt the position that an event is risky if its outcome is unknown but the distribution of its outcomes is known and uncertain if its outcome is unknown and the distribution of its outcomes is also unknown.

In this paper we consider an asset pricing environment in which it is plausible to assume that agents know the second and higher order central moments of all asset returns exactly. If agents knew the conditional mean of asset returns then they would know the complete distribution of returns. There is very little information, however, about means in data and its likely that agents have very low confidence in the information they do have.

Following the work of Merton (1980) and Foster and Nelson (1996), it is well known that precise estimation of volatility can be achieved through sampling returns over arbitrarily short time intervals. To a first degree we may therefore assume that volatility is known, although in practice prominent high-frequency data characteristics such as leptokurtosis, and intra-daily deterministic patterns, and market microstructure features such as price discreteness, nonsynchronous trading, and bid-ask spread further contaminate the data used in empirical research. Merton also showed that, in contrast to volatility, estimation of the drift component only depends on the span, not the sampling frequency. A longer span of data only yields precise estimation. In practice long data spans uncontaminated by some sort of structural breaks are next to impossible to find. Hence, the estimation of the drift component very much remains extremely difficult. We therefore take the view that future asset returns (and future values of other state variables) are risky because they might deviate from their conditional means, and uncertain because their true conditional means are not known. Under this view, uncertainty is limited to uncertainty in first moments and everything about higher order central moments is assumed to be perfectly known.

How should agents deal with uncertainty? Keynes (1937)'s prescription was:

Nevertheless, the necessity for action and decision compels us as practical men to do our best to overlook this awkward fact and to behave exactly as we should if we had behind us a good Benthamite calculation of a series of prospective advantages and disadvantages, each multiplied by its appropriate probability, waiting to be summed.

We assume agents follow Keynes advice and find approximate probabilities when faced with uncertainty. However, unlike Keynes we assume that agents treat these probabilities differently from known probabilities and do not, like good Benthamites, compute expected utilities.

For example, assume agents believe that the excess return on the market is distributed normal with mean $\mu$ and standard deviation $\sigma$ :

$$
r_{e} \sim N\left(\mu, \sigma^{2}\right)
$$

They know the scalar $\sigma$ exactly but do not know the value of $\mu$ and might or might not know its distribution. In this situation we call the risk in the market $\sigma^{2}$ and the uncertainty in the market agent's beliefs about the variance of $\mu$. 
In other words, uncertainty is a measure of the confidence of an agent in her beliefs about $\mu$ and can be thought of as an approximation to the mean squared error of her beliefs:

$$
E(\mu-\hat{\mu})^{2}
$$

where $\hat{\mu}$ is her best approximation of $\mu$.

In order to empirically identify risk and uncertainty, we do not take a hard line view on the separation of risk and uncertainty. For us it does not matter if agents know (or don't know) the distribution of $\mu$. If agents know the distribution of $\mu$ we will think of the variance of $\mu$ as uncertainty. If agents do not know the distribution of $\mu$ then we think of agents as taking Keynes's advice and measuring uncertainty with their best approximation to the variance. Because of our practical views, some of what we call uncertainty may indeed be risk as defined by Knight and Keynes. However, it seems reasonable to us that the uncertainty in $\mu$ is of an order of magnitude larger than the risk in $\mu$ and that from a practical perspective calling everything that is unknown about the true value of $\mu$ uncertainty is a reasonable approximation.

Regardless of whether agents know the distribution of $\mu$, we assume they choose to treat the uncertainty in $\mu$ differently from the variance of returns because they may be more (or less) averse to situations in which they have little confidence in $\mu$ than to situations in which the variance of returns is large. As argued by Hansen and Sargent a reasonable strategy when facing uncertain distributions is to solve a version of the robust control problem described in Section 1.

In the next two sections we propose ways to empirically measure the amount of risk and uncertainty in the economy.

\section{Measuring risk with volatility}

There are many ways to estimate volatility. When we confine our attention to models exclusively based on returns data a natural choice would be ARCH-type models. Since we estimate our models at the quarterly frequency, this would imply quarterly ARCH models. This is rather unappealing as volatility would be estimated quite imprecisely. Therefore we adopt an approach which allows us to estimate volatility at a quarterly frequency more precisely by exploiting daily returns data. In recent work, Ghysels, Santa-Clara, and Valkanov (2005) suggested that volatility can be modeled with a mixed data sampling, or MIDAS, approach. The key to modeling conditional variances is parsimony, summarizing in a convenient way the temporal dynamics which yield predictions of future volatility. In this section we review one parsimonious flexible functional form for measuring the conditional volatility of the market, which we call (market) risk. 
Ghysels, Santa-Clara, and Valkanov (2006a) suggest that a discretized Beta distribution is a flexible functional form that can conveniently capture many plausible patterns of time series decay. The discretization is based on the standard continuous Beta probability density function which is

$$
w[x]=\frac{(x-a)^{\alpha-1}(d-x)^{\chi-1}}{B(\alpha, \chi)(d-a)^{\alpha+\chi-1}}
$$

where $B$ is the Beta function and $\alpha, \chi, a$ and $d$ are parameters. The discretized Beta distribution we use is

$$
\begin{aligned}
w_{i} & =\frac{(i-a)^{\alpha-1}(d-i)^{\chi-1}}{B(\alpha, \chi)(d-a)^{\alpha+\chi-1}}\left[\sum_{j=1}^{n} \frac{(j-a)^{\alpha-1}(d-j)^{\chi-1}}{B(\alpha, \chi)(d-a)^{\alpha+\chi-1}}\right]^{-1} \\
& =\frac{(i-a)^{\alpha-1}(d-i)^{\chi-1}}{\sum_{j=1}^{n}(j-a)^{\alpha-1}(d-j)^{\chi-1}}
\end{aligned}
$$

with $n$ values $(i=1,2, \ldots n)$ that receive positive probability. We require $a \leq 1$ and $d \geq n$. In a time series application $n$ could be the number of lags used in a volatility prediction. Note that a potentially large set of weights is tightly parameterized via a small set of parameters. Ghysels, Santa-Clara, and Valkanov (2006a) and Ghysels, Sinko, and Valkanov (2006b) discuss how, by varying parameters, the discretized Beta distribution can capture many different weighting schemes associated with time series memory decay patterns observed in volatility dynamics and other persistent time series processes. They also observe that setting $\alpha=1$ yields downward sloping weighting schemes typically found in models of volatility predictions. By construction equation (21) is a well-formed probability density function since $\sum_{i=1}^{n} w_{i}=1$ and we interpret the $w_{i}$ 's as weights. This convenient scheme is used in our empirical work, both in a time series context to parameterize risk and, as we describe in the next section, in a cross-sectional setting to specify uncertainty.

To measure risk we a construct a measure of conditional variances by weighting prior daily squared (demeaned) returns. More specifically, the weight on the $i$ th prior lag is

$$
l_{i}(\omega)=\frac{(s+1-i)^{\omega-1}}{\sum_{j=1}^{s}(s+1-j)^{\omega-1}}
$$

where $s$ is the maximum number of lags. ${ }^{5}$ The functional form of these weights is determined by a discretized Beta distribution with $\alpha=1, \chi=\omega$, and $d=s+1$. The value of $a$ does not matter since $\alpha=1$. The single free

\footnotetext{
${ }^{5}$ The value of $s$ determines how many daily lags are used to predict future volatility. We set $s$ to be roughly the number of trading days in a year. Since the number of trading days per year varies slightly throughout our sample and we prefer $s$ be constant for all dates, we set $s$ to be the minimum number of trading days in the previous 12 months available throughout our sample.
} 
parameter $\omega$ models the decay pattern of the weight function and the top plot in Figure 1 provides an example of the weights. ${ }^{6}$ The resulting conditional variance is equal to

$$
V_{t}=\sigma^{2} \operatorname{vol}_{t}(\omega)
$$

where $\sigma^{2}$ is a time-invariant constant and

$$
\begin{aligned}
\operatorname{vol}_{t}(\omega)= & s \sum_{i=1}^{s} l_{i}(\omega)\left(r_{e t}^{s-i, s-i+1}-\frac{1}{s} \sum_{j=1}^{s} r_{e t}^{s-j, s-j+1}\right)^{2}+ \\
& 2 s \sum_{i=1}^{s-1} \sqrt{l_{i}(\omega) l_{i+1}(\omega)}\left(r_{e t}^{s-i, s-i+1}-\frac{1}{s} \sum_{j=1}^{s} r_{e t}^{s-j, s-j+1}\right)\left(r_{e t}^{s-i-1, s-i}-\frac{1}{s} \sum_{j=1}^{s} r_{e t}^{s-j, s-j+1}\right)
\end{aligned}
$$

is the component of the conditional variance which is determined from the volatility of daily excess returns. Here $r_{e t}^{s-i, s-i+1}$ is the daily return between trading days $s-i$ and $s-i+1$ which occur between periods $t-1$ and $t$. Note that $\operatorname{vol}_{t}$ depends on the parameter $\omega$ since the weights $l_{i}$ depend on $\omega$. The second component of vol $t$ allows for the effect on quarterly volatility of serial correlation in daily returns. Such a correction did not appear in the original formulation of Ghysels, Santa-Clara, and Valkanov (2005).

In Section 5 we estimate $\omega$ and $\sigma^{2}$ from data on excess market returns. Ghysels, Santa-Clara, and Valkanov (2005) argued that $\sigma^{2}$ should equal one and fixed it at one for their results. We estimate $\sigma^{2}$ to allow for this part of the model to be misspecified. In Section 6 we estimate $\omega$ using only information from the cross-section.

\section{Measuring uncertainty with disagreement}

This section describes how we use the dispersion of forecasts to measure uncertainty. Section 4.1 briefly describes the data on predictions we use leaving the details to Appendix A. Section 4.2 intuitively provides a rationale for measuring uncertainty with disagreement and Section 4.3 provides the details of a parsimonious flexible function form that captures uncertainty. Section 4.4 provides an example.

\subsection{Survey of Professional Forecasters}

In this paper we use predictions on macroeconomic and financial variables from the Survey of Professional Forecasters (henceforth SPF). There are many other papers that make use of data from the SPF, most of which evaluate the quality of the predictions [see, for example, Zarnowitz (1985) and Braun and Zarnowitz (1993)]. In this section we describe how we use the dispersion of forecasts as a proxy for the amount of uncertainty that agents have about

\footnotetext{
${ }^{6}$ The weights displayed in Figure 1 are those obtained from empirical estimates, discussed later.
} 
the reference model described in Section 1. The SPF is an attractive survey for this measurement because it provides a long time series of data (the data begins in 1968) and it provides predictions at many different horizons. Each quarter participants are asked for predictions of the levels of variables for the previous quarter, this quarter, and the next four quarters. ${ }^{7}$ The forecasters selected for the SPF come primarily from large financial institutions. The series we use from the SPF are forecasts of output (before 1992Q1 these consist of forecasts of GNP and after of GDP), the output deflator (before 1992Q1 these consist of forecasts of the GNP deflator and after of the GDP deflator), and Corporate Profits After Taxes.

Some of our analysis requires predictions on variables which do not directly appear in the SPF. For example, we need forecasts of the real market return and the real risk-free rate but the SPF only provides forecasts of the level of nominal corporate profits and aggregate prices. Appendix A discusses how we use the Gordon Growth Model to infer forecasts of real market returns from forecasts of corporate profits and aggregate prices; and how we construct forecasts of the real return on a nominally risk-free bond using actual nominal returns and forecasts of aggregate prices.

\subsection{Uncertainty and disagreement}

This section informally gives an overview of our procedure for measuring uncertainty. Section 4.3 provides more details. Recall from the discussion in Section 1 that the conditional expected excess return of assets in the agents' reference model is approximately $\lambda_{t}$. Agents are concerned, however, that the reference model may be misspecified and think that the expected excess return could be $\lambda_{t}+\eta_{t} g_{t}$ instead of $\lambda_{t}$. The matrix $\eta_{t} \eta_{t}^{\prime}$ represents how confident agents are in their beliefs about the expected returns on available assets. The $(1,1)$ element of $\eta_{t} \eta_{t}^{\prime}$ is a measure of market uncertainty and the other elements in the first column of $\eta_{t} \eta_{t}^{\prime}$ represent the covariance of the uncertainty in other assets with market uncertainty. In this section we will present an overview of a method for measuring the first column of the matrix $\eta_{t} \eta_{t}^{\prime}$.

Assume that agents believe that the true conditional expected excess stocks returns are approximately normally distributed with mean $\lambda_{t}$ and variance proportional to $\eta_{t} \eta_{t}^{\prime} .{ }^{8}$ We suggest that solving the robust control problem described in Section 1 is a reasonable strategy for agents. To see this first note that an approximate (1-p)\% confidence region for agents' beliefs about the true (unknown) conditional expected excess return is $\lambda_{t}+\eta_{t} g_{t}$ where $g_{t}$ satisfies

$$
g_{t}^{\prime} g_{t} \leq\left(\frac{1}{\varpi}\right) \mathcal{C}_{p}
$$

\footnotetext{
${ }^{7}$ The survey also includes annual and longer horizon forecasts. Despite the fact that surveys of professional forecasters are more reliable than other surveys, Ghysels and Wright (2005) report that responses in the SPF data appear to have some evidence of staleness with respect to the reference reporting date of the survey.

${ }^{8}$ Note that this is not a statement about the variance of excess returns but rather a statement about what agents view as the likely mean squared error of their beliefs about the conditional expected excess returns.
} 
$\varpi$ is an unknown scalar, and $\mathcal{C}_{p}$ is the $p \%$ critical value from the $\chi^{2}(m)$ distribution, with $m$ equal to the dimension of $g_{t}$.

As agents' beliefs about the distribution of $\lambda_{t}$ are only an approximation and the value of $\varpi$ is unknown they do not know how to compute the correct distribution and therefore a Bayesian approach is not feasible. ${ }^{9}$ One reasonable strategy for agents is to maximize their lifetime expected utility under "constrained" worst case values for $g_{t}$. The constrained worst case values could be found by choosing (adapted) values for $g_{t}$ for all $t$ to minimize lifetime utility while penalizing deviations from the reference model with the quadratic terms of the form $g_{t}^{\prime} g_{t}$. This is a reasonable strategy because equation (24) tells us that as $g_{t}^{\prime} g_{t}$ increases $\lambda_{t}+\eta_{t} g_{t}$ is statistically farther from the reference model. The penalty imposed in the robust control problem presented in Section 1 is an infinite horizon version of $g_{t}^{\prime} g_{t}$ with $\phi_{t}$ playing the role of $1 / \varpi$ at each date. ${ }^{10}$

We suggest that the uncertainty in the market return, which is the $(1,1)$ element of the matrix $\eta_{t} \eta_{t}^{\prime}$ and a measure of agents' beliefs about the mean-squared error of the expected market excess return $\lambda_{1 t}$, can be proxied by a weighted variance of the predictions of the market return stated by professional forecasters. The predictions of forecasters are a reasonable measure of the universe of ideas that agents in the economy are exposed to. It is reasonable that agents, at least partly, base their beliefs on the predictions of professional forecasters and assign approximate probabilities that each forecast is correct when forming their beliefs. ${ }^{11}$ A weighted variance across these probabilities is a reasonable approximation for agents' beliefs about the mean-squared error of $\lambda_{t}$. Our measured market uncertainty is just this weighted variance. If all forecasters are in agreement then agents have very little doubt that the reference model is correct and market uncertainty is small, hence the first element of the optimal endogenous perturbation $\eta_{t} g_{t}$ will also be small as agents only worry about models that are very close to their reference model. In contrast, if forecasters state very different forecasts then agents are unsure that their reference model is correct and the first element of the optimal endogenous perturbation $\eta_{t} g_{t}$ will be large so that outcomes relatively far from the reference model (as well as outcomes that are close) are of concern to agents.

To further illustrate the link between uncertainty and disagreement consider a situation where agents have very little confidence in the prediction of the reference model about the conditional mean of the market return. Subsequently, agents acquire the predictions of $n$ forecasters about the market return and use the forecasts to form their beliefs. Let the vector $y$ be the collection of all forecasts. Agents believe that approximately

$$
y=1 \mu+v
$$

\footnotetext{
${ }^{9}$ If the conditional expected excess stocks returns was exactly normally distributed, according to agents' beliefs, with mean $\lambda_{t}$ and variance $\varpi \eta_{t} \eta_{t}^{\prime}$ then one could argue that the optimal strategy would be to act like a Bayesian, put a prior probability on the value of $\lambda_{t}$, and maximize expected utility taking into account parameter uncertainty.

${ }^{10}$ Hansen, Sargent, Turmuhambetova, and Williams (2006) discuss the formal link between penalized robust controls problems and problems in which the perturbations are constrained to be close to a reference model.

${ }^{11}$ In our formulation, there is a separation between forecasters and agents. Agents are all alike and assign the same approximate probabilities while forecasters are heterogeneous.
} 
where $\mu$ is the true mean of the market return, $\mathbf{1}$ is a $n$ dimensional vector of ones, $v$ is a normally distributed vector with mean zero and covariance matrix $\sigma^{2} R$. Assume agents know $R$ perfectly but have no prior information about the value of $\sigma^{2} .^{12}$ They estimate $\mu$ and $\sigma^{2}$ from the predictions of forecasters using maximum likelihood, neglecting any prior information they might have about $\mu$ and $\sigma^{2}$. Maximum likelihood estimates are a weighted mean and a weighted variance

$$
\hat{\mu}=\left(\mathbf{1}^{\prime} R^{-1} \mathbf{1}\right)^{-1} \mathbf{1}^{\prime} R^{-1} y \quad \hat{\sigma}^{2}=\frac{1}{n}(y-\mathbf{1} \hat{\mu})^{\prime} R^{-1}(y-\mathbf{1} \hat{\mu})
$$

of forecasts. The value of $\hat{\sigma}^{2} / n$ can be taken to be an approximation of the amount of uncertainty of agents. ${ }^{13}$

As described in the next section, we will use the Beta distribution to determine the weights used to estimate $\sigma^{2}$. The Beta distribution is used because it is a convenient flexible functional form that can approximate a wide range of different weighting schemes. We will take estimates of $\sigma^{2}$ to be approximations to the amount of market uncertainty, $M_{t}$. If forecast data was plentiful and if we understood the mechanisms by which agents form expectations, an appealing research strategy would be to fully specify and estimate a structural model of how agents form beliefs about uncertainty. However, this is not feasible because there is not enough data to estimate the many unknown parameters in such a structural model. Such a structural model would also have to deal with many forecasters entering, leaving and sometimes returning to the sample.

While the above may be a plausible behavioral description of how agents compute uncertainty one may wonder whether it is optimal? In particular, is the uncertainty of a fully rational agent necessarily linked to disagreement? The answer depends crucially on how beliefs, information, and models are distributed among forecasters. In Appendix B we describe an environment in which there is a direct link. In this environment, uncertainty is always proportional to disagreement and it is reasonable to view $M_{t}$ as equaling a time-invariant constant times uncertainty. Although the environment we describe makes reasonable assumptions, in reality uncertainty probably is not always proportional to disagreement. To the extent disagreement approximates the amount of uncertainty in the economy the approach taken in this paper is reasonable. In this paper we refer to $M_{t}$ as uncertainty but it is important to remember that it is at best approximately proportional to the amount of uncertainty in the economy. ${ }^{14}$

How should the other elements of the first column of $\eta_{t} \eta_{t}^{\prime}$ be measured? The other elements represent the covariance of the uncertainty in other assets with market uncertainty. Data on the covariance of disagreement across stocks is difficult to obtain. Consequently we devise a method for computing the other elements of the first column of $\eta_{t} \eta_{t}^{\prime}$ without actually observing agents' beliefs about other stocks. The method exploits the fact the model in Section

\footnotetext{
${ }^{12}$ It is important to emphasize that this is only an approximation from the point of view of agents. The vector $v$ may not be normally distributed and agents might not know the value of $R$ perfectly.

${ }^{13}$ When computing uncertainty in later sections we do not divide by the number of forecasters, $n$, because the number of forecasters agents pay attention to is likely different from the number of forecasters in the SPF.

${ }^{14}$ In an ideal world, we would not only have mean forecasts across analysts for each stock, but we would also have some measure of dispersion of each forecasters' beliefs about the mean. Graham and Harvey (2003), using survey data of CFOs about the expected risk premium, are able to obtain a distribution of beliefs for each individual respondent. In the future, work along the lines of Graham and Harvey (2003) may eventually yield better measures of uncertainty.
} 
1 entails that covariance of the uncertainty in any asset with the market should affect expected returns. Section 6 describes the details.

Our method of measuring uncertainty, does not attempt to identify $g_{t}$ directly with data. Instead, as sketched above, we measure the first column of $\eta_{t} \eta_{t}^{\prime}$ and let the model described in Section 1 determine the endogenous worst case, summarized by $g_{t}$, that agents worry about.

\subsection{A flexible functional form for uncertainty}

We use a parsimonious flexible functional form for measuring uncertainty as we have very little information about the actual mechanisms by which agents compute uncertainty. Hence, we opt for a reduced form approximation rather than a fully specified structural approach which is impossible to implement with the data and information we have at our disposal.

To measure uncertainty the issues are different from the issues faced in measuring risk, yet the key is still parsimony. Or challenge is to summary the plentiful predictions of professional forecasters to reflect the fundamental uncertainty in the economy. Our approach makes extensive use of flexible functional forms similar to those suggested in a time series volatility prediction context by Ghysels, Santa-Clara, and Valkanov (2005). In particular, we emphasize the use of a symmetric beta distribution to weight forecasts.

To capture uncertainty we need to apply weights cross-sectionally across different forecasts. The Beta specification is suitable to tightly parameterize the distribution of forecasts and helps determine which part of the distribution of predictions matter for asset pricing. The Beta weighting scheme adapts easily to a cross-sectional application application among forecasters because setting $\alpha=\chi$ (and hence requiring an even smaller set of parameters) yields various bell-shaped weighting schemes.

To construct the weights we proceed as follows: we pick one series, call it $x$, and rank the forecasts each period of $x$ from low to high. (For us $x$ will usually be forecasts of the market return.) The weight on the $i$ th lowest forecast is

$$
w_{i t}(\nu)=\frac{i^{\nu-1}\left(f_{t}+1-i\right)^{\nu-1}}{\sum_{j=1}^{f_{t}} j^{\nu-1}\left(f_{t}+1-j\right)^{\nu-1}}
$$

where $f_{t}$ forecasts are available at time $t$ and $\nu$ is a parameter. This is the discretized Beta distribution described in section 3 with $\alpha=\nu, \chi=\nu, a=0$ and $d=f_{t}+1$. Instead of letting the first power parameter equal to one (as when we computed conditional volatility), and letting the second power parameter $\omega$ determine the decay pattern, we set both power parameters of the Beta distribution equal to each other and estimate the single common parameter 
as a free parameter $\nu$. This specification forces the weights to be symmetric. ${ }^{15}$ The disagreement or uncertainty is then measured by a Beta-weighted variance of forecasts of $x$ :

$$
\operatorname{unc}_{t}(\nu)=\sum_{i=1}^{f_{t}} w_{i t}(\nu)\left[x_{i t+1 \mid t}-\sum_{j=1}^{f_{t}} w_{j t}(\nu) x_{j t+1 \mid t}\right]^{2}
$$

The uncertainty component is thus constructed as a weighted variance of predictions on a single financial/macroeconomic variable where the weights are determined by a discretized Beta distribution.

In Section 5 we estimate $\nu$ from quarterly daily on excess market returns and in Section 6 we estimate $\nu$ using only information from the cross-section.

\subsection{An example of flexible weights}

Ghysels, Santa-Clara, and Valkanov (2006a) and Ghysels, Sinko, and Valkanov (2006b) give detailed discussions of the advantages of using flexible functional forms for capturing volatility. Here we give a brief example that illustrates one benefit of using flexible functional forms for computing cross-sectional variances.

A big problem we face when estimating cross-sectional variances is that a few outlying observations can have a large effect on estimates. Although we believe most professional forecasters state reasonable forecasts most of the time, there always is some chance there will be extreme forecasts which could introduce large amounts of noise into our estimates of variances. The extreme forecasts could occur because forecasters may occasionally make mistakes and sometimes base their forecasts on incomplete or erroneous information. We would like a measure of the cross-sectional variance that only includes informed forecasts and ignores extreme forecasts.

Consider the following example. Let there be 30 informed forecasters. Assume in the population of informed forecasts, each forecast is distributed normal with mean 0.02 and variance 0.00010 . If we randomly generate 30 forecasts from this distribution and take the sample variance we would usually get a number close to 0.00010 . For example, from one set of 30 draws, we found the estimated cross-sectional variance to be 0.0009 . Now what if in addition to these 30 informed forecasts there was one irrational forecaster who believes that the excess return was $x$. We will examine what happens to the estimated cross-sectional variance when the data consists of the 30 randomly generated forecasts from the informed population and the one extreme forecast. If the extreme forecast is close to 0.02 then it will not have a large effect on our estimated variances. For example for the same set of 30 draws discussed above, if $x=0.05$ then the estimated cross-sectional variance becomes 0.00011 . In this case the one extreme observation has a noticeable but not a large effect. If $x=0.10$ then the estimated cross-sectional variance

\footnotetext{
${ }^{15}$ See for instance the bottom plot in Figure 1 for an example of the weights.
} 
become 0.00029 . In this case, one extreme caused the estimate of the cross-sectional variance to increase by almost three times. If $x=0.20$ then the estimated cross-sectional variance is 0.00113 which is a 10 fold increase.

To deal with this problem we use the Beta weights described in this section to compute weighted variances of forecasts. ${ }^{16}$ These flexible weighting schemes can assign more or less weight to extreme forecasts. In the next section we estimate the weights. Our estimates entail ignoring the extremes and placing all the weight on the center of the distribution. The estimates entail that a forecast of $x=0.20$, in the example above, would have a very small effect on the estimated cross-sectional sample weighted variance. The flexible weights we use may cause us to underestimate the true cross-sectional variance since informed forecasts that are far from the median receive little weight. For our purposes this does not matter because, as described in the next section, in addition to estimating parameters determining flexible weights, we will estimate a parameter that scales cross-sectional variances.

\section{The empirical impact of risk and uncertainty on the market return}

In this section, we estimate the amount of market risk and market uncertainty in the economy and investigate the relative importance of risk and uncertainty for the expected market return. The estimates allow us to construct an index which measures the amount of uncertainty in the economy.

The risk-return trade-off has been the subject of much empirical research. Most papers have used an ARCH-type model, see e.g. French, Schwert, and Stambaugh (1987), Campbell and Hentschel (1992), Nelson (1991), Glosten, Jagannathan, and Runkle (1993), Harvey (2001). Recently, Ghysels, Santa-Clara, and Valkanov (2005) suggested estimating conditional volatility with MIDAS estimation methods. The MIDAS estimator forecasts the conditional variance with a weighted average of lagged daily squared returns (or alternatively lagged demeaned squared returns) using a flexible functional form to parameterize the weight given to each lagged daily squared return (or lagged squared demeaned return). Ghysels, Santa-Clara, and Valkanov (2005) estimate the coefficients of the conditional variance process jointly with other parameters from the expected return equation with quasi-maximum likelihood and show that a parsimonious weighting scheme with only two parameters works quite well. In this paper we will also measure risk using the approach of Ghysels, Santa-Clara, and Valkanov (2005).

To measure uncertainty we face a different challenge. We have data reflecting various predictions about future variables that affect expected returns such as predictions of the market return, corporate profits, etc. Our approach summarizes the cross-sectional variation among forecasters with a parametric specification that allows us to compute a measure of uncertainty in the economy. We proxy for the contribution of uncertainty to the excess return with, $\theta M_{t}$, where $\theta$ is a time-invariant constant and $M_{t}$ measures the disagreement among forecasters about the growth

\footnotetext{
${ }^{16} \mathrm{~A}$ formal statistical argument for computing weighted variances can be made. For example in the behavioral model described in Section 4.2 , it is optimal to measure uncertainty with a weighted variance.
} 
rate of a single variable. We focus on measuring $M_{t}$ with the disagreement about (1) the market return, (2) real output growth, and (3) real corporate profits growth. ${ }^{17}$

We consider again a version of the decomposition suggested in section 1

$$
E_{t}\left(r_{e t+1}\right)=b+\gamma V_{t}+\theta M_{t}
$$

where we also include a constant term $b$ even though according to the reference model this term should be zero. The constant is added to allow for the possibility that the reference model is misspecified. Including a constant also guarantees that the empirical regressions have well-behaved residuals and as discussed later, testing the statistical significance of $b$ can also be used as model validation test. We assume that market excess returns are normally distributed with time-varying volatility (the assumption of normality is made only for the purpose of estimation, yielding a quasi-MLE setting):

$$
r_{e t+1} \sim N\left[b+\gamma V_{t}+\theta M_{t}, V_{t}\right]
$$

As discussed in Sections 3 and 4 we measure risk, $V_{t}$, with $\sigma^{2} \operatorname{vol}_{t}(\omega)$ and uncertainty, $M_{t}$, with unc $t(\nu)$. To estimate the parameters $b, \tau, \theta, \omega$, and $\nu$, we maximize the (quasi-)likelihood of quarterly excess returns based on:

$$
r_{e t+1} \sim N\left[b+\tau \operatorname{vol}_{t}(\omega)+\theta \operatorname{unc}_{t}(\nu), \sigma^{2} \operatorname{vol}_{t}(\omega)\right]
$$

where $\tau=\gamma \sigma^{2}$.

It is important to remember that the agents inside our model are worried that the reference model is false and if their worries are justified then our empirical regressions are misspecified as well. The reference model may be misspecified because we have ignored the hedging component and excess returns may not really be conditionally normally distributed. In addition to including the constant $b$ we take into account the possibility that (29) is misspecified in several other ways. We report quasi-maximum likelihood standard errors. We include additional constant terms [not present in Ghysels, Santa-Clara, and Valkanov (2005)] that potentially could pick up some aspects of model misspecification in $V_{t}$. Finally, we estimate an alternative specification in which quarterly volatility partly depends on the amount of uncertainty in the economy.

\subsection{Results for risk in the absence of uncertainty}

The combination of quarterly returns and daily returns yields the MIDAS setup. Using this setup, Ghysels, SantaClara, and Valkanov (2005) find there is a significant positive relation between risk and return in the stock market. This finding is robust to asymmetric specifications of the variance process, and to controlling for variables associated

\footnotetext{
${ }^{17}$ See Appendix A for a discussion of how we construct forecasts for these variables.
} 
with the business cycle. It also holds in many subsamples. Given these empirical findings it is a good benchmark reduced form regression to introduce uncertainty. Ghysels, Santa-Clara, and Valkanov (2005) focused on monthly returns whereas we devote our attention to quarterly sampling frequencies because the professional forecast data used to construct our measure of uncertainty, $M_{t}$, is only available quarterly. We expect, however, that the focus on the quarterly sampling frequency weakens empirical evidence of the risk-return trade-off, and the results reported below confirm this.

In this section we investigate whether there is a risk-return trade-off in our data set in the absence of uncertainty. Quasi-likelihood estimates of the parameters in equation (30) which determine risk are displayed in the first three estimations in Table II. We see that according to a t-test and a likelihood ratio test, estimates of $\tau$ are not significant, though estimates of $\log \omega$ are extremely significant. The results suggest that, in our data set, although there is no evidence of a risk-return trade-off, MIDAS does provide a better measure of conditional volatility than current realized volatility.

Further evidence that MIDAS captures volatility can be provided by examining the relationship between vol $t$ and realized volatility. We define realized volatility as

$$
\begin{aligned}
Q_{t}=q_{t} \sum_{i=1}^{q_{t}}\left(r_{e t}^{q_{t}-i, q_{t}-i+1}-\frac{1}{q_{t}} \sum_{j=1}^{q_{t}} r_{e t}^{q_{t}-j, q_{t}-j+1}\right)^{2}+ \\
2 q_{t} \sum_{i=1}^{q_{t}-1}\left(r_{e t}^{q_{t}-i, q_{t}-i+1}-\frac{1}{q_{t}} \sum_{j=1}^{q_{t}} r_{e t}^{q_{t}-j, q_{t}-j+1}\right)\left(r_{e t}^{q_{t}-i-1, q_{t}-i}-\frac{1}{q_{t}} \sum_{j=1}^{q_{t}} r_{e t}^{q_{t}-j, q_{t}-j+1}\right)
\end{aligned}
$$

where $q_{t}$ is the number of days in a quarter $t .{ }^{18}$ Table III shows that future realized volatility $\left(Q_{t+1}\right)$ is more highly correlated with $\operatorname{vol}_{t}$ than it is with current realized volatility $\left(Q_{t}\right)$. This confirms that $\mathrm{vol}_{t}$ does provide a better measure of conditional volatility than current realized volatility.

Our implementation differs from the implementation in Ghysels, Santa-Clara, and Valkanov (2005) in that in this paper we estimate $\sigma^{2}$, rather than fixing it at one. If the reference model is correctly specified then $\sigma^{2}$ should equal one since we designed $\mathrm{vol}_{t}$ to be the conditional variance of the market and our model says that $\gamma \mathrm{vol}_{t}$ should be the conditional mean of the market excess return. However, if the reference model is misspecified then $\sigma^{2}$ need not be equal to one. We find estimates of $\sigma^{2}$ are significantly greater than one in models that perform poorly but are close to one in models that perform well. This provides further evidence that the poorly performing models are misspecified. Another diagnostic test of the model is if Jensen's time series alpha, denoted as $b$ in the table, is close to zero. We find Jensen's alpha is not significantly different from zero in Table II, supporting the reference model. The standard errors are computed with QMLE robust standard errors.

\footnotetext{
${ }^{18}$ Note that $Q_{t}$ is similar to vol $_{t}$ except the weights are uniform and $q_{t}$ does not necessary equal $s$. Since $Q_{t}$ is realized volatility within a quarter, $q_{t}$ corresponds to the number of days in a quarter.
} 
Our results differ from Ghysels, Santa-Clara, and Valkanov (2005). The bulk of their analysis focuses on monthly horizons though they do provide quarterly regressions between 1964 and 2000 of a specification similar to equation (30), without uncertainty, and find a significant and positive relation between risk and return. The most important reasons our results differ are that we consider a different time period (1969-2003) and our definition of a quarter refers to a calendar quarter (matching forecasts) whereas the definition of quarter in Ghysels, Santa-Clara, and Valkanov (2005) corresponds to a fixed number of trading days which are not directly related to calendar quarters. ${ }^{19}$

\subsection{Results for risk and uncertainty}

In this section investigate if there is an uncertainty-return trade-off. Quasi-likelihood estimates of the parameters appearing in equation (30) are displayed in Table II when unc $_{t}$ is a Beta-weighted variance of market return forecasts. In the fourth regression we include uncertainty but measure uncertainty with an unweighted (or flat weighted) variance which is obtained by setting $\log \nu=0$. We see in this case the estimate of $\theta$ is not significant and there is very little improvement to the log likelihood without uncertainty. Thus, including uncertainty with flat weights does not improve much upon specifications in which uncertainty is left out. In the 5th, 6th and 7th estimations we estimate $\theta$ and $\log \nu$ along with other parameters. In these regressions unc ${ }_{t}$ is a non-degenerate Beta-weighted variance. Estimates of $\theta$ and $\log \nu$ are significant (by likelihood ratio tests and t-tests) and there is a large improvement to the log-likelihood. Including Beta-weighted uncertainty significantly improves the fit. It is also interesting to note that estimates of $\sigma^{2}$ are not significantly different from one and estimates of the constant $b$ are not significantly different from zero. Both of these results confirm the predictions of the reference model.

Further informal evidence for a uncertainty-return trade-off is provided in Table III - in particular the correlation between our estimated measure of uncertainty in the last regression and the excess return is 0.28 . In comparison the correlation of our measure of risk with the excess return is only 0.15 . The visual evidence in the joint plots in Figure 2 yield additional insights into the nature of the relationship between uncertainty and excess returns. We see that when uncertainty is high, excess returns also tend to be high. When uncertainty is low however there is not a strong relationship between uncertainty and excess returns.

In Table IV we consider the uncertainty-return trade-off when uncertainty is measured by the Beta-weighted variance in variables other than the market return forecasts. One could make an argument that the dispersion of alternative variables should affect uncertainty and thus excess returns. For example uncertainty in future output could reflect underlying structural uncertainty in the economy that perhaps should be priced. In Panel A we consider

\footnotetext{
${ }^{19}$ There are several other differences in our implementation which do not have a large effect on our results. As explained earlier, we estimate $\sigma^{2}$ (rather than set it equal to one), allow for serial correlation in daily returns in equation (23) and subtract sample means in equation (23). [Some of the results in Ghysels, Santa-Clara, and Valkanov (2005) subtracted sample means.] We also use the Beta weights advocated by Ghysels, Santa-Clara, and Valkanov (2006a) and Ghysels, Sinko, and Valkanov (2006b) rather than the normal weights (Almon lags) used by Ghysels, Santa-Clara, and Valkanov (2005).
} 
the uncertainty in constructed real output growth forecasts and in Panel B we consider the uncertainty in growth rate of corporate profits at many different horizons. We see that the uncertainty in real output forecasts does not have a significant effect on excess returns. At long horizons (three and four) the uncertainty in corporate profits forecasts does have a significant effect but at shorter horizons (one and two) it has essentially no effect. The Jensen alpha time series estimate is also significant for the short horizon while it is insignificant with long horizon corporate profit model uncertainty measures. Since our market return forecasts are constructed from a combination of short term and long term corporate profits forecasts, the results in Panel B suggest that the underlying driving force for our earlier results comes from long term corporate profits forecasts and not short term forecasts.

We now briefly consider some alternative specifications to investigate if our results crucially depend on measuring uncertainty with a symmetric beta distribution. In Panel A of Table V we measure uncertainty with a symmetric normal weighted variance in which the weights are

$$
w_{i t}(\xi)=\frac{\exp \left(\frac{-\left(i-\frac{f_{t}+1}{2}\right)^{2}}{\xi^{2}}\right)}{\sum_{j=1}^{f_{t}} \exp \left(\frac{-\left(j-\frac{f_{t}+1}{2}\right)^{2}}{\xi^{2}}\right)}
$$

where $\xi$ is a parameter. The results in Panel A are very similar to the results in specifications six and seven of Table II. The coefficients on uncertainty are virtually identical. The estimated normal weights place positive weights on the same parts the distribution of forecasts that the Beta weights do. There is strong evidence for a uncertainty-return trade-off even with a different specification of the cross-section weights. The estimates of Jensen's alpha also remain insignificant in all cases.

In Panel B of Table V we measure uncertainty with weights that are not restricted to being symmetric. We consider non-symmetric weights because forecasters might have significantly different beliefs than agents. The bias of forecasters might lead agents to be concerned about the uncertainty in pessimistic (or alternatively optimistic) forecasts. To allow for the possibility of bias, we use Beta weights in which the weights are

$$
w_{i t}(\alpha, \chi)=\frac{i^{\alpha-1}\left(f_{t}+1-i\right)^{\chi-1}}{\sum_{j=1}^{n} j^{\alpha-1}\left(f_{t}+1-j\right)^{\chi-1}}
$$

where $\alpha$ and $\chi$ are free parameters. This is the discretized Beta distribution described in Section 3 with $a=0$ and $d=f_{t}+1$. Allowing the weights to be non-symmetric lets the agents' perceived uncertainty depend on any part of the distribution of forecasts. If agents pay more attention to the variance in worse case forecasts then $\chi$ should be greater than $\alpha$ likewise if agents focus on rosy forecasts then $\chi$ should be less than $\alpha$. We find in Table $\mathrm{V}$ that the estimates of $\alpha$ and $\chi$ are not significantly different from each other. Since the estimate value of $\chi$ is slightly greater than $\alpha$, the estimated weights slightly emphasize the variance of pessimistic forecasts over optimistic forecasts, 
however there is not compelling evidence to suggest that non-symmetric weights more precisely measure perceived uncertainty than symmetric weights. ${ }^{20}$

In Panel $\mathrm{C}$ of Table V we measure uncertainty by the Beta-weighted variance of constructed market return forecasts when the long term horizon is three periods rather than four periods. Setting the long term horizon at three does better than setting the long term horizon at four. ${ }^{21}$ The Gordon growth model requires a long term horizon forecast and it is most natural to let the long term horizon be four because that is the longest horizon for which data is plentiful. It is slightly puzzling that a horizon of three performs better empirically than a horizon of four. Perhaps a horizon of four is too far ahead for forecasters to accurately report their beliefs. In this paper we choose to emphasize a horizon of four rather than three but it is important to note that our results would become stronger if we used a horizon of three. In particular, there is much stronger evidence for a uncertainty trade-off when the long term horizon is three rather than four. Finally, it is also worth noting again that the estimates of Jensen's alpha remain insignificant in all cases.

In Table VI we display results for several different types of fixed weighting schemes. In Panel A we fix, rather than estimate, $\log \nu$ at many different values. We see that uncertainty has a significant effect on market excess returns when $\log \nu$ is not small. In Panel B we measure uncertainty with a truncated variance where the lowest $p$ percent of forecasts and the highest $p$ percent of forecasts are discarded each quarter. We see that as long as $p$ is not small, uncertainty has a significant effect on market excess returns. In Panel $\mathrm{C}$ we Winsorize forecasts each quarter by replacing the lowest $p$ percent of forecasts and the highest $p$ percent of forecasts with lowest and highest forecasts in the middle $1-2 p$ percent of forecasts. We again see that as long as $p$ is not small, uncertainty has a significant effect on market excess returns. ${ }^{22}$ We also see that the likelihoods using the best settings of $p$ with truncated variances or Winsoration are virtually identical to the likelihoods with the optimal setting of $\log \nu$. Because less parameters are being estimated the standard errors for the uncertainty-return tradeoff can appear to be much smaller when $\log \nu$ or $p$ is fixed. One advantage of our weighting scheme is that it allows a researcher to estimate the weights and it provides a truer picture of standard errors. We conclude that our results are robust to weighting/truncation/Winsorization as long as extreme forecasts are down-weighted, removed or replaced.

To allow for additional ways in which the reference model could be misspecified we estimate a specification in which

$$
r_{e t+1} \sim N\left[b+\tau \operatorname{vol}_{t}(\omega)+\theta \operatorname{unc}_{t}(\nu), \sigma_{v}^{2} \operatorname{vol}_{t}(\omega)+\sigma_{u}^{2} \mathbf{u n c}_{t}(\nu)\right]
$$

\footnotetext{
${ }^{20}$ This is not a test of whether or not agents are worried about worst case outcomes. According to our approach agents choose the worst case based on their perceived amount of uncertainty [see equation (9)]. The issue in this paragraph is simply when computing perceived uncertainty should the weights across forecasts be symmetric or should they place more weight on the low or high end of the distribution.

${ }^{21}$ Given our results in Panel B of Table IV this is perhaps not surprising. Corporate profit growth forecasts at a horizon of three are more related to excess returns than corporate profit growth forecasts at a horizon of three.

${ }^{22}$ When $\log \nu$ is extremely large and $p$ is close to 50 , the significance can start to break down because only the very middle part of the distribution of forecasts are considered. For example, when $p$ is 49 only the middle two percent of forecasts are used to compute uncertainty.
} 
where $\sigma_{v} \geq 0$ and $\sigma_{u} \geq 0$. The term $\sigma_{u}^{2}$ unc $_{t}(\nu)$ in the variance of $r_{e t+1}$ embodies the notion that if the reference model is false then at the quarterly frequency the expected excess return should have a higher variance than is found in previous daily returns and the variance should depend on the magnitude of unc $t_{t}(\nu)$. In Table VII we show that estimates of $\sigma_{u}$ are not statistically significant. Moreover the mean of estimates of $\sigma_{u}^{2} \mathrm{unc}_{t}(\nu)$ is typically at least an order of magnitude smaller than the mean of estimates of $\sigma_{v}^{2} \operatorname{vol}_{t}(\omega)$ and sometimes much smaller. In Panel A, we estimate $\sigma_{u}, \log \nu$, and $\theta$ simultaneously which, because of singularities, leads to high standard errors for most parameters, including $\theta$. In Panel B, we fix the value of $\log \nu$ at several different values and show that $\theta$ is significant, provided $\log \nu$ is not small, and $\sigma_{u}$ is never significant. In all of the specifications allowing $\sigma_{u}$ to be greater than zero has almost no effect on the likelihood. We conclude that it is reasonable to assume that $\sigma_{u}$ is close to zero and in the rest of the paper we keep $\sigma_{u}$ fixed exactly at zero.

One possible concern about our empirical measure of model uncertainty is the implementation of a modified Gordon growth model to construct aggregate forecasts of market returns. Given that the first term of the model employs forecasted aggregate corporate profits scaled by a price variable, the critique exists that prices are driving our results. However this is not the case. Panel B of Table IV shows that the underlying driving force for our results is the second term, disagreement in long term forecasts of profits, which is not scaled by a price variable. In line four we see that disagreement in long term forecasts of profits does nearly as well as disagreement about our constructed market return. Moreover, one can show that the first term of the model is quantitatively small. This makes sense because there is more disagreement about long term profits than short term profits. The first term does have some predictive power and we include it because our theoretical model says it should be included.

Finally, as an additional robustness check, we break our sample into four subsamples of equal length and allow for time-varying aversion to uncertainty. Because this introduces several new parameters we do not also consider a risk-return tradeoff. We estimate different $\theta$ 's for each subsample simultaneously with $b, \sigma^{2}, \log \omega, \operatorname{and} \log \nu$. The later parameters are required to have the same value throughout the sample. In particular we estimate

$$
r_{e t+1} \sim N\left[b+\sum_{k \in \Omega} \theta_{k} \mathbf{1}_{t, k} \operatorname{unc}_{t}(\nu), \sigma^{2} \operatorname{vol}_{t}(\omega)\right]
$$

where

$$
\Omega=\{1968: 4-1977: 2,1977: 3-1986: 1,1986: 2-1994: 4,1995: 1-2003: 3\}
$$

and where the indicator function $\mathbf{1}_{t, k}$ is one if $t \in k$ and zero otherwise. The results in Table VIII show that estimates of $\theta_{k}$ are positive in all four subperiods and significantly different from zero in three of the four subperiods. When we allow for time-varying aversion to uncertainty, the increase in the likelihood, as compared to the likelihoods Table II, is small. We can not reject the hypothesis that all of the $\theta$ 's are equal and aversion to uncertainty is constant over time. 


\subsection{An index of uncertainty}

This section discusses a few of the empirical properties of estimated uncertainty. We let the index of uncertainty be the uncertainty series, unc $_{t}(15.346)$, estimated in the last regression in Table II. We plot the index in Figure 3 along with plots of excess returns and volatility. We provide some simple statistics in Table III and estimates of autoregressions in Table IX. Table III also presents correlations of $u_{t} c_{t}$ with the Fama-French factors.

It is well known that volatility is highly persistent. In our data, Table IX shows that quarterly volatility is positively and significantly related to its first three lags, that is three quarters. Uncertainty is also persistent but not as much as volatility. Uncertainty is positively and significantly related to its first two lags, or half a year.

Panel A of Table IX shows there is not a significant relationship between uncertainty and lagged volatility. We see from Table III, there is very little contemporaneous correlation between uncertainty and volatility. This suggests that the actual conditional variance (past volatility) has some, but not much, impact on the beliefs of agents about uncertainty.

Uncertainty is not highly correlated with future volatility. Past uncertainty does not predict future volatility and vice versa. Hence, volatility and uncertainty appear as nearly orthogonal processes. From Table III we see that unweighted uncertainty is slightly more related to future volatility than the optimally weighted uncertainty. Maybe the fringes of forecasts matter for volatility (i.e. maybe they are noise traders) but not for expected returns. However, this effect is not strong.

In Figure 4 we graph uncertainty with several different events. We see that uncertainty is often large just before the onset and just before the end of a recession. Whenever uncertainty has been unusually large, the market excess return in the following quarter has also been large. Two of the lowest readings of uncertainty occurred when incumbent presidents were re-elected (Nixon in 1972 and Clinton in 1996).

\section{Risk, uncertainty, and the cross-section of stocks}

In the previous section, we showed that market uncertainty matters for market returns. In this section, we investigate whether market risk and uncertainty matter for the cross-section by (1) studying the returns on portfolios with varying degrees of exposure to risk and uncertainty and (2) testing if exposure to risk and uncertainty can explain the returns on many other often studied portfolios.

The model presented in Section 1 implies that the conditional expected excess return of any asset $k$ is

$$
E_{t} r_{k t+1}=\beta_{v k} \gamma V_{t}+\beta_{u k} \theta M_{t}
$$


where $\beta_{v k}$ and $\beta_{u k}$ are regression coefficients of the the risk in asset $k$ on market risk and of the uncertainty in asset $k$ on market uncertainty. ${ }^{23}$ In Section 5 we estimated equation (36) for the market excess return using flexible functional forms for risk $V_{t}=\sigma^{2} \operatorname{vol}_{t}(\omega)$ and uncertainty $M_{t}=u_{n c}(\nu)$. In particular we estimated the nonlinear regression

$$
r_{e t+1}=b+\tau \operatorname{vol}_{t}(\omega)+\theta \mathrm{unc}_{t}(\nu)+\epsilon_{e t+1}
$$

where $\tau=\gamma \sigma^{2}$ and the conditional variance of $\epsilon_{e t+1}$ is $\sigma^{2} \operatorname{vol}_{t}(\omega)$. In most of this section we keep $b, \tau, \theta, \omega$ and $\nu$ fixed at their optimal market estimates, $\hat{b}=-0.012, \hat{\tau}=0.120, \hat{\theta}=1453.191, \hat{\omega}=14.939$ and $\hat{\nu}=15.346$ from Section 5, though we do present some results in which $\omega$ and $\nu$ are estimated entirely from the cross-section using no information (directly) from the market.

Taking unconditional expected values of equation (36) yields an expected return beta-formulation of our model

$$
E r_{k t+1}=\beta_{v k} \lambda_{v}+\beta_{u k} \lambda_{u}
$$

where the prices of risk and uncertainty are

$$
\begin{aligned}
& \lambda_{v}=E \gamma V_{t} \\
& \lambda_{u}=E \theta M_{t} .
\end{aligned}
$$

This formulation is straightforward but does not take advantage of the information about $\beta_{v k}$ in the contemporaneous correlation of $r_{e t+1}$ and $r_{k t+1}$.

An alternative expected return beta-formulation which exploits the contemporaneous correlation recovers $\beta_{v k}$ and $\beta_{u k}$ from a time series regression of $r_{k t+1}$ on $\left[r_{e t+1}-b-\theta \mathrm{unc}_{t}(\nu)\right]$ and $\theta \mathrm{unc}_{t}(\nu)$. To verify the alternative we write equation (36) for asset $k$ as

$$
r_{k t+1}=\beta_{v k} \tau \operatorname{vol}_{t}(\omega)+\beta_{u k} \theta \mathrm{unc}_{t}(\nu)+\epsilon_{k t+1}
$$

and decompose the error term $\epsilon_{k t+1}$ into two components:

$$
\epsilon_{k t+1}=\beta_{v k} \epsilon_{e t+1}+\varrho_{k t+1} .
$$

\footnotetext{
${ }^{23}$ We make the assumption throughout this paper that $\beta_{v k}$ and $\beta_{u k}$ are constant over time. As noted earlier, this assumption implies restrictions on the exogenous processes for the state vector and asset prices.
} 
The first component $\beta_{v k} \epsilon_{e t+1}$ depends on market noise and the second component $\varrho_{k t+1}$ is idiosyncratic noise for asset $k$ which is uncorrelated with market noise, $\epsilon_{e t+1}$, market risk, and market uncertainty. ${ }^{24}$ The time $t$ expected values of both errors terms, $\epsilon_{e t+1}$ and $\varrho_{k t+1}$, are zero. Substituting (41) into (40) and rearranging yields

$$
r_{k t+1}=\beta_{v k}\left[\tau \operatorname{vol}_{t}(\omega)+\epsilon_{e t+1}\right]+\beta_{u k} \theta \mathrm{unc}_{t}(\nu)+\varrho_{k t+1} .
$$

Since $\varrho_{k t+1}$ is orthogonal to $\operatorname{vol}_{t}(\omega), \epsilon_{e t+1}$, and unc ${ }_{t}(\nu)$ it follows that a population regression of $r_{k t+1}$ on $\left[r_{e t+1}-\right.$ $\left.b-\theta \operatorname{unc}_{t}(\nu)\right]$ and $\theta \operatorname{unc}_{t}(\nu)$ will yield estimates of the coefficients $\beta_{v k}$ and $\beta_{u k}{ }^{25}$ When we run the regression we also include a constant term, denoted $a_{k}$. We can think of this representation as a two factor model with the factors being a measure of market risk and a measure of market uncertainty.

In Section 6.1 we construct portfolios that are designed to have large and small values of $\beta_{v k}$ and $\beta_{u k}$ and study their returns. In Section 6.2 we use GMM to estimate $\beta_{v k}$ and $\beta_{u k}$ for 130 portfolios that have been studied in recent research and investigate the prices of risk and uncertainty. In Section 6.3 we use GMM to estimate a stochastic discount factor formulation of our model which allows us to easily estimate market risk, market uncertainty, and their impact on the cross-section of returns simultaneously.

\subsection{The return on uncertainty and risk portfolios}

We regress individual stock returns on $\left[r_{e t+1}-\hat{b}-\hat{\theta} \mathrm{unc}_{t}(\hat{\nu})\right]$ and $\hat{\theta} \mathrm{unc}_{t}(\hat{\nu})$ to yield estimates of $\beta_{v k}$ and $\beta_{u k}$ from equation (42). In order to efficiently estimate the betas we use a rolling sample regression method approach for each firm in the sample. We require that firms have a minimum of 20 quarters of returns in order to have well-behaved estimates. From the over 25,000 firms in the CRSP universe between fourth quarter 1969 and fourth quarter 2003, only 14,252 meet the requirements for rolling sample regressions. Rolling sample regressions are run for each firm where at least 20 quarters of returns are available, and estimates of $\beta_{v k}$ and $\beta_{u k}$ are collected from each firm in each quarter.

Portfolios of individual stocks are formed in two ways. First, we investigate portfolios sorted only on sensitivities to uncertainty, $\hat{\theta}$ unc $_{t}(\hat{\nu})$. In order to form portfolios, stocks are ranked each quarter according to the coefficient $\beta_{u k}$ on uncertainty. Stocks are then sorted into quintiles based on the exposure to uncertainty in each quarter. Within each quintile, stocks are value-weighted relative to the other firms in the quintile, which are then cumulated to form the portfolio return. Table X presents summary statistics for the five portfolios over the 121 quarters of the sample. Average returns to portfolios sorted on sensitivities to uncertainty range from $1.7 \%$ to $3.6 \%$ per quarter on average.

\footnotetext{
${ }^{24}$ The assumption that $\beta_{v k}$ is constant over time allows us to make this decomposition.

${ }^{25}$ Note that equation (37) guarantees that $\left[r_{e t+1}-b-\theta \operatorname{unc}_{t}(\nu)\right]=\tau$ vol $(\omega)+\epsilon_{t+1}$. Also note that since $\left(\beta_{v k} \epsilon_{e t+1}+\varrho_{k t+1}\right)$ and $\epsilon_{t+1}$ are orthogonal to unc $t_{t}(\nu)$, it follows that $\varrho_{k t+1}$ is orthogonal to unc $t(\nu)$.
} 
Even though our standard errors for all of the portfolios are large and the returns cannot be statistically distinguished due to our small sample size, it is still interesting to investigate if there is any evidence that firms with large exposure to uncertainty have higher returns. Excluding the quintile of stocks with the very lowest exposure to uncertainty, stocks with a larger exposure to uncertainty have higher returns. The returns on stocks with the most exposure to uncertainty are especially large. Table $\mathrm{X}$ also provides summary statistics on the weights of each portfolio over the time period relative to the CRSP universe. Because the sample contains approximately $60 \%$ of the number of stocks in the CRSP universe, the weights do not sum to $100 \%$. Portfolios with extreme sensitivity to uncertainty tend to be smaller as a fraction of the CRSP universe; however, the distributional characteristics show that there is high variation in the weights of stocks within the portfolios over the sample.

We also form portfolios by sorting on sensitivities to risk and uncertainty. Similar to the method described above, we first rank stocks according to $\beta_{u k}$ and form three portfolios. For each of these portfolios, we then rank stocks by $\beta_{v k}$ and sort into three portfolios. The resulting nine portfolios have varying exposure to risk and uncertainty and we examine summary statistics for these portfolios in Table XI. Even though our standard errors for all of the portfolios are again large and the returns cannot be statistically distinguished due to our small sample size, it is again interesting to investigate if there is any evidence that firms with large exposure to risk and uncertainty have higher returns. Regardless of the level of risk exposure, the average returns on portfolios are increasing in exposure to uncertainty with one exception: medium uncertainty, low risk stocks have a higher return than high uncertainty, low risk stocks. Regardless of the level of uncertainty exposure, the average returns on portfolios are increasing in exposure to risk with two exceptions: medium risk stocks have lower returns that low risk stocks when the stocks have either a low or medium exposure to uncertainty. As in Table X, a summary of portfolio weights is also included. Stocks with low exposure of risk are generally larger than stocks with high exposure to risk, while stocks with moderate uncertainty exposure tend to be larger on average than stocks in either the low or high uncertainty portfolios.

\subsection{Estimating an expected return-beta representation}

In this section we use GMM to estimate an expected-return beta representation and investigate if risk and uncertainty can help explain the returns on 130 portfolios which have been the subject of many previous studies. The 130 portfolios include 25 portfolios sorted on size and book to market, 25 portfolios sorted on size and short-term reversal, 25 portfolios sorted on size and momentum, 25 portfolios sorted on size and long-term reversal, 10 portfolios sorted on earnings to price, 10 portfolios sorted on dividend to price, and 10 portfolios sorted on cashflow to price. Data for all the portfolios was obtained from Kenneth French's web site. Real excess returns were formed by subtracting the nominal risk-free rate and adjusting for inflation with the CPI. ${ }^{26}$

\footnotetext{
${ }^{26}$ Summary statistics are available upon request.
} 
Our two factor risk and uncertainty model implies that the expected excess return on any portfolio, $E r_{k t+1}$, should be linearly related

$$
E r_{k t+1}=\beta_{v k} \lambda_{v}+\beta_{u k} \lambda_{u}+\iota_{k}
$$

to sensitivities to market risk $\beta_{v k}$ and market uncertainty $\beta_{u k}$ where $\iota_{k}$ is a pricing error for asset $k$ which according to our model should be zero. Here $\beta_{v k}$ and $\beta_{u k}$ are coefficients in a time-series regression of $r_{k t+1}$ on a constant $a_{k}$, market risk and market uncertainty:

$$
r_{k t+1}=a_{k}+\beta_{v k} \dot{V}_{t}+\beta_{u k} \dot{M}_{t}+\varrho_{k t+1}
$$

where

$$
\begin{aligned}
\dot{V}_{t} & =\hat{\tau} \operatorname{vol}_{t}(\hat{\omega})+\hat{\epsilon}_{e t+1} \\
\dot{M}_{t} & =\hat{\theta} \operatorname{unc}_{t}(\hat{\nu})
\end{aligned}
$$

and where the hats denote variables fixed at market estimates. We investigate if the price of risk, $\lambda_{v}$, and the price of uncertainty, $\lambda_{u}$, are significant; and if the pricing errors, $\iota_{k}$, for all assets are jointly close to zero.

We estimate the cross-sectional relationships in equation (43) and the time-series regressions in equation (44) simultaneously using GMM. For each asset $k$ we have the moment conditions

$$
E\left[\begin{array}{c}
r_{k t+1}-a_{k}-\beta_{v k} \dot{V}_{t}-\beta_{u k} \dot{M}_{t} \\
\left(r_{k t+1}-a_{k}-\beta_{v k} \dot{V}_{t}-\beta_{u k} \dot{M}_{t}\right) \dot{V}_{t} \\
\left(r_{k t+1}-a_{k}-\beta_{v k} \dot{V}_{t}-\beta_{u k} \dot{M}_{t}\right) \dot{M}_{t} \\
r_{k t+1}-\beta_{v k} \lambda_{v}-\beta_{u k} \lambda_{u}
\end{array}\right]=0 .
$$

The moment conditions for all assets combined yield a system for which we can estimate the scalars $\lambda_{v}$ and $\lambda_{u}$ (which do not vary across assets) as well as $a_{k}, \beta_{v k}$, and $\beta_{u k}$ (which vary across assets). When there are $n$ assets there are $4 n$ moment conditions and $(3 n+2)$ parameters.

The GMM estimation of our joint system involves setting $(3 n+2)$ linear combinations of the sample moments equal to zero. More formally GMM sets

$$
a_{T} g_{T}=0
$$

where $a_{T}$ is a $(3 n+2)$ by $4 n$ matrix and $g_{T}$ is a $4 n$ by 1 vector of sample means corresponding to the moment conditions in equation (45) for all assets. Similar to Cochrane (2005) we specify the matrix $a_{T}$ so that GMM estimates of the time series parameters $\left(a_{k}, \beta_{v k}\right.$, and $\beta_{u k}$ for all assets) are identical to their least squares estimates and GMM estimates of the cross-sectional parameters (the scalars $\lambda_{v}$ and $\lambda_{u}$ ) are identical to their GLS estimates. 
Unlike Cochrane (2005) we use the covariance matrix of all assets as the weighting matrix for the GLS estimates of $\lambda_{v}$ and $\lambda_{u}$ rather than the covariance matrix of the residuals from the time series regressions. ${ }^{27}$ Even though our GMM estimates are identical to least squares and GLS estimates, estimating our system with GMM is convenient because GMM allows us to easily produce asymptotic standard errors for $\lambda_{v}$ and $\lambda_{u}$ which take into account that the time-series and cross-sectional regressions are estimated simultaneously. ${ }^{28}$

We find in Table XII that the price of risk is negative and not significant. While our sample has a quarterly frequency, this result is in line with the analysis of Ang, Hodrick, Xing, and Zhang (2006) who examine the pricing of aggregate volatility risk in a monthly cross-sectional analysis of stock returns. In contrast to the price of risk, the price of uncertainty is relatively large and positive. In estimating the prices of risk and uncertainty we have used standard reduced form econometric techniques even though our model has predictions for these values which were displayed in equations (38) and (39). The price of uncertainty, $\lambda_{u}$, should be the unconditional expectation of $\hat{\theta} \mathrm{unc}_{t}(\hat{\nu})$ and the price of risk should be the unconditional expectation of $\hat{\tau} \operatorname{vol}_{t}(\hat{\omega})$. We see that in model one of Table XII the estimate of $\lambda_{u}, 0.027$, is very close to the sample mean of $\hat{\theta} \mathrm{unc}_{t}(\hat{\nu})$ which is 0.025 . The standard error of the estimate of $\lambda_{u}$ tell us that we can not reject its value being 0.025 , confirming a prediction of our model. Our estimate of the price of risk, $\lambda_{v},-0.011$, is also statistically close to the sample mean of $\hat{\tau} \operatorname{vol}_{t}(\hat{\omega})$ which is $0.001 .^{29}$

In Table XII we also present results for the CAPM and the Fama-French factors (including factors for momentum, short-term reversal, and long-term reversal). We use GMM to estimate various versions of the joint time-series and cross-sectional system where in some specification we include the market excess return, the HML, the SMB, the UMD, the STR (Short-Term Reversal), and the LTR (Long-Term Reversal) factors, in addition to risk and uncertainty factors. ${ }^{30}$ The results for specification six in Table XII shows that including additional factors does not affect estimates of the price of uncertainty or its standard error. The prices of all of the Fama-French factors are significantly positive except for the price of SMB which is insignificantly negative. In specifications five, six and seven the estimates of the standard errors of the price of uncertainty are smaller than estimates of the standard errors for the price of any other factor and estimates of its t-statistics are larger than the estimates for any other factor.

In specifications two and seven we measure risk with $\hat{\tau} \operatorname{vol}_{t}(\hat{\omega})$ rather than with $\left[r_{e t+1}-b-\theta\right.$ unc $\left._{t}(\hat{\nu})\right]$ and find that the price of risk is not significantly altered.

One way to evaluate the performance of models is to look at pricing errors. The J-stats presented in Table XII provide a measure of how big the pricing errors are for all of assets and the corresponding P-values tell us how likely it is to see pricing errors at least this large. Our results show that with probability one we should see pricing errors

\footnotetext{
${ }^{27}$ In our approach the GLS weighting matrix does not depend on the time-series estimates and thus is the same regardless of which factors are included, though using the weighting matrix advocated by Cochrane (2005) would not lead to a substantial change in our results.

${ }^{28}$ To compute the spectral density matrix at frequency zero, a key ingredient of GMM standard errors, we use the method of Newey and West (1987) with eight lags.

${ }^{29}$ Note that the sample mean of $\hat{\tau} \operatorname{vol}_{t}(\hat{\omega})$ is equal to the sample mean of $\left[r_{e t+1}-b-\theta\right.$ unc $\left._{t}(\hat{\nu})\right]$.

${ }^{30}$ The data for these factors were obtained from Kenneth French's web page. The factors were adjusted for inflation with the CPI.
} 
as large as observed for all our models. However given the large number of moment conditions and the fact that $\mathrm{J}$-stats require the pseudo-inversion of a term which involves the spectral density matrix, $S$, the results for the J-stats should be viewed with caution. Estimates of standard errors of parameters do not require an inversion of $S$ and can be viewed as being more reliable. ${ }^{31}$

One drawback of the approach taken in this section is that although the standard errors reported in Tables XII are GMM standard errors for joint time-series and cross-sectional system that take into account that the betas are estimated, they do not take into account that the nonlinear parameters $\omega$ and $\nu$ were pre-estimated from the market. The next section will study the same 130 portfolios with a stochastic discount factor representation that allows us to jointly estimate the betas, the lambdas, and the nonlinear parameters $\omega$ and $\nu$ using information from the crosssection.

\subsection{Estimating a stochastic discount factor representation}

In this section we estimate a stochastic discount factor representation of our model. We form the stochastic discount factor

$$
s_{t+1}=a+s_{v}\left[\hat{\tau} \operatorname{vol}_{t}(\omega)\right]+s_{u}\left[\hat{\theta} \operatorname{unc}_{t}(\nu)\right]
$$

and use the implication of our model that

$$
E s_{t+1} r_{j t+1}=1
$$

for any asset return $r_{j t+1}$, at any date, to estimate $a, s_{v}$, and $s_{u}$ as well as $\omega$ and $\nu \cdot{ }^{32}$ As discussed by Cochrane (2005) estimates of $s_{v}$ and $s_{u}$ are directly related to estimates of $\lambda_{v}$ and $\lambda_{u}$ in the expected return beta-formulation of our model, equation (43), but answer the question whether risk and and uncertainty can help explain the return on assets given the other factors rather than the question are risk and uncertainty priced. For us the stochastic discount factor representation is especially convenient because it is easily amendable to estimating the nonlinear parameters $\omega$ and $\nu$ from the cross-section. For asset returns, we use data on gross returns rather than excess returns and emphasize the measure $\hat{\tau} \operatorname{vol}_{t}(\omega)$ of risk though we present results for both of our specifications of risk. ${ }^{33}$ We discuss results for the fixed weighting matrix proposed by Hansen and Jagannathan (1997) [hereafter referred to as the HJ weighting matrix] and the optimal GMM weighting matrix discussed by Hansen (1982). For comparison purposes we also study specifications of the stochastic discount factor where the Fama-French factors enter linearly.

\footnotetext{
${ }^{31}$ When computing the spectral density matrix we did not subtract sample means. Asymptotically, subtracting sample means should not matter if our models are correct. However in finite samples it does matter and would drastically change our reported J-stats and P-values. It would however have no noticeable effect on our estimates of standard errors.

${ }^{32}$ The parameters $\tau$ and $\theta$ are fixed at $\hat{\tau}$ and $\hat{\theta}$ throughout to achieve a convenient scaling of risk and uncertainty. This has no effect on the fit of the model.

${ }^{33} \mathrm{We}$ emphasize $\hat{\tau} \operatorname{vol}_{t}(\omega)$ as a measure of risk because it is not possible to estimate $\omega$ and $\nu$ together when risk is measured with $\left[r_{e t+1}-b-\theta \mathrm{unc}_{t}(\nu)\right]$.
} 
In Table XIII we estimate the contributions of risk and uncertainty to the stochastic discount factor when attempting to explain the returns on the same 130 portfolios studied in Section 6.2. Estimates of the contribution of uncertainty, $s_{u}$, are fairly constant across specifications and independent of the weighting matrix employed. For the HJ weighting matrix estimates of $s_{u}$ are significant: (1) in the two factor model both when $\nu$ is estimated and when it is fixed, and (2) in the presence of the Fama-French factors when $\nu$ is fixed but not when $\nu$ is re-estimated. For the optimal weighting matrix, estimates of $s_{u}$ are significant in all specifications regardless of which factors are present or if $\nu$ is re-estimated.

When we re-estimate the nonlinear parameters, $\omega$ and $\nu$, we find that estimates are similar to the market estimates presented in Section 5. Estimates of $\log \nu$ range from 2.230 to 2.717 which are very close to its market estimate of 2.731. Estimates of $\log \omega$ range from 4.116 to 4.491 which, given its large standard errors, are statistically close to its market estimate of 2.704. This provides additional confirming evidence for our estimated weighting scheme that emphasizes the dispersion of non-extreme forecasts and the MIDAS weighting scheme which places more weight on recent daily volatility.

In Panel A of Table XIII we provide results for the Hansen-Jagannathan distance (hereafter the HJ-dist) which measures how far a candidate stochastic discount factor is from a stochastic discount factor which can unconditionally exactly price all assets. We find that all models perform poorly on this criteria and the standard errors of the HJ-dist indicate that the performance of the models are indistinguishable. There is not a significant drop in the HJdist when uncertainty is added to the Fama-French factors or the CAPM. The Fama-French factors and the CAPM do not perform any better: there is not a significant drop in the HJ-dist when the Fama-French factors are added to the CAPM or, in results available upon request, when the market is added to a constant stochastic discount factor.

Given the large number of moment conditions used and the fact that the optimal weighting matrix requires the inversion of the spectral density matrix the results for the optimal weighting matrix should be viewed with caution. The results for the $\mathrm{HJ}$ weighting matrix, including the HJ-dist and the standard errors for parameters, do not require inverting $S$ and are not as problematic.

\subsection{Summary}

Uncertainty by no means provide a complete explanation of the cross-section of stocks but there is evidence that uncertainty matters. In particular for portfolios often studied in the literature we find that: (1) estimates of the price of uncertainty are very significant in all specifications considered and are consistent with market estimates; (2) in the two factor model, uncertainty significantly contributes to the stochastic discount factor for both the optimal weighting matrix and the HJ weighting matrix regardless of whether the nonlinear parameters are fixed or re-estimated; (3) in the presence of the Fama-French factors, uncertainty significantly contributes to the stochastic discount factor when 
the optimal weighting matrix is used (regardless of whether the nonlinear parameters are fixed or re-estimated) and with the HJ weighting matrix, uncertainty significantly contributes to the stochastic discount factor when the nonlinear parameters are fixed but not when they are re-estimated; and (4) estimates of the nonlinear parameter $\nu$ are very significant and similar to its market estimate for both the optimal weighting matrix and the HJ weighting matrix.

On the other hand, there is not a significant drop in the HJ-dist when uncertainty is added to the CAPM or when uncertainty is added to the Fama-French factors. The problems we face in the cross-section are similar to the problems all models face in explaining the cross-section. For example, when Fama-French factors are added to the market return there is not a significant drop in the HJ-dist. Similar negative results for asset pricing models are abundant in the literature. Hansen and Jagannathan (1997) show that the CAPM and consumption based models are not much of an improvement over a constant discount factor. Lewellen, Nagel, and Shanken (2006) show that although many models perform well on the 25 portfolios sorted on size and book to market the same models perform poorly on other assets.

\section{Conclusions}

An important strand of recent research in finance contends that uncertainty, in addition to risk, should matter for asset pricing. Uncertainty exists when agents are unsure of the correct probability law governing the mean market return and thus demand a higher premium to hold the market return and stocks whose uncertainty is correlated with the uncertainty of the market. We derive equilibrium implications for the market excess return and the cross-section of returns in the presence of uncertainty. Although uncertainty is difficult to measure, we suggest a reasonable proxy for the amount of uncertainty in the economy is the degree of disagreement of professional forecasters. In contrast to prior literature, which has focused on disagreement about individual stocks, our emphasis is on aggregate measures of disagreement. In addition, we offer an alternative explanation for why disagreement is priced, namely that economic agents interpret disagreement as model uncertainty.

We propose a measure of uncertainty which is constructed using a flexible weighting scheme that can accommodate assigning more or less weight to extreme forecasts. Our estimates of the optimal weights entail ignoring the extremes and placing nearly all of the weight on the center of the distribution. We find that uncertainty is empirically significantly related to market returns only when unequal weighting schemes are implemented. Flat weighted measures of uncertainty are not highly correlated with the market return and do not have a significant effect in regressions.

Uncertainty seems to be different from risk and seems to have a different effect on returns than risk. Uncertainty is highly correlated with the market excess return whereas risk is not. Uncertainty has a very weak correlation with 
risk and past uncertainty has no predictive ability of future risk or vice versa. We find stronger empirical evidence for a uncertainty-return trade-off than for the traditional risk-return trade-off. Further, our measure of uncertainty does not seem to encompass risk.

Our results are generally not sensitive to the measure of uncertainty we construct as long as extreme forecasts are removed, replaced or down-weighted. We find similar results if aggregate corporate profits forecasts are used instead of constructed aggregate market return forecasts. Uncertainty aversion is significant across sub-periods of our sample and whenever uncertainty has been unusually large, the market excess return the subsequent quarter has also been large. Interestingly, two of the lowest values of uncertainty occurred when Presidents Nixon and Clinton were re-elected.

We also investigated the importance of uncertainty for the cross-section and found that the price of uncertainty is significantly positive and that uncertainty contributes to the explanation of the returns on other assets in the presence of the Fama-French factors. However uncertainty can not explain the complete cross-section of stocks and does not lead to a significant reduction in the HJ-dist.

Our results, thus, provide empirical support to recent research in finance which contends that uncertainty, in addition to risk, matters for asset pricing. 


\section{A. Data}

This Appendix describes the details of the data and is organized into several subsections. Subsection A.1 describes the Survey of Professional Forecasters. Subsection A.2 discusses how we compute growth rate forecasts from level forecasts and how we compute real forecasts from nominal forecasts. Subsection A.3 explains the computations of asset return forecasts.

\section{A.1. The Survey of Professional Forecasters}

The Survey of Professional Forecasters (henceforth SPF) began in the fourth quarter of 1968 as a joint project between the American Statistical Association (ASA) and the National Bureau of Economic Research (NBER). In the first quarter of 1990, the ASA/NBER discontinued the project. The Federal Reserve Bank of Philadelphia (FRB-Philadelphia) reinstated the SPF in the third quarter of $1990 .{ }^{34}$ The SPF provides a long time series of data. Each quarter participants are asked for predictions of the levels for the previous quarter, this quarter, next quarter, two quarters ahead, three quarters ahead and four quarters ahead. ${ }^{35}$

The number of forecasters participating in the SPF has varied through time. The average (median) number of forecasts between 1968 and 2004 is 39.5 (36). In the early years, the number occasionally increased to greater than 100 forecasters, but began to decline nearly monotonically throughout the 1970s and 1980s. After the FRB-Philadelphia took over the SPF in 1990, the average (median) number of forecasters each quarter is 36 (35), with a low of 29 and a high of $52 .{ }^{36}$ Not all forecasts are usable because some are incomplete. Across all dates, we were able to use a median of 26 forecasts, a min of 9 , and a max of 74 .

Since the survey began, several series have been added, a few have been dropped, and some have been replaced with similar series. In the early 1990's, (1992Q1) output forecasts switched from being forecasts of GNP to being forecasts of GDP. At the same time forecasts of the GNP deflator were replaced by forecasts of the GDP deflator. The switch coincided with the substitution of GNP by GDP undertaken by the Bureau of Economic Analysis. Forecasts of real consumption expenditures and the consumer price index were both added to the survey in the third quarter of 1981.

The series we use from the SPF are nominal GDP (GNP), GDP (GNP) deflator, and corporate profits after taxes. We discard forecasts that were incomplete at a particular date. In order for a forecaster's forecasts to be included at a particular date it is necessary that he provide forecasts for the three variables for this quarter, next quarter, two quarters ahead, and three quarters ahead. Forecasts were not dropped if forecasts four quarters ahead were not provided.

\section{A.2. Computing quarterly real growth rate forecasts}

For some of our variables we need to construct implied real growth rates from nominal forecasts. For example, we need forecasts of the real rate of corporate profit growth but in the SPF only forecasts of the nominal level of corporate profits are provided. We compute approximate

\footnotetext{
${ }^{34}$ See the web-page http://www.phil.frb.org/econ/spf/index.html and a comprehensive overview Croushore (1993) for more information about the survey.

${ }^{35}$ Data on forecasts four quarters ahead is sparse in the initial years of the survey. Data on forecasts for the previous quarter are included because the actual final values for last quarter may not be known perfectly. Respondents are given preliminary estimates of last quarter's values and most respondents report these estimates as their forecasts.

${ }^{36}$ There are some extreme low numbers in the second and third quarters of 1990 and they correspond to the transfer of the survey from the ASA/NBER to the FRB-Philadelphia. To avoid having a missing data point, they included a 1990Q2 survey with the 1990Q3 survey. The total number of respondents was nine.
} 
real forecasts from nominal forecasts and forecasts of the price level. The constructed gross quarterly forecasted rate of real growth, according to forecaster $i$, in the nominally forecasted variable $X$ between quarters $m$ and $n$ is

$$
\left(\frac{E_{i t} X_{n} E_{i t} P_{m}}{E_{i t} X_{m} E_{i t} P_{n}}\right)^{\frac{1}{n-m}}
$$

where $P_{q}$ is the price level at time $q$. In general this is only an approximation since usually

$$
E_{i t}\left[\left(\frac{X_{n} P_{m}}{X_{m} P_{n}}\right)^{\frac{1}{n-m}}\right] \neq\left(\frac{E_{i t} X_{n} E_{i t} P_{m}}{E_{i t} X_{m} E_{i t} P_{n}}\right)^{\frac{1}{n-m}}
$$

even when $t=m$ and $n=m+1$. For forecasts of the price level we use forecasts of the output deflator since forecasts of the CPI only became available in the fourth quarter of $1991 .^{37}$

\section{A.3. Computing asset return forecasts}

In this section we discuss how we compute forecasts of the real market return and forecasts of the real return on a nominally risk-free bond. We construct forecasts of the real market return from forecasts of nominal corporate profits and the price level by using the Gordon growth model. We construct forecasts of the real return on a nominally risk-free bond from the known (actual) nominal risk-free rate and forecasts of the price level.

The Gordon growth model (or dividend discount model) is a widely used method of stock valuation linking the current stock price, the current level of the dividend, the expected growth rate of dividends, and the capitalization rate. Wiese (1930) and Williams (1938) were among the first to apply present value theory to common stocks; however, their models suffered from the assumptions about the magnitude and timing of dividend payouts. Gordon (1962) popularized the model by assuming a constant growth rate of dividends into the future and a terminal price for the holding period. Anderson, Ghysels, and Juergens (2005), Brav, Lehavy, and Michaely (2004), Crombez (2001), Gebhardt, Lee, and Swaminathan (2001), and Guay, Kothari, and Shu (2003), among others, have utilized short-term earnings and long-term earnings growth forecasts of investment analysts as inputs to the Gordon growth model. Jagannathan, McGrattan, and Scherbina (1996) have used variations of the Gordon growth model, related to Campbell and Shiller (1988), in resolving the equity premium puzzle.

In this paper we use corporate profits forecasts rather than earnings forecasts as inputs to the Gordon growth model. Let $\pi_{t}$ be aggregate corporate profits and $q_{t}$ the market value of all domestic corporations at time $t .{ }^{38}$ For us, the Gordon growth model amounts to assuming that forecaster $i$ 's constructed prediction of the return on the market is

$$
E_{i t} r_{m t+1}=E_{i t}\left[\frac{\pi_{t+1}}{q_{t}}\right]+\xi_{i t}
$$

where $\xi_{i t}$ is forecaster $i$ 's predicted gross growth rate of corporate profits over a long horizon.

We face a difficult timing issue when implementing equation (3). Forecasts in the SPF are given in the middle of a quarter. For example forecasts made during the first quarter of 2001 had to be returned to the Federal Reserve Bank of Philadelphia no later than February $12,2001$. In the 2001Q1 survey, forecasters were asked to provide predictions for the previous quarter (2000Q4), the current quarter (2001Q1), the next quarter (2001Q2), two quarters ahead (2001Q3), three quarters ahead (2001Q4), and four quarters ahead (2002Q1). Since some information about the values of the variables in the first quarter may be learned in January it would be inappropriate to view the forecasts for the current quarter as being forecasts stated during $t=2000 Q 4$ of $t+1=2001 Q 1$ values. One could view the forecasts for next quarter as stated during

\footnotetext{
${ }^{37}$ When we deflate the actual level of variables we do use the CPI.

${ }^{38}$ Ideally we would like forecasts of corporate profits without any seasonal adjustment but in the SPF forecasters are asked to predict deseasonalized corporate profits.
} 
$t=2001 Q 1$ and of $t+1=2001 Q 2$ values. However this neglects the short term information in the current quarter forecasts. Consequently, when implementing the Gordon growth model, we interpret the sum of forecasts stated for the current quarter's and next quarter's corporate profits (deflated by forecasts of the price level), divided by two, as effectively being forecasts stated during $t=2001 Q 1$ of $t+1=2001 Q 2$ corporate profits. $^{39}$

For the long term growth rate, $\xi_{i t}$, we use forecaster $i$ 's predicted growth rate of corporate profits over the longest horizon available in the SPF. Since in the early years of the survey forecasts for levels four quarters ahead are very sparse, we usually let the forecast horizon be from last quarter to three quarters ahead. We refer to this as a horizon of four. So in the first quarter of 1975 we consider the forecasted growth rate from the fourth quarter of 1974 to the fourth quarter of 1975.

We also need to compute the expected real return on a nominally risk-free bond. We approximate forecaster $i$ 's prediction of the real return on a nominally risk-free bond with

$$
E_{i t} r_{b t+1}=\frac{R_{b+1} P_{t}}{E_{i t} P_{t+1}}
$$

where $R_{b t+1}$ is nominal return on the bond (which is known at time $t$ ) and $P_{t}$ is the time $t$ value of the output deflator. In general this is an approximation because usually

$$
\frac{R_{b+1} P_{t}}{E_{i t} P_{t+1}} \neq R_{b+1} P_{t} E_{i t}\left[\frac{1}{P_{t+1}}\right]
$$

Table I shows that for the real market, the Gordon growth model gives a reasonable approximation of the unconditional mean return. For the period between 1968 and 2003 the average median forecast of the market return computed from the Gordon growth model (with $\xi_{t}$ being the forecasted average return from the last period to three quarters ahead - a horizon of four) slightly overestimates the actual average market return. Table I also shows that the average median forecasts computed using the formula in equation (4) are very close to the actual average real return on a nominally risk-free bond.

\section{B. Uncertainty and disagreement}

In this appendix we describe an environment in which disagreement is directly related to uncertainty. We assume forecasters have prior information about the market return and every period observe a vector of information that is related to the market return. We provide conditions under which the amount of uncertainty in the economy is always proportional to the amount of disagreement.

In order to illustrate the relationship between uncertainty and disagreement we take strong stand on the types of models forecasters are using. We assume each forecaster's uncertainty is limited to uncertainty in the mean of the market return. Assume there are $n$ forecasters and that before observing a vector of observations at time $t$ forecaster $i$ believes that the mean of the market return is approximately $\mu_{i t-1}$. The confidence of forecaster $i$ in this belief is measured with

$$
P_{i t-1}=E_{i t-1}\left[\left(\mu_{i t-1}-\mu_{t-1}\right)^{2}\right]
$$

where $\mu_{t-1}$ is the true mean of the market return and $E_{i t-1}$ denotes the expectation with respect to information available to forecaster $i$ at time $t-1 .^{40}$ We call $P_{i t-1}$ the uncertainty of forecaster $i$. We assume $P_{i t-1}$ (but not $\mu_{i t-1}$ ) is constant across forecasters. We will call $P_{t-1}=P_{i t-1}$ the amount of uncertainty in the economy at the end of period $t-1$.

\footnotetext{
${ }^{39}$ This assumption does not have a large effect on our results. If we implemented the Gordon growth model literally and ignored current quarter stated corporate profits forecasts, our results are essentially the same.

${ }^{40}$ In this appendix we recycle notation. The definitions of symbols apply only for this appendix.
} 
The true mean of the market return evolves over time:

$$
\mu_{t}=A_{t-1} \mu_{t-1}+\iota_{t}
$$

where $\iota_{t}$ is an unobserved scalar standard normal random variable with mean zero and variance $Q_{t-1}$. Forecasters know the values of $A_{t-1}$ and $Q_{t-1}$ at time $t-1$.

Each period, all forecasters simultaneously observe a different vector of random variables. Forecaster $i$ observes the vector

$$
z_{i t}=G_{t-1} \mu_{t-1}+w_{t}+w_{i t}
$$

where $\mu_{t-1}$ is the true mean of the market return; $w_{t}$ is a vector of independent normal random variables with mean zero and covariance matrix $H_{t-1}$; and $w_{i t-1}$ is a vector of normal random variables with mean zero and covariance matrix $K_{t-1}$. We assume $G_{t-1}, H_{t-1}$ and $K_{t-1}$ are constant across forecasters and that their values are known at time $t-1$. We assume $w_{i t}$ is independent of $w_{s}$ for any $s$, independent of $w_{i s}$ when $s \neq t$, and independent of $w_{j s}$ when $j \neq i$ for any $s$, The vector $w_{t}$ includes information that is common to all forecasters and the vector $w_{i t}$ includes information that is specific to forecaster $i$. Forecaster $i$ does not observe $z_{j t}$ or $\mu_{j t-1}$ for $j \neq i, \mu_{t-1}, w_{t}$ or $w_{i t}$ for any $i$. He only observes $z_{i t}$. We assume $K_{t-1}$ is positive semi-definite, $H_{t-1}$ is positive semi-definite, and the sum $K_{t-1}+H_{t-1}$ is positive definite.

After seeing $z_{i t}$, forecaster $i$ 's belief about the mean of the market return for the next period is

$$
\mu_{i t}=A_{t-1}\left[1+P_{t-1} G_{t-1}^{\prime}\left(H_{t-1}+K_{t-1}\right)^{-1} G_{t-1}\right]^{-1}\left(\mu_{i t-1}+P_{t-1} G_{t-1}^{\prime}\left(H_{t-1}+K_{t-1}\right)^{-1} z_{i t}\right)
$$

and a measure of his confidence in this belief is

$$
P_{t}=A_{t-1}^{2} P_{t-1}\left[1+G_{t-1}^{\prime}\left(H_{t-1}+K_{t-1}\right)^{-1} G_{t-1} P_{t-1}\right]^{-1}+Q_{t-1}
$$

These formulas are a special case of the updating equations for the Kalman filter. Here $P_{t}$ is the amount of uncertainty at the end of period $t$.

Let the amount of disagreement before forecasters observe $z_{i t}$ be denoted $\mathcal{D}_{t-1}$. This is measured as the variance of $\mu_{i t-1}$ across forecasters. Since in this simple example all forecasters have the same amount of uncertainty an equally weighted variance is sensible. After observing $z_{i t}$ the amount of disagreement about the return at time $t+1$, which is the variance of $\mu_{i t}$ across forecasters, is

$$
\begin{aligned}
\mathcal{D}_{t}=A_{t-1}^{2}\left[1+P_{t-1} G_{t-1}^{\prime}\right. & \left.\left(H_{t-1}+K_{t-1}\right)^{-1} G_{t-1}\right]^{-1} \\
\left(\mathcal{D}_{t-1}+P_{t-1} G_{t-1}^{\prime}\left(H_{t-1}+K_{t-1}\right)^{-1} K_{t-1}\left(H_{t-1}+K_{t-1}\right)^{-1} G_{t-1} P_{t-1}\right) & {\left[1+P_{t-1} G_{t-1}^{\prime}\left(H_{t-1}+K_{t-1}\right)^{-1} G_{t-1}\right]^{-1} . }
\end{aligned}
$$

Define the scalars

$$
\phi_{d t-1}=\frac{\mathcal{D}_{t-1}}{P_{t-1}} \quad \phi_{f t-1}=\frac{G_{t-1}^{\prime}\left(H_{t-1}+K_{t-1}\right)^{-1} K_{t-1}\left(H_{t-1}+K_{t-1}\right)^{-1} G_{t-1}}{G_{t-1}^{\prime}\left(H_{t-1}+K_{t-1}\right)^{-1} G_{t-1}}
$$

to be respectively the ratios of the amount of a priori disagreement to uncertainty and a measure of the ratio of the amount of idiosyncratic observation noise to the total observation noise. The interpretation of $\phi_{f t-1}$ is valid when $G_{t-1}, H_{t-1}$ and $K_{t-1}$ are all scalars, in which case

$$
\phi_{f t-1}=\frac{K_{t-1}}{H_{t-1}+K_{t-1}},
$$

and heuristic otherwise. 
Consider an example in which $Q_{t}=0$ for all $t$. In this case if $\phi_{d t-1}$ and $\phi_{f t-1}$ are equal to each other, call their common value $\phi_{t-1}$, then $\mathcal{D}_{t-1}=\phi_{t-1} P_{t-1}$ and

$$
\mathcal{D}_{t}=\phi_{t-1} P_{t}
$$

so that the ratio of uncertainty to disagreement will be the same at time $t-1$ and time $t$. More generally, if $\phi_{d t}$ and $\phi_{f t}$ are are equal to the same time-invariant constant at all dates

$$
\phi_{d t}=\phi_{f t}=\phi, \quad \forall t
$$

then the ratio of uncertainty to disagreement will always be constant:

$$
\mathcal{D}_{t}=\phi P_{t}, \quad \forall t
$$

Over time, since $Q=0$, eventually $\mathcal{D}_{\infty}=P_{\infty}=0$ regardless of the values of $\phi$ under weak assumptions on the other parameter values.

More generally when $Q_{t}$ is not necessarily zero at all dates, there are conditions on $\phi_{d t}$ and $\phi_{f t}$ which guarantee that the ratio of uncertainty to disagreement will always be constant. The condition is that $\phi_{d t}=\tau_{t} \phi_{f t}$ be constant over time for a particular sequence of time-varying constants $\left\{\tau_{t}\right\}$. If the parameters $A_{t}, Q_{t}, G_{t}, H_{t}$ and $K_{t}$ are constant over time then under weak assumptions, $P_{t}$ will converge to a positive number, $\mathcal{P}_{\infty}$ and $\mathcal{D}_{t}$ will also converge to a positive number, $\mathcal{D}_{\infty}$. At the limit the ratio of uncertainty to disagreement is necessarily constant over time.

If $K_{t-1}$ is not positive definite it is possible that $\phi_{f t-1}$ is zero which would make the link between disagreement and uncertainty not very useful. For example, if $K_{t-1}$ is a matrix of zeros then eventually $\mu_{i t}$ would be identical across agents and there would be no disagreement, even if there was a large amount of uncertainty. In this case all forecasters are eventually alike, so that even if each forecaster has a large amount of uncertainty there is no disagreement. It is not essential that $K_{t-1}$ have large eigenvalues. For example if $K_{t-1}$ is a scalar then it is fine if $K_{t-1}$ is arbitrarily close to zero.

In this appendix, we have provided conditions in two different examples that guarantee uncertainty is proportional to disagreement. We have shown how with the accumulation of new information it is possible that the proportionality is preserved. In reality the beliefs of forecasters may respond to new information in more complicated ways than we have described. In addition the dispersion of models across forecasters may be more heterogeneous. 


\section{References}

Anderson, E. W., Ghysels, E., and Juergens, J. L. (2005), “Do Heterogeneous Beliefs Matter for Asset Pricing?” Review of Financial Studies, $18,875-924$.

Anderson, E. W., Hansen, L. P., and Sargent, T. J. (2003), “A Quartet of Semigroups for Model Specification, Robustness, Prices of Risk, and Model Detection," Journal of the European Economic Association, 1, 68-123.

Ang, A., Hodrick, R., Xing, Y., and Zhang, X. (2006), “The Cross-Section of Volatility and Expected Returns,” Journal of Finance, 61, 259-299.

Baillie, R. T. and DeGennaro, R. P. (1990), "Stock Returns and Volatility,” Journal of Financial and Quantitative Analysis, 25, $203-214$.

Brandt, M. and Kang, Q. (2004), "On the Relationship Between the Conditional Mean and Volatility of Stock Returns: A Latent VAR Approach,” Journal of Financial Economies, 72, 217-259.

Braun, P. and Zarnowitz, V. (1993), "Twenty-two Years of the NBER-ASA Quarterly Economic Outlook Surveys: Aspects and Comparisons of Forecasting Performance," in Business Cycles, Indicators, and Forecasting, eds. Stock, J. and Watson, M., Chicago: University of Chicago Press.

Brav, A., Lehavy, R., and Michaely, R. (2004), “Using Expectations to Test Asset Pricing Models,” Working Paper, Duke University.

Campbell, J. Y. (1987), “Stock Returns and the Term Structure,” Journal of Financial Economies, 18, 373-399.

Campbell, J. Y. and Hentschel, L. (1992), "No News is Good News: An Asymmetric Model of Changing Volatility in Stock Returns,” Journal of Financial Economies, 31, 281-318.

Campbell, J. Y. and Shiller, R. J. (1988), “The Dividend-Price Ratio and Expectations of Future Dividends and Discount Factors,” Review of Financial Studies, 1, 195-228.

Chen, Z. and Epstein, L. G. (2002), “Ambiguity, Risk and Asset Returns in Continuous Time,” Econometrica, 70, $1403-1443$.

Cochrane, J. H. (2005), Asset pricing, Princeton University Press, Revised ed.

Crombez, J. (2001), “Updating Expected Returns Based on Consensus Forecasts,” Working Paper, Ghent University.

Croushore, D. (1993), "Introducing: The Survey of Professional Forecasters," Federal Reserve Bank of Philadelphia Business Review, 3-13.

Diether, K. B., Malloy, C. J., and Scherbina, A. (2002), "Differences of Opinion and the Cross-Section of Stock Returns," Journal of Finance, $57,2113-2141$.

Foster, D. P. and Nelson, D. B. (1996), “Continuous Record Asymptotics for Rolling Sample Variance Estimators,” Econometrica, 64, 139174.

French, K. R., Schwert, W., and Stambaugh, R. F. (1987), "Expected Stock Returns and Volatility,” Journal of Financial Economies, 19, $3-29$.

Gebhardt, W. R., Lee, C. M., and Swaminathan, B. (2001), “A Test of Efficiency of a Given Portfolio,” Journal of Accounting Research, 39, 135-176.

Ghysels, E., Santa-Clara, P., and Valkanov, R. (2005), “There is a Risk-Return Tradeoff After All,” Journal of Financial Economics, 76, 509-548. 
— (2006a), "Predicting Volatility: Getting the Most out of Return Data Sampled at Different Frequencies," Journal of Econometrics, 131, 59-95.

Ghysels, E., Sinko, A., and Valkanov, R. (2006b), "MIDAS Regressions: Further Results and New Directions,” Econometric Reviews, 26, 53-90.

Ghysels, E. and Wright, J. (2005), "Forecasting Professional Forecasters,” Working paper, UNC and Board of Governors, Federal Reserve.

Glosten, L. R., Jagannathan, R., and Runkle, D. E. (1993), “On the Relation Between the Expected Value and the Volatility of the Nominal Excess Return on Stocks," Journal of Finance, 48, 1779-1801.

Gordon, M. J. (1962), The Investment, Financing, and Valuation of the Corporation, Homewood, Illinois, Irwin Publishers.

Graham, J. and Harvey, C. (2003), "Expectations of Equity Risk Premia Volatility and Asymmetry From a Corporate Finance Perspective," Working Paper, Duke University.

Guay, W. R., Kothari, S. P., and Shu, S. (2003), “Properties of Implied Cost of Capital Using Analysts' Forecasts,” Working Paper, MIT Sloan School of Management.

Hansen, L. P. (1982), “Large Sample Properties of Generalized Method of Moments Estimators,” Econometrica, 50, $1029-1054$.

Hansen, L. P. and Jagannathan, R. (1997), “Assessing Specification Errors in Stochastic Discount Factor Models,” Journal of Finance, 52, $557-590$.

Hansen, L. P. and Sargent, T. J. (1995), “Discounted Linear Exponential Quadratic Gaussian Control,” IEEE Transactions on Automatic Control, 40, 968-971.

— (2001), “Acknowledging Misspecification in Macroeconomic Theory," Review of Economic Dynamics, 4, 519-535.

— (2003), "Robust Control of Forward-Looking Models," Journal of Monetary Economics, 50, 581-604.

— (2005), "Robust Estimation and Control Under Commitment," Journal of Economic Theory, 124, 258-301.

— (2006), "Recursive Robust Estimation and Control Without Commitment," Working Paper.

Hansen, L. P., Sargent, T. J., and Tallarini, Jr., T. D. (1999), "Robust Permanent Income and Pricing," Review of Economic Studies, 66, 873-907.

Hansen, L. P., Sargent, T. J., Turmuhambetova, G. A., and Williams, N. (2006), “Robust Control and Model Misspecification,” Journal of Economic Theory, 128, 45-90.

Harvey, C. R. (2001), “The Specification of Conditional Expectations,” Journal of Empirical Finance, 8, 573-638.

Jagannathan, R., McGrattan, E., and Scherbina, A. (1996), “The Declining US Equity Premium,” Federal Reserve Bank of Minneapolis Quarterly Review, 24, 3-19.

Johnson, T. C. (2004), “Forecast Dispersion and the Cross Section of Expected Returns,” Journal of Finance, 59, 1957-1979.

Keynes, J. M. (1937), “The General Theory of Employment,” Quarterly Journal of Economics.

Knight, F. H. (1921), Risk, Uncertainty and Profit, Houghton Mifflin Company. 
Kogan, L. and Wang, T. (2002), “A Simple Theory of Asset Pricing Under Model Uncertainty,” Working Paper.

Lewellen, J., Nagel, S., and Shanken, J. (2006), “A Skeptical Appraisal of Asset-Pricing Tests,” Working Paper.

Liu, J., Pan, J., and Wang, T. (2005), “An Equilibrium Model of Rare-Event Premia and Its Implication for Option Smirks,” Review of Financial Studies, 18, 131-164.

Maenhout, P. J. (2004), “Robust Portfolio Rules and Asset Prices,” Review of Financial Studies, 17, 951-983.

— (2006), "Robust Portfolio Rules and Detection Error Probabilities for a Mean-reverting Risk Premium," Journal of Economic Theory, 128, 136-163.

Merton, R. C. (1973), “An Intertemporal Capital Asset Pricing Model,” Econometrica, 41, 867-887.

— (1980), “On Estimating the Expected Return on the Market: An Exploratory Investigation,” Journal of Financial Economies, 8, 323-361.

Miller, E. M. (1977), “Risk, Uncertainty, and Divergence of Opinion,” Journal of Finance, 32, 1151-1168.

Nelson, D. B. (1991), “Conditional Heteroskedasticity in Asset Returns: A New Approach,” Econometrica, 59, 347-370.

Newey, W. K. and West, K. D. (1987), "A Simple, Positive Semi-Definite, Heteroskedasticity and Autocorrelation Consistent Covariance Matrix," Econometrica, 55, 703-708.

Qu, S., Starks, L. T., and Yan, H. (2003), "Risk Dispersion of Analyst Forecasts and Stock Returns,” Working Paper, University of Texas at Austin.

Turner, C. M., Startz, R., and Nelson, C. R. (1989), “A Markov Model of Heteroskedasticity, Risk, and Learning in the Stock Market,” Journal of Financial Economies, 25, 3-22.

Uppal, R. and Wang, T. (2003), “Model Misspecification and Underdiversification,” Journal of Finance, 58, 2465-2486.

Wiese, R. (1930), “Investing for True Value,” Barron's, 5.

Williams, J. B. (1938), The Theory of Investment Value, Fraser Publishing.

Zarnowitz, V. (1985), "Rational Expectations and Macroeconomic Forecasts," Journal of Business and Economic Statistics, 3, $293-312$. 


\section{Table I}

\section{Data summary and description}

In each row, we list a number of different statistics for the actuals and constructed forecasts of a single variable. In the row beginning with the label $r_{m t}$, the "actuals" columns provide statistics for the actual real market return. In the row beginning with the label $r_{b t}$, the "actuals" columns provide statistics for the actual real return on the nominally risk-free bond. $E x_{t+1}$ is the unconditional actual expected value of $x$ measured with the sample mean of $x . S x_{t}$ is the unconditional actual standard deviation of $x$ measured with the sample standard deviation of $x . E \operatorname{med}_{t} \mu_{x i t+1 \mid t}$ is the unconditional expected value of the median forecasts. $S \operatorname{med}_{t} \mu_{x i t+1 \mid t}$ is the unconditional standard deviation of the median forecast. med $S_{t} \mu_{x i t+1 \mid t}$ is the unconditional median of the conditional standard deviations of the forecasted means. $\sqrt{E\left[\left(x_{t+1}-\operatorname{med}_{t} \mu_{x i t+1 \mid t}\right)^{2}\right]}$ is the square root of the unconditional expected squared forecast error. The forecast data starts with forecasts made in the fourth quarter of 1968 and ends with forecasts made in the third quarter of 2003. The actual data runs from the first quarter of 1969 to the fourth quarter of 2003. Daily and monthly nominal actual asset pricing data is from Kenneth French's web site. They are deflated by the CPI from FRED II to obtain real returns. Flow of funds data, used to compute the constructed market return forecasts, is from the Federal Reserve Board.

\begin{tabular}{lcc|ccc|c}
\multicolumn{2}{c}{ Actuals } & Forecasts & Forecast errors \\
\hline \hline Variable & $E x_{t+1}$ & $S x_{t+1}$ & $E \operatorname{med}_{t} \mu_{x i t+1 \mid t}$ & $S \operatorname{med}_{t} \mu_{x i t+1 \mid t}$ & $\operatorname{med}_{t} \mu_{x i t+1 \mid t}$ & $\sqrt{E\left[\left(x_{t+1}-\operatorname{med}_{t} \mu_{x i t+1 \mid t}\right)^{2}\right.}$ \\
\hline$r_{m t}$ & 1.0168 & 0.0901 & 1.0230 & 0.0179 & 0.0173 & 0.0917 \\
$r_{b t}$ & 1.0034 & 0.0064 & 1.0051 & 0.0045 & 0.0025 & 0.0050 \\
\hline \hline
\end{tabular}


Table II

Risk-return and uncertainty-return trade-offs

This table displays estimates of several versions of the nonlinear regression

$$
r_{e t+1}=b+\tau \operatorname{vol}_{t}(\omega)+\theta \operatorname{unc}_{t}(\nu)+\epsilon_{t+1}
$$

of quarterly excess returns $r_{e t+1}$ on the measure of risk, $\operatorname{vol}_{t}(\omega)$, specified in equation (23), and the measure of uncertainty, unc $t_{t}(\nu)$, specified in equation (27). Uncertainty is measured by the Beta-weighted variance of market return forecasts. The estimates of $b$ represent time series Jensen alpha estimates. The variance of the error term, $\epsilon_{t+1}$, is $\sigma^{2} \operatorname{vol}_{t}(\omega)$ where $\sigma^{2}$ is a constant which we estimate. The measures vol $t_{t}$ and unc $_{t}$ are based on information available in the previous quarter (the quarter before $t+1$ ). Quasi-likelihood standard errors are listed under the estimates in parenthesis. If there is no standard error present then the variable was fixed and not estimated. In this case the value of the variable in the estimate column is the value at which it is fixed. The data for $r_{e t+1}$ is quarterly from 1969:1 to 2003:4. The forecast data and the daily data used to compute $\operatorname{vol}_{t}$ are from 1968:4 to 2003:3.

\begin{tabular}{rrrrrrrr}
\hline \hline Specification & $b$ & $\tau$ & $\theta$ & $\log \omega$ & $\log \nu$ & $\sigma^{2}$ & Log Likelihood \\
\hline 1 & 0.012 & 0.000 & 0.000 & 0.000 & 0.000 & 1.277 & 147.297 \\
& $(0.007)$ & & & & & $(0.160)$ & \\
2 & 0.011 & 0.000 & 0.000 & 2.780 & 0.000 & $\begin{array}{r}1.582 \\
(0.237)\end{array}$ & 151.111 \\
& $(0.006)$ & & & $(0.446)$ & & \\
3 & 0.009 & 0.812 & 0.000 & 2.768 & 0.000 & 1.577 & 151.184 \\
& $(0.009)$ & $(1.759)$ & & $(0.448)$ & & $(0.240)$ & \\
4 & 0.007 & 0.742 & 4.626 & 2.764 & 0.000 & 1.576 & 151.193 \\
& $(0.011)$ & $(1.840)$ & $(34.170)$ & $(0.450)$ & & $(0.240)$ & \\
5 & -0.012 & 0.000 & 1540.556 & 0.000 & 2.708 & 1.179 & 152.867 \\
& $(0.010)$ & & $(658.146)$ & & $(0.564)$ & $(0.148)$ & \\
6 & -0.012 & 0.000 & 1455.415 & 2.705 & 2.730 & 1.459 & 155.800 \\
& $(0.009)$ & & $(677.966)$ & $(0.515)$ & $(0.548)$ & $(0.229)$ & \\
7 & -0.012 & 0.120 & 1453.191 & 2.704 & 2.731 & 1.458 & 155.802 \\
& $(0.010)$ & $(1.713)$ & $(678.866)$ & $(0.515)$ & $(0.549)$ & $(0.230)$ & \\
\hline \hline
\end{tabular}




\section{Table III}

\section{Properties of uncertainty and volatility}

This table displays quarterly statistics of realized volatility $Q$, the estimated $\operatorname{vol}_{t}(\hat{\omega})$ series, with $\hat{\omega}=14.939$ and the estimated unc ${ }_{t}(\hat{\nu})$ series with $\hat{\nu}=15.346$. Panel A reports means and standard deviations and Panel B reports correlations. Panel C reports correlations at the quarterly frequency among unc, the market excess return and the Fama-French factors.

Panel A: Means and standard deviations of vol and unc

\begin{tabular}{crr}
\hline \hline & Mean & Standard Deviation \\
\hline$Q$ & 0.006592 & 0.007634 \\
$\operatorname{vol}(\hat{\omega})$ & 0.005876 & 0.005428 \\
$\operatorname{unc}(1)$ & 0.000345 & 0.000233 \\
$\operatorname{unc}(\hat{\nu})$ & 0.000017 & 0.000016 \\
\hline \hline
\end{tabular}

Panel B: Correlations of market excess returns with vol and unc

\begin{tabular}{ccrrrrr}
\hline \hline & $r_{e t+1}$ & $Q_{t+1}$ & $Q_{t}$ & $\operatorname{vol}_{t}(\hat{\omega})$ & unc $_{t}(1)$ & unc $_{t}(\hat{\nu})$ \\
\hline$r_{e t+1}$ & 1.000 & -0.397 & 0.128 & 0.154 & 0.175 & 0.283 \\
$Q_{t+1}$ & & 1.000 & 0.202 & 0.312 & 0.051 & 0.004 \\
$Q_{t}$ & & & 1.000 & 0.748 & 0.145 & 0.081 \\
$\operatorname{vol}_{t}(\hat{\omega})$ & & & & 1.000 & 0.211 & 0.075 \\
$\operatorname{unc}_{t}(1)$ & & & & & 1.000 & 0.662 \\
$\operatorname{unc}_{t}(\hat{\nu})$ & & & & & & 1.000 \\
\hline \hline
\end{tabular}

Panel C: Correlations of unc, the excess market return, and the Fama-French factors

\begin{tabular}{|c|c|c|c|c|c|c|c|}
\hline & $\operatorname{unc}_{t}(\hat{\nu})$ & $r_{e t+1}$ & $r_{\mathrm{hml} t+1}$ & $r_{\mathrm{smb} t+1}$ & $r_{\text {umd } t+1}$ & $r_{\mathrm{str} t+1}$ & $r_{1 \operatorname{ltr} t+1}$ \\
\hline $\mathrm{unc}_{t}(\hat{\nu})$ & 1.000 & 0.283 & -0.073 & 0.240 & -0.122 & 0.157 & 0.084 \\
\hline$r_{e t+1}$ & & 1.000 & -0.482 & 0.478 & -0.227 & 0.313 & -0.146 \\
\hline$r_{\mathrm{hml} t+1}$ & & & 1.000 & -0.179 & -0.092 & -0.077 & 0.489 \\
\hline$r_{\mathrm{smb} t+1}$ & & & & 1.000 & -0.358 & 0.383 & 0.237 \\
\hline$r_{\text {umd } t+1}$ & & & & & 1.000 & -0.514 & -0.151 \\
\hline$r_{\operatorname{str} t+1}$ & & & & & & 1.000 & 0.071 \\
\hline$r_{\operatorname{ltr} t+1}$ & & & & & & & 1.000 \\
\hline
\end{tabular}


Table IV

\section{The effect of uncertainty in output and the effect of uncertainty in corporate profits}

This table displays estimates of the same regression as in Table II except the variables used to measure uncertainty are different. In Panel A uncertainty is measured by the Beta-weighted variance of constructed forecasts of real output growth between last quarter and different horizons and in Panel B uncertainty is measured by the Beta-weighted variance of corporate profits growth forecasts between last quarter and different horizons. If the horizon is 1 (respectively 2,3 , or 4 ) then uncertainty in the growth between last quarter and this quarter (respectively next quarter, two quarters ahead, or three quarters ahead) is considered.

\begin{tabular}{rrrrrrr} 
Panel A: The effect of uncertainty in constructed real output & growth forecasts \\
\hline \hline Horizon & $b$ & $\theta$ & $\log \omega$ & $\log \nu$ & $\sigma^{2}$ & Log Likelihood \\
\hline 1 & 0.008 & 166.650 & 2.675 & 0.319 & 1.540 & 151.626 \\
& $(0.007)$ & $(173.054)$ & $(0.528)$ & $(0.361)$ & $(0.246)$ & \\
2 & 0.010 & 123.087 & 2.745 & 0.074 & 1.570 & 151.180 \\
& $(0.008)$ & $(402.416)$ & $(0.483)$ & $(0.651)$ & $(0.242)$ & \\
3 & 0.017 & -4653.506 & 2.808 & 1.452 & 1.583 & 151.462 \\
& $(0.009)$ & $(6298.592)$ & $(0.448)$ & $(0.438)$ & $(0.234)$ & \\
4 & 0.020 & -69343.288 & 2.737 & 3.404 & 1.543 & 152.305 \\
& $(0.009)$ & $(84256.607)$ & $(0.414)$ & $(1.552)$ & $(0.221)$ & \\
\hline \hline
\end{tabular}

Panel B: The effect of uncertainty in constructed real corporate profit growth forecasts

\begin{tabular}{|c|c|c|c|c|c|c|}
\hline$\overline{\text { Horizon }}$ & $\bar{b}$ & $\bar{\theta}$ & $\log \omega$ & $\overline{\log \nu}$ & $\overline{\overline{\sigma^{2}}}$ & Log Likelihood \\
\hline 1 & $\begin{array}{r}0.020 \\
(0.006)\end{array}$ & $\begin{array}{r}-2.922 \\
(0.837)\end{array}$ & $\begin{array}{r}2.838 \\
(0.436)\end{array}$ & $\begin{array}{r}-29.102 \\
\left(4.4 \times 10^{7}\right)\end{array}$ & $\begin{array}{r}1.583 \\
(0.227)\end{array}$ & 151.887 \\
\hline 2 & $\begin{array}{r}0.003 \\
(0.008)\end{array}$ & $\begin{array}{r}263.542 \\
(182.651)\end{array}$ & $\begin{array}{r}2.831 \\
(0.457)\end{array}$ & $\begin{array}{r}2.630 \\
(0.494)\end{array}$ & $\begin{array}{r}1.574 \\
(0.243)\end{array}$ & 152.181 \\
\hline 3 & $\begin{array}{r}-0.008 \\
(0.008)\end{array}$ & $\begin{array}{r}930.048 \\
(234.035)\end{array}$ & $\begin{array}{r}3.009 \\
(0.379)\end{array}$ & $\begin{array}{r}2.760 \\
(0.238)\end{array}$ & $\begin{array}{r}1.537 \\
(0.218)\end{array}$ & 156.436 \\
\hline 4 & $\begin{array}{r}-0.010 \\
(0.009)\end{array}$ & $\begin{array}{r}1551.778 \\
(807.618)\end{array}$ & $\begin{array}{r}2.759 \\
(0.481)\end{array}$ & $\begin{array}{r}2.796 \\
(0.591)\end{array}$ & $\begin{array}{r}1.480 \\
(0.228)\end{array}$ & 155.492 \\
\hline
\end{tabular}


Table V

\section{Alternative specifications of the uncertainty regressions}

This table displays estimates of the same regression as in Table II except the specification of unc t $_{t}$ is different. In Panel A uncertainty is measured with the a symmetric normal weighted variance of the same constructed market return forecast as in Table II. In Panel B, non-symmetric cross-sectional weights are allowed and uncertainty is measured with a Beta-weighted variance of the same constructed market return forecast as in Table II with two free parameters $\alpha$ and $\chi$. In Panel C uncertainty is measured by a Beta-weighted variance of constructed market return forecasts when the long term horizon is three periods rather than four periods. The specifications numbers for each row correspond to the specification numbers in Table II.

Panel A: Normal weighted variance

\begin{tabular}{rrrrrrrr}
\hline \hline Specification & $b$ & $\tau$ & $\theta$ & $\log \omega$ & $\log \xi$ & $\sigma^{2}$ & Log Likelihood \\
\hline 6 & -0.011 & 0.000 & 1546.979 & 2.699 & -2.113 & 1.458 & 155.763 \\
& $(0.009)$ & & $(654.824)$ & $(0.519)$ & $(0.239)$ & $(0.230)$ & \\
& -0.012 & 0.121 & 1544.776 & 2.698 & -2.113 & 1.457 & 155.764 \\
& $(0.010)$ & $(1.706)$ & $(655.849)$ & $(0.519)$ & $(0.239)$ & $(0.230)$ & \\
\hline \hline
\end{tabular}

Panel B: Non-symmetric cross-sectional weights

\begin{tabular}{|c|c|c|c|c|c|c|c|c|}
\hline Specification & $\overline{\bar{b}}$ & $\tau$ & $\bar{\theta}$ & $\log \omega$ & $\overline{l o g} \alpha$ & $\overline{l o g} \beta$ & $\overline{\sigma^{2}}$ & Log Likelihood \\
\hline 6 & $\begin{array}{r}-0.012 \\
(0.009)\end{array}$ & 0.000 & $\begin{array}{r}2281.821 \\
(1386.986)\end{array}$ & $\begin{array}{r}2.743 \\
(0.550)\end{array}$ & $\begin{array}{r}3.096 \\
(0.761)\end{array}$ & $\begin{array}{r}3.241 \\
(0.788)\end{array}$ & $\begin{array}{r}1.458 \\
(0.238)\end{array}$ & 156.321 \\
\hline 7 & $\begin{array}{r}-0.012 \\
(0.010)\end{array}$ & $\begin{array}{r}-0.085 \\
(1.716)\end{array}$ & $\begin{array}{r}2290.205 \\
(1397.800)\end{array}$ & $\begin{array}{r}2.743 \\
(0.554)\end{array}$ & $\begin{array}{r}3.099 \\
(0.759)\end{array}$ & $\begin{array}{r}3.244 \\
(0.786)\end{array}$ & $\begin{array}{r}1.458 \\
(0.238)\end{array}$ & 156.322 \\
\hline
\end{tabular}

Panel C: Uncertainty in the constructed market return with a long term horizon of three

\begin{tabular}{rrrrrrrr}
\hline \hline Specification & $b$ & $\tau$ & $\theta$ & $\log \omega$ & $\log \nu$ & $\sigma^{2}$ & Log Likelihood \\
\hline \multirow{2}{*}{6} & -0.009 & 0.000 & 899.286 & 2.977 & 2.713 & 1.519 & 156.630 \\
& $(0.008)$ & & $(231.007)$ & $(0.387)$ & $(0.219)$ & $(0.218)$ & \\
& & & & & & & \\
7 & -0.009 & 0.046 & 899.091 & 2.977 & 2.713 & 1.519 & 156.763 \\
& $(0.009)$ & $(1.734)$ & $(230.739)$ & $(0.391)$ & $(0.221)$ & $(0.220)$ & \\
\hline \hline
\end{tabular}




\section{Table VI}

\section{Fixed weighting schemes}

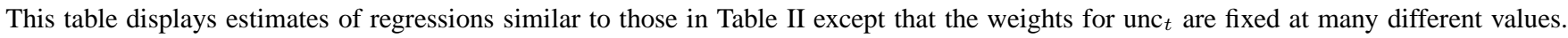
In Panel $\mathrm{A}$, we fix $\log \nu$ at several different values. In Panel B we measure uncertainty with a truncated variance in which the lowest $p$ and highest $p$ percent of forecasts are discarded and flat weights are used on the middle $(1-2 p)$ percent of forecasts. In Panel C we measure uncertainty with Winsorized forecasts in which the lowest $p$ and highest $p$ percent of forecasts are replaced with the lowest and highest forecasts in the middle $(1-2 p)$ percent of forecasts.

Panel A: Fixed $\log \nu$

\begin{tabular}{|c|c|c|c|c|c|c|c|}
\hline Specification & $\bar{b}$ & $\bar{\tau}$ & $\overline{\theta \theta}$ & $\overline{l o g} \omega$ & $\overline{\log \nu}$ & $\overline{\sigma^{2}}$ & Log Likelihood \\
\hline 1 & $\begin{array}{r}-0.004 \\
(0.011)\end{array}$ & $\begin{array}{l}0.259 \\
(1.767)\end{array}$ & $\begin{array}{r}144.161 \\
(97.594)\end{array}$ & $\begin{array}{l}2.754 \\
(0.453)\end{array}$ & 1.000 & $\begin{array}{l}1.547 \\
(0.237)\end{array}$ & 152.344 \\
\hline 2 & $\begin{array}{r}-0.009 \\
(0.011)\end{array}$ & $\begin{array}{l}0.131 \\
(1.748)\end{array}$ & $\begin{array}{r}356.786 \\
(146.648)\end{array}$ & $\begin{array}{l}2.759 \\
(0.462)\end{array}$ & 1.500 & $\begin{array}{l}1.518 \\
(0.233)\end{array}$ & 153.731 \\
\hline 3 & $\begin{array}{r}-0.012 \\
(0.010)\end{array}$ & $\begin{array}{l}0.102 \\
(1.739)\end{array}$ & $\begin{array}{r}701.305 \\
(214.382)\end{array}$ & $\begin{array}{l}2.750 \\
(0.476)\end{array}$ & 2.000 & $\begin{array}{l}1.488 \\
(0.228)\end{array}$ & 155.026 \\
\hline 4 & $\begin{array}{r}-0.011 \\
(0.010)\end{array}$ & $\begin{array}{l}0.142 \\
(1.696)\end{array}$ & $\begin{array}{r}1779.780 \\
(432.869)\end{array}$ & $\begin{array}{l}2.680 \\
(0.529)\end{array}$ & 3.000 & $\begin{array}{l}1.454 \\
(0.230)\end{array}$ & 155.716 \\
\hline 5 & $\begin{array}{r}-0.004 \\
(0.009)\end{array}$ & $\begin{array}{l}0.340 \\
(1.653)\end{array}$ & $\begin{array}{r}2877.538 \\
(697.124)\end{array}$ & $\begin{array}{l}2.632 \\
(0.564)\end{array}$ & 4.000 & $\begin{array}{l}1.464 \\
(0.237)\end{array}$ & 154.609 \\
\hline 6 & $\begin{array}{l}0.002 \\
(0.009)\end{array}$ & $\begin{array}{l}0.495 \\
(1.658)\end{array}$ & $\begin{array}{r}3583.219 \\
(1071.177)\end{array}$ & $\begin{array}{l}2.674 \\
(0.525)\end{array}$ & 5.000 & $\begin{array}{l}1.503 \\
(0.238)\end{array}$ & 153.290 \\
\hline
\end{tabular}

\begin{tabular}{|c|c|c|c|c|c|c|c|}
\hline Specification & $\bar{b}$ & $\overline{\bar{\tau}}$ & $\overline{\bar{\theta}}$ & $\overline{\bar{l} \log \omega}$ & $\bar{p}$ & $\overline{\sigma^{2}}$ & Log Likelihood \\
\hline 1 & $\begin{array}{r}-0.006 \\
(0.011)\end{array}$ & $\begin{array}{l}0.201 \\
(1.777)\end{array}$ & $\begin{array}{r}135.773 \\
(75.561)\end{array}$ & $\begin{array}{l}2.782 \\
(0.454)\end{array}$ & 10 & $\begin{array}{l}1.546 \\
(0.232)\end{array}$ & 152.765 \\
\hline 2 & $\begin{array}{r}-0.008 \\
(0.010)\end{array}$ & $\begin{array}{l}0.119 \\
(1.755)\end{array}$ & $\begin{array}{r}217.263 \\
(95.362)\end{array}$ & $\begin{array}{l}2.783 \\
(0.452)\end{array}$ & 15 & $\begin{array}{l}1.530 \\
(0.233)\end{array}$ & 153.501 \\
\hline 3 & $\begin{array}{r}-0.012 \\
(0.011)\end{array}$ & $\begin{array}{l}0.064 \\
(1.729)\end{array}$ & $\begin{array}{r}395.563 \\
(133.198)\end{array}$ & $\begin{array}{l}2.725 \\
(0.455)\end{array}$ & 20 & $\begin{array}{l}1.479 \\
(0.221)\end{array}$ & 155.096 \\
\hline 4 & $\begin{array}{r}-0.013 \\
(0.010)\end{array}$ & $\begin{array}{l}0.121 \\
(1.757)\end{array}$ & $\begin{array}{r}608.248 \\
(178.836)\end{array}$ & $\begin{array}{l}2.746 \\
(0.503)\end{array}$ & 25 & $\begin{array}{l}1.474 \\
(0.231)\end{array}$ & 155.618 \\
\hline 5 & $\begin{array}{r}-0.012 \\
(0.010)\end{array}$ & $\begin{array}{l}0.064 \\
(1.767)\end{array}$ & $\begin{array}{r}956.099 \\
(248.391)\end{array}$ & $\begin{array}{l}2.799 \\
(0.463)\end{array}$ & 30 & $\begin{array}{l}1.483 \\
(0.224)\end{array}$ & 155.924 \\
\hline 6 & $\begin{array}{r}-0.002 \\
(0.009)\end{array}$ & $\begin{array}{l}0.311 \\
(1.659)\end{array}$ & $\begin{array}{r}1836.949 \\
(483.508)\end{array}$ & $\begin{array}{l}2.625 \\
(0.622)\end{array}$ & 40 & $\begin{array}{l}1.473 \\
(0.248)\end{array}$ & 154.094 \\
\hline
\end{tabular}

Panel C: Winsorization

\begin{tabular}{rrrrrrrrr}
\hline \hline Specification & $b$ & $\tau$ & $\theta$ & $\log \omega$ & $p$ & $\sigma^{2}$ & Log Likelihood \\
\hline 1 & -0.003 & 0.290 & 74.634 & 2.757 & 10 & 1.553 & 152.105 \\
& $(0.011)$ & $(1.793)$ & $(57.550)$ & $(0.456)$ & & $(0.233)$ & \\
2 & -0.005 & 0.104 & 121.159 & 2.768 & 15 & 1.539 & 152.878 \\
& $(0.010)$ & $(1.765)$ & $(64.195)$ & $(0.464)$ & & $(0.235)$ & \\
& & & & & \\
3 & -0.009 & 0.089 & 199.377 & 2.752 & 20 & 1.511 & 153.945 \\
& $(0.010)$ & $(1.752)$ & $(81.381)$ & $(0.447)$ & & $(0.225)$ & \\
4 & -0.011 & 0.148 & 323.817 & 2.724 & 25 & 1.481 & 154.998 \\
& $(0.011)$ & $(1.750)$ & $(112.623)$ & $(0.528)$ & & $(0.236)$ & \\
5 & -0.010 & 0.091 & 486.001 & 2.841 & 30 & 1.515 & 154.985 \\
& $(0.010)$ & $(1.803)$ & $(154.000)$ & $(0.445)$ & & $(0.227)$ & \\
& & & & & & & \\
& -0.001 & 0.182 & 1173.149 & 2.693 & 40 & 1.508 & \\
& $(0.009)$ & $(1.719)$ & $(404.200)$ & $(0.580)$ & & $(0.247)$ & \\
\hline \hline
\end{tabular}




\section{Table VII \\ The impact of uncertainty on volatility}

This table displays estimates of regressions in which uncertainty is permitted to have an effect on quarterly volatility. We run several versions of the nonlinear regression

$$
r_{e t+1}=b+\tau \operatorname{vol}_{t}(\omega)+\theta \operatorname{unc}_{t}(\nu)+\epsilon_{t+1}
$$

of quarterly excess returns $r_{e t+1}$ on a constant, the measure of volatility, $\operatorname{vol}_{t}(\omega)$, specified in equation (23), and the measure of uncertainty, $\operatorname{unc}_{t}(\nu)$, specified in equation (27). The variance of the error term, $\epsilon_{t+1}$, is

$$
\sigma_{v}^{2} \operatorname{vol}_{t}(\omega)+\sigma_{u}^{2} \mathrm{unc}_{t}(\nu)
$$

where $\sigma_{u}$ and $\sigma_{v}$ are constants which we estimate. In Panel A we estimate $\log \nu$ along with other parameters and in Panel B we fix $\log \nu$.

\begin{tabular}{|c|c|c|c|c|c|c|c|c|}
\hline Specification & $\bar{b}$ & $\overline{\tau \tau}$ & $\bar{\theta}$ & $\log \omega$ & $\overline{l o g} \nu$ & $\overline{\sigma_{v}^{2}}$ & $\overline{\overline{\sigma_{u}^{2}}}$ & Log Likelihood \\
\hline 1 & $\begin{array}{r}0.011 \\
(0.006)\end{array}$ & 0.000 & 0.000 & 0.000 & $\begin{array}{r}0.924 \\
(0.383)\end{array}$ & $\begin{array}{r}1.051 \\
(0.219)\end{array}$ & $\begin{array}{r}9.105 \\
(7.301)\end{array}$ & 148.053 \\
\hline 2 & $\begin{array}{r}0.010 \\
(0.006)\end{array}$ & 0.000 & 0.000 & $\begin{array}{r}3.215 \\
(0.475)\end{array}$ & $\begin{array}{r}1.306 \\
(0.584)\end{array}$ & $\begin{array}{r}1.172 \\
(0.260)\end{array}$ & $\begin{array}{r}23.693 \\
(18.992)\end{array}$ & 152.967 \\
\hline 3 & $\begin{array}{r}0.009 \\
(0.009)\end{array}$ & $\begin{array}{r}0.491 \\
(1.781)\end{array}$ & 0.000 & $\begin{array}{r}3.187 \\
(0.498)\end{array}$ & $\begin{array}{r}1.315 \\
(0.582)\end{array}$ & $\begin{array}{r}1.170 \\
(0.265)\end{array}$ & $\begin{array}{r}23.726 \\
(19.112)\end{array}$ & 152.997 \\
\hline 4 & $\begin{array}{r}0.008 \\
(0.011)\end{array}$ & $\begin{array}{r}0.202 \\
(1.905)\end{array}$ & $\begin{array}{r}13.496 \\
(33.321)\end{array}$ & $\begin{array}{r}3.155 \\
(0.599)\end{array}$ & 0.000 & $\begin{array}{r}1.191 \\
(0.287)\end{array}$ & $\begin{array}{r}5.220 \\
(3.608)\end{array}$ & 152.402 \\
\hline 6 & $\begin{array}{r}-0.011 \\
(0.011)\end{array}$ & 0.000 & $\begin{array}{r}1196.519 \\
(2073.468)\end{array}$ & $\begin{array}{r}2.874 \\
(1.495)\end{array}$ & $\begin{array}{r}2.553 \\
(1.519)\end{array}$ & $\begin{array}{r}1.389 \\
(0.648)\end{array}$ & $\begin{array}{l}21.063 \\
(153.534)\end{array}$ & 155.822 \\
\hline 7 & $\begin{array}{r}-0.012 \\
(0.012)\end{array}$ & $\begin{array}{r}0.122 \\
(1.729)\end{array}$ & $\begin{array}{r}1196.632 \\
(2070.585)\end{array}$ & $\begin{array}{r}2.869 \\
(1.477)\end{array}$ & $\begin{array}{r}2.555 \\
(1.518)\end{array}$ & $\begin{array}{r}1.389 \\
(0.646)\end{array}$ & $\begin{array}{l}20.856 \\
(152.610)\end{array}$ & 155.824 \\
\hline
\end{tabular}

Panel A: Impact when $\log \nu$ is estimated

Panel B: Impact when $\log \nu$ is fixed

\begin{tabular}{rrrrrrrrrr}
\hline \hline Specification & $b$ & $\tau$ & $\theta$ & $\log \omega$ & $\log \nu$ & $\sigma_{v}^{2}$ & $\sigma_{u}^{2}$ & Log Likelihood \\
\hline 1 & 0.008 & 0.202 & 13.496 & 3.155 & 0.000 & 1.191 & 5.220 & 152.402 \\
& $(0.011)$ & $(1.905)$ & $(33.321)$ & $(0.599)$ & & $(0.287)$ & $(3.608)$ & \\
2 & -0.003 & 0.092 & 143.135 & 3.150 & 1.000 & 1.155 & 15.640 & 153.930 \\
& $(0.012)$ & $(1.793)$ & $(98.851)$ & $(0.513)$ & & $(0.265)$ & $(9.029)$ & \\
3 & -0.008 & 0.084 & 331.960 & 3.101 & 1.500 & 1.209 & 22.958 & 154.834 \\
& $(0.011)$ & $(1.768)$ & $(160.395)$ & $(0.481)$ & & $(0.279)$ & $(16.644)$ & \\
4 & -0.010 & 0.083 & 651.765 & 3.038 & 2.000 & 1.286 & 27.866 & 155.534 \\
& $(0.011)$ & $(1.762)$ & $(248.298)$ & $(0.533)$ & & $(0.295)$ & $(32.160)$ & \\
5 & -0.011 & 0.142 & 1779.780 & 2.680 & 3.000 & 1.454 & 0.000 & 155.716 \\
& $(0.012)$ & $(1.832)$ & $(965.816)$ & $(1.377)$ & & $(0.429)$ & $(207.629)$ & \\
& & & & & & & \\
& -0.004 & 0.340 & 2877.538 & 2.632 & 4.000 & 1.464 & 0.000 & 154.609 \\
& $(0.009)$ & $(1.640)$ & $(754.125)$ & $(0.646)$ & & $(0.279)$ & $(222.246)$ & \\
7 & 0.002 & 0.495 & 3583.219 & 2.674 & 5.000 & 1.503 & 0.000 & 153.290 \\
& $(0.010)$ & $(1.675)$ & $(2795.576)$ & $(0.934)$ & & $(0.341)$ & $(869.256)$ & \\
\hline \hline
\end{tabular}




\section{Table VIII}

\section{Time-varying uncertainty aversion}

This table displays estimates of regressions in which uncertainty aversion is permitted to be time-varying. We run the nonlinear regression

$$
r_{e t+1}=b+\left(\sum_{k \in \Omega} \theta_{k} \mathbf{1}_{t, k} \operatorname{unc}_{t}(\nu)\right)+\epsilon_{t+1}
$$

of quarterly excess returns $r_{e t+1}$ on a constant and the measure of uncertainty, unc $t_{t}(\nu)$, specified in equation (27). Here

$$
\Omega=\{1968: 4-1977: 2,1977: 3-1986: 1,1986: 2-1994: 4,1995: 1-2003: 3\}
$$

and uncertainty aversion assumes four different values one value for each of the periods in $\Omega$. The variance of the error term, $\epsilon_{t+1}$, is $\sigma^{2} \operatorname{vol}_{t}(\omega)$ where $\sigma^{2}$ and $\omega$ are constants which we estimate.

\begin{tabular}{rrrrrrrrr}
\hline \hline$b$ & $\theta_{1968: 4-1977: 2}$ & $\theta_{1977: 3-1986: 1}$ & $\theta_{1986: 2-1994: 4}$ & $\theta_{1995: 1-2003: 3}$ & $\log \omega$ & $\log \nu$ & $\sigma^{2}$ & Log Likelihood \\
\hline-0.013 & 764.199 & 1332.698 & 1505.093 & 2179.550 & 2.645 & 2.660 & 1.427 & 156.540 \\
$(0.010)$ & $(1083.007)$ & $(571.077)$ & $(644.735)$ & $(952.561)$ & $(0.594)$ & $(0.469)$ & $(0.242)$ & \\
\hline \hline
\end{tabular}




\section{Table IX}

\section{Time series properties of uncertainty and volatility}

The table displays estimates of regressions

$$
y_{t}=b+\sum_{i=1}^{n} \psi_{i} \operatorname{vol}_{t-i}(\hat{\omega})+\sum_{i=1}^{m} \varphi_{i} \operatorname{unc}_{t-i}(\hat{\nu})+e_{t+1}
$$

on past predictors of volatility $\operatorname{vol}_{t-i}(\omega)$ and measures of past uncertainty unc $t_{t-i}(\nu)$ where the variance of the error term, $e_{t+1}$, is assumed constant over time. We vary the dependent variables and the values of $n$ and $m$. Ordinary least squares standard errors are listed under the estimates in parenthesis. If there is no standard error present then the variable was fixed and not estimated. In this case the value of the variable in the estimate column is the value at which it is fixed. In Panel A we set $y_{t}=\operatorname{unc}_{t}(\hat{\nu})$ where $\hat{\nu}=15.346$ and consider regressions of uncertainty on past predictors of volatility and past uncertainty. In Panel B we set $y_{t}=Q_{t}$ and consider regressions of realized volatility on past predictors volatility and past uncertainty. In Panel C we set $y_{t}=\operatorname{vol}_{t}(\hat{\omega})$ with $\hat{\omega}=14.939$ and consider regressions of predictors of volatility on past predictors volatility and past uncertainty. We report estimates of the coefficients $\{\psi\}_{i=1}^{n}$ and $\{\varphi\}_{i=1}^{m}$ for various values of $n$ and $m$.

Panel A: Regressions of uncertainty on past predictors of volatility and uncertainty

\begin{tabular}{|c|c|c|c|c|c|c|c|}
\hline$b$ & $\psi_{1}$ & $\psi_{2}$ & $\psi_{3}$ & $\varphi_{1}$ & $\varphi_{2}$ & $\sigma^{2}$ & Log Likelihood \\
\hline $\begin{array}{r}0.000 \\
(0.000)\end{array}$ & $\begin{array}{r}0.00043 \\
(0.00039)\end{array}$ & 0.000 & 0.000 & $\begin{array}{r}0.288 \\
(0.119)\end{array}$ & 0.000 & $\begin{array}{c}2.3 \times 10^{-10} \\
\left(0.9 \times 10^{-10}\right)\end{array}$ & 1325.435 \\
\hline $\begin{array}{r}0.000 \\
(0.000)\end{array}$ & $\begin{array}{r}0.00044 \\
(0.00038)\end{array}$ & 0.000 & 0.000 & $\begin{array}{r}0.211 \\
(0.106)\end{array}$ & $\begin{array}{r}0.238 \\
(0.066)\end{array}$ & $\begin{array}{c}2.2 \times 10^{-10} \\
\left(0.8 \times 10^{-10}\right)\end{array}$ & 1329.742 \\
\hline
\end{tabular}

Panel B: regressions of realized volatility on past predictors of volatility and uncertainty

\begin{tabular}{|c|c|c|c|c|c|c|c|}
\hline $\bar{b}$ & $\psi_{1}$ & $\psi_{2}$ & $\psi_{3}$ & $\varphi_{1}$ & $\varphi_{2}$ & $\overline{\sigma^{2}}$ & Log Likelihood \\
\hline $\begin{array}{r}0.004 \\
(0.001)\end{array}$ & $\begin{array}{r}0.440 \\
(0.088)\end{array}$ & 0.000 & 0.000 & $\begin{array}{r}-10.264 \\
(32.786)\end{array}$ & 0.000 & $\begin{array}{l}5.323 \times 10^{-5} \\
\left(3.455 \times 10^{-10}\right)\end{array}$ & 479.700 \\
\hline $\begin{array}{r}0.003 \\
(0.001)\end{array}$ & $\begin{array}{r}0.388 \\
(0.092)\end{array}$ & $\begin{array}{r}0.033 \\
(0.064)\end{array}$ & $\begin{array}{r}0.174 \\
(0.087)\end{array}$ & 0.000 & 0.000 & $\begin{array}{c}5.230 \times 10^{-5} \\
\left(3.470 \times 10^{-5}\right)\end{array}$ & 480.914 \\
\hline
\end{tabular}

Panel C: Regressions of predictors of volatility on past predictors of volatility and uncertainty

\begin{tabular}{rrrrrrrr}
\hline \hline$b$ & $\psi_{1}$ & $\psi_{2}$ & $\psi_{3}$ & $\varphi_{1}$ & $\varphi_{2}$ & $\sigma^{2}$ & Log Likelihood \\
\hline 0.004 & 0.290 & 0.000 & 0.000 & -0.620 & 0.000 & $\begin{array}{r}2.733 \times 10^{-5} \\
\left(0.628 \times 10^{-5}\right)\end{array}$ & 525.365 \\
$(0.001)$ & $(0.065)$ & & & $(18.734)$ & & & \\
& & & & & & & \\
0.002 & 0.190 & 0.077 & 0.339 & 0.000 & 0.000 & $\begin{array}{r}2.359 \times 10^{-5} \\
\left(0.501 \times 10^{-5}\right)\end{array}$ \\
$(0.001)$ & $(0.064)$ & $(0.057)$ & $(0.130)$ & & & & 535.438 \\
& & & & & & & \\
\hline \hline
\end{tabular}


Table X

\section{Summary statistics on uncertainty-sorted portfolios}

This table presents summary statistics on portfolios sorted on sensitivity to uncertainty. Portfolios are constructed from rolling sample regressions of equation (42), where regressions are rolled forward each quarter throughout the life of the stock. Only firms with at least 20 quarters of return data are used in the sample $(\mathrm{N}=14,252)$. Once sensitivities are obtained, firms are sorted into quintiles based on those sensitivities in each quarter, and portfolios are constructed by value-weighting the stocks within the portfolio each quarter. The sample span ranges from fourth quarter 1973 through fourth quarter 2003, however, in order to construct rolling samples, data is used from first quarter 1969. In addition to summary statistics on the returns to the portfolios presented in Panel A, summary statistics on the weights of each portfolio are described in Panel B. The weights do not sum to 100\% since the firms analyzed are only a fraction of the entire CRSP universe in each quarter.

Panel A: Portfolio returns

\begin{tabular}{r|rrrrrrr}
\hline \hline Portfolios & Average & StdDev & Min & Q1 & Median & Q3 & Max \\
\hline Low & 1.02166 & 0.10975 & 0.6985 & 0.9693 & 1.03686 & 1.08081 & 1.55788 \\
2 & 1.01746 & 0.07946 & 0.7308 & 0.9755 & 1.02470 & 1.06202 & 1.24392 \\
3 & 1.02036 & 0.08987 & 0.7483 & 0.9743 & 1.03362 & 1.06667 & 1.38004 \\
4 & 1.02196 & 0.11226 & 0.7291 & 0.9634 & 1.02372 & 1.07857 & 1.54622 \\
High & 1.03620 & 0.16307 & 0.6667 & 0.9525 & 1.01698 & 1.10283 & 1.95674 \\
\hline \hline
\end{tabular}

Panel B: Portfolio weights

\begin{tabular}{r|rrrrrrr}
\hline \hline Portfolios & Average & StdDev & Min & Q1 & Median & Q3 & Max \\
\hline Low & 0.14060 & 0.10054 & 0.02266 & 0.05674 & 0.12068 & 0.17859 & 0.39831 \\
2 & 0.22441 & 0.05014 & 0.12242 & 0.18890 & 0.22669 & 0.25365 & 0.39153 \\
3 & 0.22513 & 0.04715 & 0.10865 & 0.19435 & 0.21913 & 0.25818 & 0.38801 \\
4 & 0.19359 & 0.06514 & 0.04486 & 0.15450 & 0.19912 & 0.22849 & 0.32638 \\
High & 0.09411 & 0.04443 & 0.01685 & 0.06085 & 0.08706 & 0.12631 & 0.23053 \\
\hline \hline
\end{tabular}




\section{Table XI}

\section{Summary statistics on risk and uncertainty sorted portfolios}

This table presents summary statistics on portfolios sorted on sensitivity to risk and uncertainty. Portfolios are constructed from rolling sample regressions of equation (42), where regressions are rolled forward each quarter throughout the life of the stock. Only firms with at least 20 quarters of return data are used in the sample $(\mathrm{N}=14,252)$. Once sensitivities are obtained, firms are sorted first into three portfolios based on those sensitivities to uncertainty in each quarter and then sorted again into three portfolios based on sensitivities to risk. Portfolios are constructed by value-weighting the stocks within the portfolio each quarter. The sample span ranges from fourth quarter 1973 through fourth quarter 2003, however, in order to construct rolling samples, data is used from first quarter 1969. In addition to summary statistics on the returns to the portfolios presented in Panel A, summary statistics on the weights of each portfolio are described in Panel B. The weights do not sum to $100 \%$ since the firms analyzed are only a fraction of the entire CRSP universe in each quarter. LU = low uncertainty; MU = medium uncertainty; $\mathrm{HU}=$ high uncertainty; $\mathrm{LV}=$ low risk; $\mathrm{MV}=$ medium risk; and $\mathrm{HV}=$ high risk.

Panel A: Portfolio returns

\begin{tabular}{r|rrrrrrr}
\hline \hline Portfolios & Average & StdDev & Min & Q1 & Median & Q3 & Max \\
\hline LULV & 1.01633 & 0.05776 & 0.8229 & 0.9849 & 1.02470 & 1.05283 & 1.15094 \\
LUMV & 1.01535 & 0.08951 & 0.7258 & 0.9733 & 1.02970 & 1.07391 & 1.20936 \\
LUHV & 1.02070 & 0.15469 & 0.6239 & 0.9386 & 1.03697 & 1.11232 & 1.61220 \\
MULV & 1.02382 & 0.06551 & 0.7819 & 0.9901 & 1.02123 & 1.05749 & 1.32888 \\
MUMV & 1.01829 & 0.09110 & 0.6966 & 0.9770 & 1.02146 & 1.06727 & 1.40082 \\
MUHV & 1.02281 & 0.13446 & 0.6371 & 0.9512 & 1.03233 & 1.09148 & 1.41384 \\
HULV & 1.01902 & 0.10581 & 0.7531 & 0.9667 & 1.00554 & 1.06709 & 1.61462 \\
HUMV & 1.02806 & 0.13635 & 0.6950 & 0.9551 & 1.03415 & 1.09470 & 1.70379 \\
HUHV & 1.04302 & 0.20693 & 0.5936 & 0.9165 & 1.03637 & 1.14097 & 1.99053 \\
\hline \hline
\end{tabular}

Panel B: Portfolio weights

\begin{tabular}{r|rrrrrrr}
\hline \hline Portfolios & Average & StdDev & Min & Q1 & Median & Q3 & Max \\
\hline LULV & 0.10887 & 0.06575 & 0.01356 & 0.05077 & 0.09404 & 0.15556 & 0.28723 \\
LUMV & 0.12195 & 0.06061 & 0.04003 & 0.07193 & 0.10475 & 0.15985 & 0.29937 \\
LUHV & 0.05740 & 0.03133 & 0.01812 & 0.03079 & 0.04715 & 0.08371 & 0.13159 \\
MULV & 0.11474 & 0.05342 & 0.02224 & 0.06833 & 0.12251 & 0.15229 & 0.27020 \\
MUMV & 0.15562 & 0.04251 & 0.06769 & 0.12456 & 0.15268 & 0.18736 & 0.26384 \\
MUHV & 0.10065 & 0.04579 & 0.02468 & 0.06104 & 0.09219 & 0.14001 & 0.21620 \\
HULV & 0.08006 & 0.04463 & 0.01712 & 0.05273 & 0.06514 & 0.09897 & 0.19952 \\
HUMV & 0.09344 & 0.04752 & 0.01667 & 0.06279 & 0.08106 & 0.13111 & 0.22539 \\
HUHV & 0.04511 & 0.01949 & 0.00923 & 0.03010 & 0.04499 & 0.05436 & 0.11598 \\
\hline \hline
\end{tabular}




\section{Table XII \\ GMM estimates of the prices of factors}

This table displays GMM estimates of the prices of factors for various versions of the joint time series and cross-sectional system

$$
\begin{aligned}
r_{k t+1} & =a_{k}+\beta_{k}^{\prime} f_{t+1}+\varrho_{k t+1}, \\
E r_{k t+1} & =\beta_{k}^{\prime} \lambda+\iota_{k}
\end{aligned} \quad k=1 \ldots n,
$$

where $a_{k}$ is a time-series pricing error, $\iota_{k}$ is a cross-sectional pricing error, $\beta_{k}$ is a vector of regression coefficients, $f_{t+1}$ is a vector of factors, and $\lambda$ is a vector of prices. In some of our specifications we include a market risk factor, an alternative measure of the market risk factor, a market uncertainty factor, the market excess return, the HML factor, the SMB factor, the UMD factor, the STR factor, and the LTR factor:

$$
\begin{aligned}
& \beta_{k}=\left[\begin{array}{lllllllll}
\beta_{v k} & \bar{\beta}_{v k} & \beta_{u k} & \beta_{m k} & \beta_{\mathrm{hml} k} & \beta_{\mathrm{smb} k} & \beta_{\mathrm{umd} k} & \beta_{\mathrm{str} k} & \beta_{\operatorname{ltr} k}
\end{array}\right]^{\prime}, \\
& \lambda=\left[\begin{array}{lllllllll}
\lambda_{v} & \bar{\lambda}_{v} & \lambda_{u} & \lambda_{m} & \lambda_{\mathrm{hml}} & \lambda_{\mathrm{smb}} & \lambda_{\mathrm{umd}} & \lambda_{\mathrm{str}} & \lambda_{\mathrm{ltr}}
\end{array}\right]^{\prime}, \\
& f_{t+1}=\left[\begin{array}{lllllllll}
\hat{\tau} \operatorname{vol}_{t}(\hat{\omega})+\hat{\epsilon}_{e t+1} & \hat{\tau} \operatorname{vol}_{t}(\hat{\omega}) & \hat{\theta} \operatorname{unc}_{t}(\hat{\nu}) & r_{m t+1} & r_{\mathrm{hml} t+1} & r_{\mathrm{smb} t+1} & r_{\text {umd } t+1} & r_{\mathrm{str} t+1} & r_{\text {ltr } t+1}
\end{array}\right]^{\prime} .
\end{aligned}
$$

The moments conditions for asset $k$ are

$$
E\left[\begin{array}{c}
r_{k t+1}-a_{k}-\beta_{k}^{\prime} f_{t} \\
\left(r_{k t+1}-a_{k}-\beta_{k}^{\prime} f_{t}\right) \otimes f_{t} \\
r_{k t+1}-\beta_{k}^{\prime} \lambda
\end{array}\right]=0 .
$$

The moment conditions for all assets are combined and GMM estimates of the prices of factors are listed below for the fixed weighting matrix described in the text. GMM standard errors are listed in parenthesis below estimates and are computed using the method of Newey and West (1987) with eight lags. Variables without standard errors were fixed at zero. (When $\lambda_{x}$ is fixed at zero for some factor $x$ we remove the corresponding regression coefficient $\beta_{x k}$ from the vector $\beta_{k}$ for each $k$.) Estimates of $a_{k}$ and $\beta_{k}$ are not displayed but are available upon

\begin{tabular}{|c|c|c|c|c|c|c|c|c|c|c|c|}
\hline Specification & $\lambda_{v}$ & $\bar{\lambda}_{v}$ & $\lambda_{u}$ & $\lambda_{m}$ & $\lambda_{\mathrm{hml}}$ & $\lambda_{\mathrm{smb}}$ & $\lambda_{\text {umd }}$ & $\lambda_{\text {ltr }}$ & $\lambda_{\text {str }}$ & $\mathrm{J}_{\text {stat }}$ & $\mathrm{P}_{\mathrm{val}}$ \\
\hline 1 & $\begin{array}{r}-0.011 \\
(0.007)\end{array}$ & 0.000 & $\begin{array}{l}0.027 \\
(0.003)\end{array}$ & 0.000 & 0.000 & 0.000 & 0.000 & 0.000 & 0.000 & 16.420 & 1.000 \\
\hline 2 & 0.000 & $\begin{array}{r}-0.000 \\
(0.000)\end{array}$ & $\begin{array}{l}0.027 \\
(0.003)\end{array}$ & 0.000 & 0.000 & 0.000 & 0.000 & 0.000 & 0.000 & 16.421 & 1.000 \\
\hline 3 & 0.000 & 0.000 & 0.000 & $\begin{array}{l}0.016 \\
(0.007)\end{array}$ & 0.000 & 0.000 & 0.000 & 0.000 & 0.000 & 16.408 & 1.000 \\
\hline 4 & 0.000 & 0.000 & 0.000 & $\begin{array}{l}0.016 \\
(0.007)\end{array}$ & $\begin{array}{l}0.019 \\
(0.005)\end{array}$ & $\begin{array}{r}-0.004 \\
(0.006)\end{array}$ & $\begin{array}{l}0.024 \\
(0.005)\end{array}$ & $\begin{array}{l}0.012 \\
(0.005)\end{array}$ & $\begin{array}{l}0.023 \\
(0.005)\end{array}$ & 16.390 & 1.000 \\
\hline 5 & 0.000 & 0.000 & $\begin{array}{l}0.027 \\
(0.003)\end{array}$ & $\begin{array}{l}0.016 \\
(0.007)\end{array}$ & $\begin{array}{l}0.019 \\
(0.005)\end{array}$ & $\begin{array}{r}-0.004 \\
(0.005)\end{array}$ & $\begin{array}{l}0.023 \\
(0.005)\end{array}$ & $\begin{array}{l}0.012 \\
(0.005)\end{array}$ & $\begin{array}{l}0.023 \\
(0.005)\end{array}$ & 16.397 & 1.000 \\
\hline 6 & $\begin{array}{r}-0.011 \\
(0.007)\end{array}$ & 0.000 & $\begin{array}{l}0.027 \\
(0.003)\end{array}$ & 0.000 & $\begin{array}{l}0.019 \\
(0.005)\end{array}$ & $\begin{array}{r}-0.004 \\
(0.005)\end{array}$ & $\begin{array}{l}0.023 \\
(0.005)\end{array}$ & $\begin{array}{l}0.012 \\
(0.005)\end{array}$ & $\begin{array}{l}0.023 \\
(0.005)\end{array}$ & 16.397 & 1.000 \\
\hline 7 & 0.000 & $\begin{array}{r}-0.000 \\
(0.000)\end{array}$ & $\begin{array}{l}0.027 \\
(0.003)\end{array}$ & 0.000 & $\begin{array}{l}0.019 \\
(0.005)\end{array}$ & $\begin{array}{r}-0.004 \\
(0.005)\end{array}$ & $\begin{array}{l}0.023 \\
(0.005)\end{array}$ & $\begin{array}{l}0.012 \\
(0.005)\end{array}$ & $\begin{array}{l}0.023 \\
(0.005)\end{array}$ & 16.413 & 1.000 \\
\hline
\end{tabular}
request. The nonlinear parameters $\omega$ and $\nu$ are fixed at their market estimates of 14.939 and 15.346 throughout this table. The asset return data is quarterly from 1969:1 to 2003:4 and consists of real excess returns for 130 portfolios which includes 25 portfolios sorted on size and book to market, 25 portfolios sorted on size and short-term reversal, 25 portfolios sorted on size and momentum, 25 portfolios sorted on size and long-term reversal, 10 portfolios sorted on earnings to price, 10 portfolios sorted on dividend to price, and 10 portfolios sorted on cashflow to price. 


\section{Table XIII \\ GMM estimates of the stochastic discount factor}

This table estimates

$$
E s_{t+1} r_{j t+1}=1 \quad j \ldots n
$$

for various formulations of the stochastic discount factor:

$$
s_{t+1}=a+s^{\prime} f_{t+1}
$$

where

$$
\begin{aligned}
s & =\left[\begin{array}{lllllllll}
s_{v} & \bar{s}_{v} & s_{u} & s_{m} & s_{\mathrm{hml}} & s_{\mathrm{smb}} & s_{\mathrm{umd}} & s_{\mathrm{str}} & s_{\mathrm{ltr}}
\end{array}\right]^{\prime}, \\
f_{t+1} & =\left[\begin{array}{lllllllll}
\hat{\hat{\tau}} \operatorname{vol}_{t}(\hat{\omega})+\epsilon_{e t+1} & \hat{\tau} \operatorname{vol}_{t}(\omega) & \hat{\theta} \mathrm{unc}_{t}(\nu) & r_{m t+1} & r_{\mathrm{hml} t+1} & r_{\mathrm{smb} t+1} & r_{\mathrm{umd} t+1} & r_{\mathrm{str} t+1} & r_{\operatorname{ltr} t+1}
\end{array}\right]^{\prime} .
\end{aligned}
$$

The assets considered are the same 130 portfolios used in Table XII though the returns are gross real returns rather than real excess returns.

\begin{tabular}{|c|c|c|c|c|c|c|c|c|c|c|c|c|c|}
\hline Specification & $a$ & $s_{v}$ & $\overline{\bar{s}_{v}}$ & $s_{u}$ & $s_{m}$ & $s_{\mathrm{hml}}$ & $s_{\mathrm{smb}}$ & $s_{\text {umd }}$ & $s_{\text {ltr }}$ & $s_{\text {str }}$ & $\log \omega$ & $\log \nu$ & $\overline{\mathrm{HJ}_{\text {dist }}}$ \\
\hline 1 & $\begin{array}{l}2.319 \\
(0.334)\end{array}$ & $\begin{array}{r}-0.975 \\
(1.586)\end{array}$ & 0.000 & $\begin{array}{r}-52.384 \\
(16.188)\end{array}$ & 0.000 & 0.000 & 0.000 & 0.000 & 0.000 & 0.000 & 2.705 & 2.731 & $\begin{array}{l}6.856 \\
(0.571)\end{array}$ \\
\hline 2 & $\begin{array}{l}2.027 \\
(0.376)\end{array}$ & 0.000 & $\begin{array}{r}4493.637 \\
(3557.785)\end{array}$ & $\begin{array}{r}-53.443 \\
(16.072)\end{array}$ & 0.000 & 0.000 & 0.000 & 0.000 & 0.000 & 0.000 & 2.705 & 2.731 & $\begin{array}{l}6.851 \\
(0.574)\end{array}$ \\
\hline 3 & $\begin{array}{l}1.084 \\
(0.049)\end{array}$ & 0.000 & 0.000 & 0.000 & $\begin{array}{r}-4.797 \\
(1.368)\end{array}$ & 0.000 & 0.000 & 0.000 & 0.000 & 0.000 & 2.705 & 2.731 & $\begin{array}{l}6.948 \\
(0.568)\end{array}$ \\
\hline 4 & $\begin{array}{l}1.864 \\
(0.166)\end{array}$ & 0.000 & 0.000 & 0.000 & $\begin{array}{r}-11.330 \\
(2.220)\end{array}$ & $\begin{array}{r}-11.994 \\
(2.940)\end{array}$ & $\begin{array}{l}7.425 \\
(2.881)\end{array}$ & $\begin{array}{r}-10.865 \\
(2.139)\end{array}$ & $\begin{array}{r}-3.472 \\
(3.563)\end{array}$ & $\begin{array}{r}-11.980 \\
(3.235)\end{array}$ & 2.705 & 2.731 & $\begin{array}{l}6.871 \\
(0.577)\end{array}$ \\
\hline 5 & $\begin{array}{l}3.031 \\
(0.394)\end{array}$ & 0.000 & 0.000 & $\begin{array}{r}-51.368 \\
(16.997)\end{array}$ & $\begin{array}{r}-7.891 \\
(2.366)\end{array}$ & $\begin{array}{r}-11.462 \\
(3.824)\end{array}$ & $\begin{array}{l}9.219 \\
(3.784)\end{array}$ & $\begin{array}{r}-10.714 \\
(2.464)\end{array}$ & $\begin{array}{r}-1.554 \\
(5.345)\end{array}$ & $\begin{array}{r}-11.100 \\
(3.832)\end{array}$ & 2.705 & 2.731 & $\begin{array}{l}6.782 \\
(0.580)\end{array}$ \\
\hline 6 & $\begin{array}{l}3.126 \\
(0.402)\end{array}$ & $\begin{array}{r}-7.891 \\
(2.366)\end{array}$ & 0.000 & $\begin{array}{r}-59.259 \\
(17.281)\end{array}$ & 0.000 & $\begin{array}{r}-11.462 \\
(3.824)\end{array}$ & $\begin{array}{l}9.219 \\
(3.784)\end{array}$ & $\begin{array}{r}-10.714 \\
(2.464)\end{array}$ & $\begin{array}{r}-1.554 \\
(5.345)\end{array}$ & $\begin{array}{r}-11.100 \\
(3.832)\end{array}$ & 2.705 & 2.731 & $\begin{array}{l}6.782 \\
(0.580)\end{array}$ \\
\hline 7 & $\begin{array}{l}2.549 \\
(0.410)\end{array}$ & 0.000 & $\begin{array}{r}6845.720 \\
(5460.552)\end{array}$ & $\begin{array}{r}-55.725 \\
(16.509)\end{array}$ & 0.000 & $\begin{array}{r}-6.706 \\
(3.963)\end{array}$ & $\begin{array}{l}5.370 \\
(3.299)\end{array}$ & $\begin{array}{r}-9.322 \\
(2.660)\end{array}$ & $\begin{array}{r}-1.152 \\
(4.929)\end{array}$ & $\begin{array}{r}-15.790 \\
(6.630)\end{array}$ & 2.705 & 2.731 & $\begin{array}{l}6.791 \\
(0.583)\end{array}$ \\
\hline 9 & $\begin{array}{l}3.132 \\
(0.404)\end{array}$ & 0.000 & 0.000 & $\begin{array}{r}-40.718 \\
(30.969)\end{array}$ & $\begin{array}{r}-7.858 \\
(2.440)\end{array}$ & $\begin{array}{r}-11.473 \\
(3.873)\end{array}$ & $\begin{array}{l}9.342 \\
(3.974)\end{array}$ & $\begin{array}{r}-10.712 \\
(2.521)\end{array}$ & $\begin{array}{r}-1.383 \\
(5.440)\end{array}$ & $\begin{array}{r}-11.297 \\
(3.962)\end{array}$ & 2.705 & $\begin{array}{l}2.423 \\
(0.663)\end{array}$ & $\begin{array}{l}6.781 \\
(0.580)\end{array}$ \\
\hline 10 & $\begin{array}{l}2.470 \\
(0.426)\end{array}$ & 0.000 & $\begin{array}{r}10703.046 \\
(6143.905)\end{array}$ & $\begin{array}{r}-46.665 \\
(32.043)\end{array}$ & 0.000 & $\begin{array}{r}-5.212 \\
(4.056)\end{array}$ & $\begin{array}{l}7.024 \\
(3.894)\end{array}$ & $\begin{array}{r}-9.166 \\
(2.973)\end{array}$ & $\begin{array}{r}-1.466 \\
(5.246)\end{array}$ & $\begin{array}{r}-18.179 \\
(7.154)\end{array}$ & $\begin{array}{l}4.393 \\
(1.143)\end{array}$ & $\begin{array}{l}2.496 \\
(0.621)\end{array}$ & $\begin{array}{l}6.754 \\
(0.589)\end{array}$ \\
\hline
\end{tabular}
(The factors are real excess returns.) In Panel A, the fixed weighting matrix proposed by Hansen and Jagannathan (1997) is employed and we report the HJ-dist and its standard error. In Panel B, the optimal GMM weighting matrix is employed and we report the J-stat and its P-value.

\begin{tabular}{|c|c|c|c|c|c|c|c|c|c|c|c|c|c|c|}
\hline Specification & $a$ & $s_{v}$ & $\overline{s_{v}}$ & $s_{u}$ & $s_{m}$ & $s_{\mathrm{hml}}$ & $s_{\mathrm{smb}}$ & $s_{\text {umd }}$ & $s_{1 \operatorname{tr}}$ & $s_{\text {str }}$ & $\log \omega$ & $\log \nu$ & $\mathrm{J}_{\text {stat }}$ & $\overline{\mathrm{P}_{\mathrm{val}}}$ \\
\hline 1 & $\begin{array}{l}2.337 \\
(0.012)\end{array}$ & $\begin{array}{r}-1.664 \\
(0.086)\end{array}$ & 0.000 & $\begin{array}{r}-51.896 \\
(0.372)\end{array}$ & 0.000 & 0.000 & 0.000 & 0.000 & 0.000 & 0.000 & 2.705 & 2.731 & 16.414 & 0.000 \\
\hline 2 & $\begin{array}{l}2.080 \\
(0.028)\end{array}$ & 0.000 & $\begin{array}{r}3594.745 \\
(346.567)\end{array}$ & $\begin{array}{r}-53.478 \\
(0.304)\end{array}$ & 0.000 & 0.000 & 0.000 & 0.000 & 0.000 & 0.000 & 2.705 & 2.731 & 16.420 & 0.000 \\
\hline 3 & $\begin{array}{l}1.102 \\
(0.004)\end{array}$ & 0.000 & 0.000 & 0.000 & $\begin{array}{r}-5.110 \\
(0.067)\end{array}$ & 0.000 & 0.000 & 0.000 & 0.000 & 0.000 & 2.705 & 2.731 & 16.400 & 0.000 \\
\hline 4 & $\begin{array}{l}1.913 \\
(0.010)\end{array}$ & 0.000 & 0.000 & 0.000 & $\begin{array}{r}-11.698 \\
(0.121)\end{array}$ & $\begin{array}{r}-12.336 \\
(0.192)\end{array}$ & $\begin{array}{l}8.166 \\
(0.170)\end{array}$ & $\begin{array}{r}-10.612 \\
(0.153)\end{array}$ & $\begin{array}{r}-3.511 \\
(0.136)\end{array}$ & $\begin{array}{r}-12.747 \\
(0.217)\end{array}$ & 2.705 & 2.731 & 16.391 & 0.000 \\
\hline 5 & $\begin{array}{l}3.068 \\
(0.021)\end{array}$ & 0.000 & 0.000 & $\begin{array}{r}-49.192 \\
(0.663)\end{array}$ & $\begin{array}{r}-8.516 \\
(0.226)\end{array}$ & $\begin{array}{r}-12.684 \\
(0.335)\end{array}$ & $\begin{array}{l}8.341 \\
(0.264)\end{array}$ & $\begin{array}{r}-11.403 \\
(0.194)\end{array}$ & $\begin{array}{r}-1.426 \\
(0.371)\end{array}$ & $\begin{array}{r}-11.454 \\
(0.259)\end{array}$ & 2.705 & 2.731 & 16.393 & 0.000 \\
\hline 6 & $\begin{array}{l}3.171 \\
(0.022)\end{array}$ & $\begin{array}{r}-8.516 \\
(0.226)\end{array}$ & 0.000 & $\begin{array}{r}-57.708 \\
(0.638)\end{array}$ & 0.000 & $\begin{array}{r}-12.683 \\
(0.335)\end{array}$ & $\begin{array}{l}8.341 \\
(0.264)\end{array}$ & $\begin{array}{r}-11.403 \\
(0.194)\end{array}$ & $\begin{array}{r}-1.426 \\
(0.371)\end{array}$ & $\begin{array}{r}-11.454 \\
(0.259)\end{array}$ & 2.705 & 2.731 & 16.395 & 0.000 \\
\hline 7 & $\begin{array}{l}2.539 \\
(0.028)\end{array}$ & 0.000 & $\begin{array}{r}7380.880 \\
(397.807)\end{array}$ & $\begin{array}{r}-56.989 \\
(0.858)\end{array}$ & 0.000 & $\begin{array}{r}-6.704 \\
(0.259)\end{array}$ & $\begin{array}{l}5.589 \\
(0.345)\end{array}$ & $\begin{array}{r}-9.484 \\
(0.186)\end{array}$ & $\begin{array}{r}-1.130 \\
(0.346)\end{array}$ & $\begin{array}{r}-15.151 \\
(0.454)\end{array}$ & 2.705 & 2.731 & 16.413 & 0.000 \\
\hline 8 & $\begin{array}{l}1.736 \\
(0.025)\end{array}$ & 0.000 & $\begin{array}{r}9249.235 \\
(356.096)\end{array}$ & $\begin{array}{r}-51.730 \\
(0.968)\end{array}$ & 0.000 & 0.000 & 0.000 & 0.000 & 0.000 & 0.000 & $\begin{array}{l}4.262 \\
(0.065)\end{array}$ & $\begin{array}{l}2.717 \\
(0.014)\end{array}$ & 16.420 & 0.000 \\
\hline 9 & $\begin{array}{l}3.206 \\
(0.023)\end{array}$ & 0.000 & 0.000 & $\begin{array}{r}-32.700 \\
(1.103)\end{array}$ & $\begin{array}{r}-8.383 \\
(0.212)\end{array}$ & $\begin{array}{r}-12.481 \\
(0.350)\end{array}$ & $\begin{array}{l}9.207 \\
(0.267)\end{array}$ & $\begin{array}{r}-11.624 \\
(0.216)\end{array}$ & $\begin{array}{r}-1.627 \\
(0.296)\end{array}$ & $\begin{array}{r}-11.809 \\
(0.341)\end{array}$ & 2.705 & $\begin{array}{l}2.230 \\
(0.031)\end{array}$ & 16.361 & 0.000 \\
\hline 10 & $\begin{array}{l}2.480 \\
(0.026)\end{array}$ & 0.000 & $\begin{array}{r}10737.625 \\
(300.410)\end{array}$ & $\begin{array}{r}-46.165 \\
(0.946)\end{array}$ & 0.000 & $\begin{array}{r}-5.603 \\
(0.257)\end{array}$ & $\begin{array}{l}6.842 \\
(0.305)\end{array}$ & $\begin{array}{r}-9.982 \\
(0.221)\end{array}$ & $\begin{array}{r}-1.773 \\
(0.203)\end{array}$ & $\begin{array}{r}-19.144 \\
(0.400)\end{array}$ & $\begin{array}{l}4.116 \\
(0.066)\end{array}$ & $\begin{array}{l}2.471 \\
(0.020)\end{array}$ & 16.410 & 0.000 \\
\hline
\end{tabular}

Panel A: The Hansen and Jagannathan (1997) weighting matrix

Panel B: Optimal GMM weighting matrix 
Figure 1. Volatility and uncertainty weights

Quasi-likelihood estimates of the parameters appearing in Table II are used to compute volatility $\operatorname{vol}_{t}(\omega)$, specified in equation (23), and a measure of uncertainty $u_{n}(\nu)$, appearing in (27). The top graph displays the weights on lagged daily volatility when $\omega=14.939$ and the bottom graph displays the weights on forecasters when $\nu=15.346$. In the top graph, the x-axis represents lagged trading days within a quarter and the y-axis represent weights. The weight on daily volatility on the last day of the quarter corresponds to $x=1$ and is a little less than 0.1. The bottom graph displays the weights on forecasters for a quarter in which there are 26 available forecasters $\left(f_{t}=26\right)$. The weights on the lowest and highest indexed forecasters are nearly zero and the weights on the 13th and 14th indexed forecasters are about 0.16 .
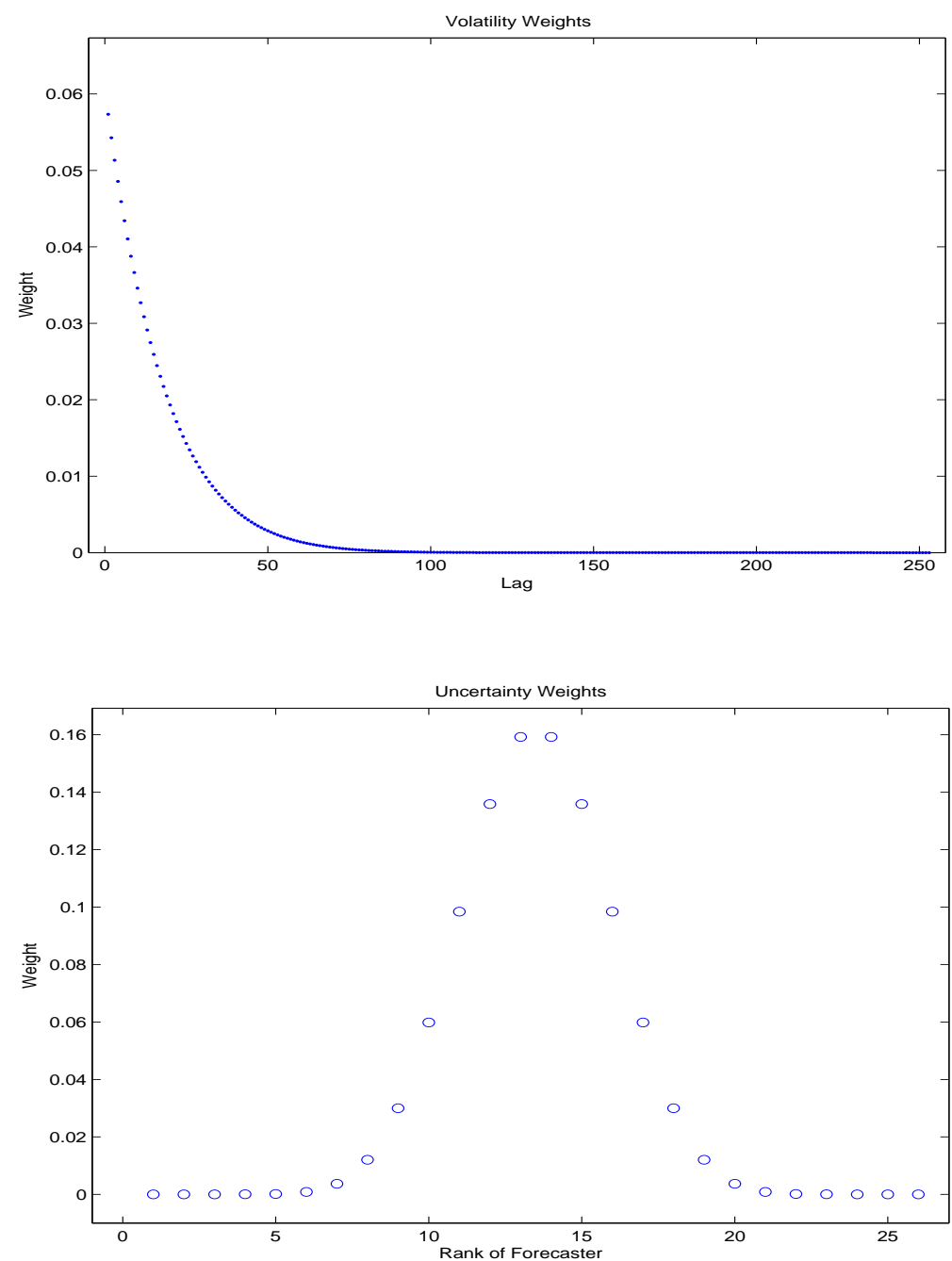


\section{Figure 2. Uncertainty and returns}

The top graph displays a quarterly scatter plot of the actual real market excess return (x-axis) $r_{e t+1}$ and the unweighted (or flat-weighted) lagged variance of market return forecasts (y-axis) $u_{n} c_{t}(1)$. The bottom graph displays a quarterly scatter plot of the actual real market excess return (x-axis) $r_{e t+1}$ and the Beta-weighted lagged variance of market return forecasts (y-axis) unc $t_{t}(\hat{\nu})$.
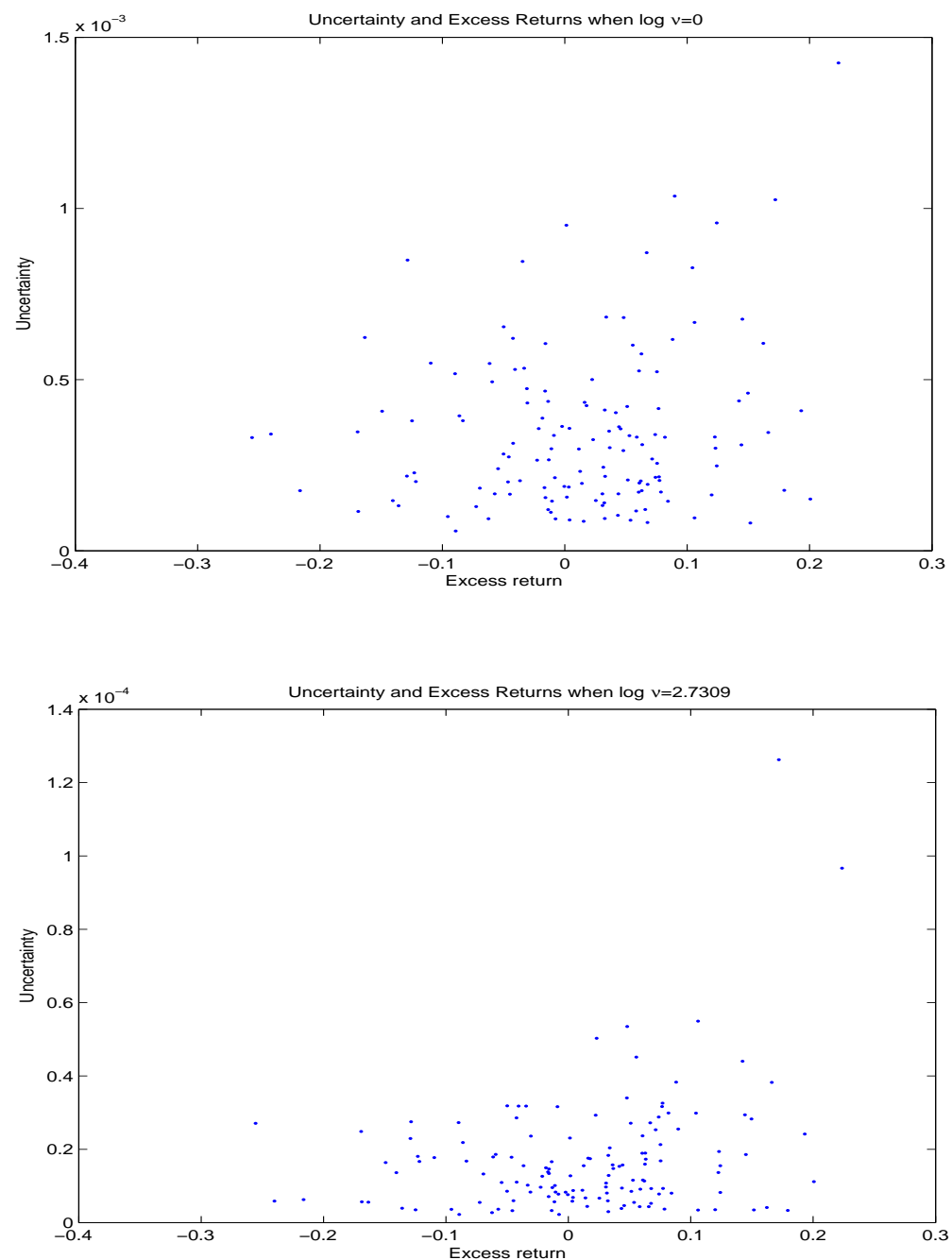
Figure 3. Time series plots

In the top row the left figure displays a plot of the quarterly excess return $r_{e t+1}$ and the right figure displays a plot of uncertainty, $\theta$ unc $_{t}(\nu)$, where $\theta=\hat{\theta}=1453.191$ and $\nu=\hat{\nu}=15.346$ are set at their optimal estimates from specification seven of Table II. In the bottom row the left figure displays a plot of quarterly realized volatility, $Q_{t}$, and the right figure displays a plot of volatility, $\tau \operatorname{vol}_{t}(\omega)$, where $\tau=\hat{\tau}=0.120$ and $\omega=\hat{\omega}=14.939$ are set at their optimal estimates from specification seven of Table II.
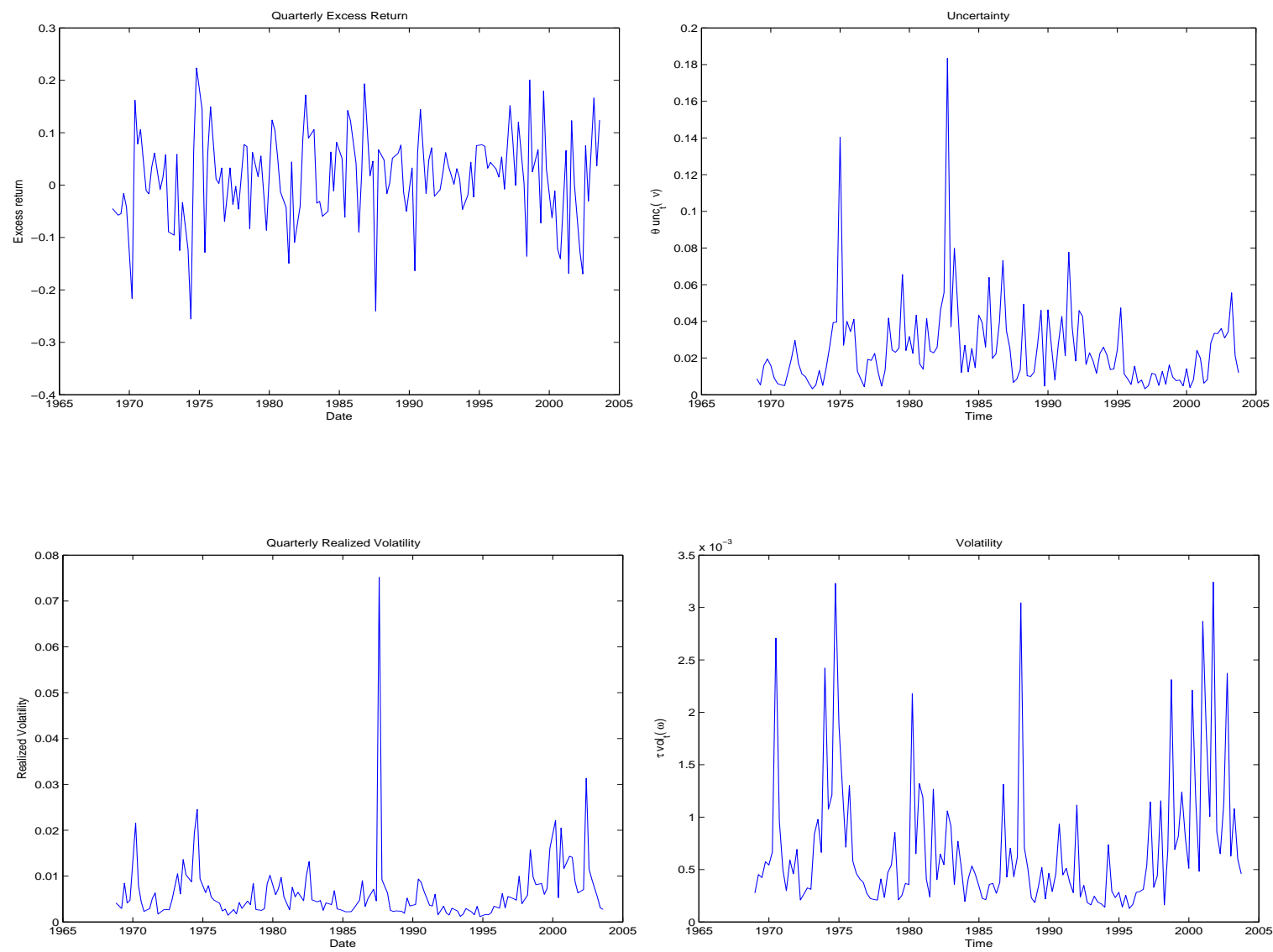


\section{Figure 4. Uncertainty and events}

All of the figures plot $\theta \operatorname{unc}_{t}(\nu)$ with other events where $\theta=\hat{\theta}=1453.191$ and $\nu=\hat{\nu}=15.346$ are set at their optimal estimates from specification seven of Table II. The top figure includes recessions (as defined by the NBER) in the shaded regions. The middle figure displays the excess return in the following quarter at the peaks of uncertainty. The bottom figure indicates changes in presidency with a circle.
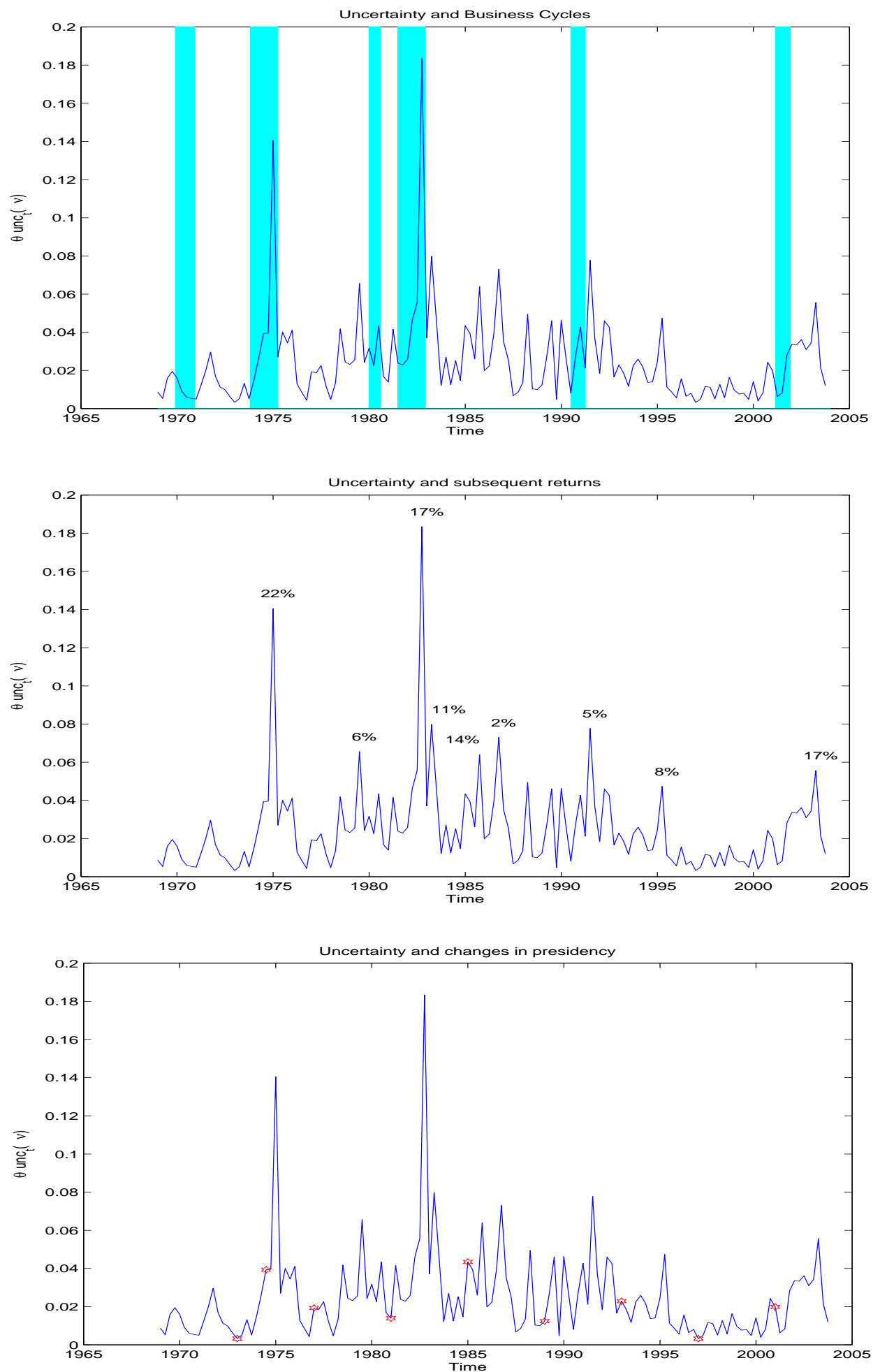